\title{
Optimization of breeding schemes for Nile tilapia (Oreochromis niloticus) in smallholder production systems in Kenya
}




\section{Thesis committee}

\section{Promotor}

Prof. Dr J. Komen

Personal chair at the Animal Breeding and Genomics group

Wageningen University and Research

\section{Thesis co-promotors}

Prof. Dr J.A.M. van Arendonk

Professor of Animal Breeding and Genetics

Wageningen University and Research

Prof. Dr A.K. Kahi

Professor of Animal Breeding and Genetics

Egerton University, Kenia

\section{Other members}

Prof Dr J.A.J. Verreth, Wageningen University and Research

Dr I. Nawawi, Research Institute for Fish Breeding, West Java, Republic of Indonesia

Prof Dr. D-J de Koning, Swedish University of Agricultural Sciences, Uppsala, Sweden

Dr H. W. Saatkamp, Wageningen University and Research

This research was conducted under the auspices of the Graduate School of Wageningen Institute of Animal Sciences (WIAS). 


\title{
Optimization of breeding schemes for Nile tilapia (Oreochromis niloticus) in smallholder production systems in Kenya
}

\author{
Simion Kipkemboi Omasaki
}

\section{Thesis}

submitted in fulfillment of the requirements for the degree of doctor at Wageningen University

by the authority of the Rector Magnificus

Prof. Dr A. P.J. Mol,

in the presence of the

Thesis Committee appointed by the Academic Board

to be defended in public

on Monday May 1, 2017

at 11 a.m. in the Aula. 
Omasaki, S.K.

Optimization of breeding schemes for Nile tilapia (Oreochromis niloticus) in smallholder production systems in Kenya

PhD thesis, Wageningen University, the Netherlands (2017)

With references, with summary in English

ISBN 978-94-6343-106-4

DOI/ISBN=10.18174/406573 


\begin{abstract}
Omasaki, S.K. (2017). Optimization of breeding schemes for Nile tilapia (Oreochromis niloticus) in smallholder production systems in Kenya. PhD thesis, Wageningen University, The Netherlands.
\end{abstract}

The aim of this thesis was to develop a sustainable low cost breeding program for Nile tilapia that addresses both genetic and economic aspects of smallholder fish farmers in Kenya. First, Analytical Hierarchy Process Technique was used to define a breeding goal based on farmer's preferences for traits. Farmers' preferences for traits differed significantly depending on income and market orientation. Low and medium income farmers preferred harvest weight (HW) while high income farmers preferred growth (GR) and survival (S) traits. Grouping farmers according to market objective (fingerling production or fattening) showed that fingerling producers preferred $\mathrm{GR}$ and $\mathrm{S}$ while fattening farmers preferred HW and $\mathrm{S}$. Consensus preference values were obtained using weighted goal programming and these values were used to derive desired gains for a breeding goal that takes into account farmers' diverse backgrounds and preferences for traits. Secondly, the existence of genetic variation for traits of interest was investigated. Substantial additive genetic effects for HW, GR and shape traits were present that can be exploited through selection under low input production system. Heritability estimates for HW, GR and shape were $0.21 \pm 0.03,0.26 \pm 0.04$ and $0.12 \pm 0.03$ for mixed sex (nucleus) respectively. The calculation of economic values for breeding goal traits revealed that economic values for GR differed depending on the definition of the breeding goal and that selection for feed efficiency is the key factor to economic profitability of Nile tilapia breeding programs. A significant genotype by environment re-ranking was found for GR between the mixed sex nucleus and monosex production environments. Genotype by environment interaction ( $\mathrm{G} \times \mathrm{E}$ ) led to lower genetic gain for $G R$ in production environment. Incorporating sib information from monosex production environment into the selection index resulted in a more accurate estimation of breeding values which increased genetic gain in growth. Using desired gain approach, weights for desired gains in harvest weight, growth rate and survival were derived that maximized genetic gains for these breeding goal traits. It is concluded that these results can be used to develop a sustainable centralized breeding program. However, a reliable well planned and organized decentralized strategy for dissemination of genetically improved fry of Nile tilapia to farmers is paramount. 



\section{Contents}

$5 \quad$ Abstract

$9 \quad 1-$ General introduction

212 - Defining a breeding objective for Nile tilapia that takes into account the diversity of smallholder production systems

433 - Genotype by environment interaction for harvest weight, growth rate and shape between monosex and mixed sex Nile tilapia (Oreochromis niloticus)

69 4-Economic values of growth rate, feed intake, feed conversion ratio, mortality and uniformity for Nile tilapia

975 -Optimization of Nile tilapia breeding schemes for monosex culture conditions in smallholder production systems

$1216-$ General discussion

143 Summary

149 Publications

153 About the author

157 Training and education

161 Acknowledgements

165 Colophon 

1

General Introduction 



\subsection{Overview of global aquaculture production}

To feed a world whose population is expected to grow to 9.6 billion by 2050, current agricultural production from crops, livestock, fisheries and aquaculture must increase by over 60\% (FAO, 2014). To meet these increasing demands, the contribution from sustainable aquaculture production would be fundamental. Aquaculture farming now represents the fastest growing animal food producing sector of the world, with an annual average growth of $8.6 \%$ over the last decade. The sector also remains an important source of essential nutrients, accounting for over $17 \%$ of the global population's consumption of animal protein (FAO, 2014). In 2012, the total global aquaculture production was estimated to be over 90.4 million tons (FAO, 2014) with freshwater fish representing the bulk. In the same year, the total production from inland aquaculture of both herbivorous and omnivorous finfish species was estimated to be 42 million tons (FAO, 2014b).

Aquaculture is a vital economic activity and provides livelihood to many people in the world. It especially provides a good alternative source of income for rural communities (World-bank, 2013). In 2012, 4.4\% of the 1.3 billion people economically active in the broad agriculture sector worldwide were active in aquaculture, with women dominating the sector (FAO, 2014). The FAO estimates that, overall, fisheries and aquaculture support the livelihoods of $10-12 \%$ of the world's population.

In Africa, aquaculture has a huge potential for expansion, but currently it contributes only $2 \%$ of the total world aquaculture production. In 2012, its production was estimated at 1.4 million tons with Egypt being the major producer while sub-Saharan Africa produced 359,790 tons in 2010 , only $0.6 \%$ of the world production (FAO, 2014). Smallholder aquaculture production accounts for $95 \%$ of the total aquaculture production. Of these, Nile tilapia farming contributes $40 \%$ (Jamu and Brummett, 2004; Charo-Karisa, 2006) and is largely characterized by semi intensive production systems using earthen ponds with low and few inputs and diverse farming conditions (El-Sayed, 2006).

\subsection{Nile tilapia and aquaculture}

Globally, Nile tilapia (Oreochromis niloticus), and its hybrids, are the most cultivated and widely farmed fish freshwater species after carps. Nile tilapia is the most important species, accounting for more than $90 \%$ of the total tilapia production (Fitzsimmons, 2016). Farmed Nile tilapia production has increased 
significantly. In 2015, the production was estimated at 5.5 million tons and but the production is projected to exceed 8 million tons by 2026 (Figure 1.1) (Fitzsimmons, 2016). Cultured Nile tilapia are herbivorous and accept a wide range of diets ranging from natural organisms, garden wastes and greens to formulated feeds (Fryer and Iles, 1972; Guerrero, 1980; Charo-Karisa, 2006). Principally, production of cultured Nile tilapia takes place under extensive and semi intensive systems using earthen ponds, cages and tanks in tropical areas with water temperatures well above $20^{\circ} \mathrm{C}$ (El-Sayed, 2006).

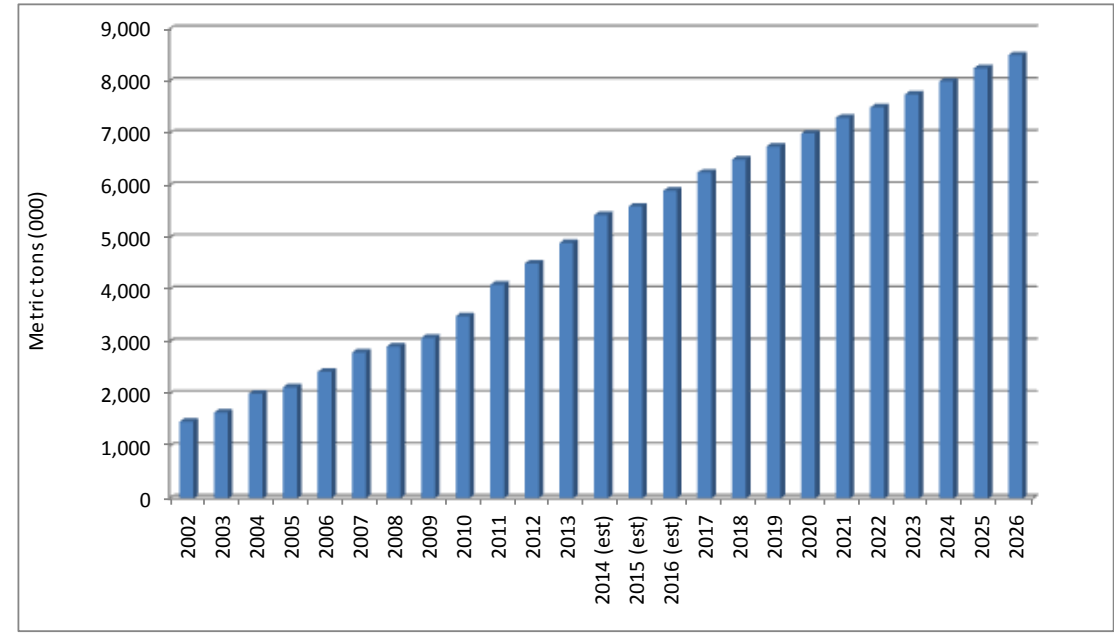

Figure 1.1 Global Nile tilapia productions (Fitzsimmons, 2016).

\subsubsection{Selective breeding of Nile tilapia}

Selective breeding and feed formulation are the main driving technologies for the development of resource efficient, sustainable and increased aquaculture productivity (Rye, 2012). Genetic improvement programs have contributed to dramatic increase in production of Nile tilapia (Komen and Trong, 2014). Nile tilapia has the highest number of mass and family based breeding programs in aquaculture, with a remarkable genetic progress realized over the last few decades (Gjedrem et al., 2012; Komen and Trong, 2014). Ponzoni et al. (2011) reviewed a number of selective breeding programs for Nile tilapia where harvest weight has been the main trait of interest. These programs include Genetically Improved Farmed Tilapia (GIFT) (Eknath et al., 1993), FaST (Bolivar, 1998), GenomMar Supreme Tilapia (GST) (Zimmermann and Natividad, 2004), Genetically Enhanced Tilapia - an Excellent strain (GET-EXCEL) (Tayamen, 2004) and Hainan Progift (Thodesen et al., 2011). These selective programs were implemented mainly in 
Asia, in relatively favorable environments where high quality commercially formulated feeds were provided and growth is expected to be high.

In Progift Nile tilapia, selection responses for growth after six generations of multitrait selection were on average, $11.4 \%$ per generation. In addition to growth, survival has been the main trait of interest (Thodesen et al., 2013). In the GST strain growth rate has increased by $35 \%$ after 17 generations of selection. Currently, GST produces a new generation every nine months with a genetic gain in growth rate of more than 10\% per generation (GenoMar Breeding Services, 2016). Since the development of GET-EXCEL strain in 2002, it is purported to be $38 \%$ better in growth and yield compared to unimproved tilapia stocks (Tayamen, 2004). The GIFT strain is the best documented strain, with genetic gains for harvest weight ranging from 10 to 15 percent per generation over 10 generations of selection (Khaw, 2015). In addition to harvest weight, other traits e.g., body dimension, fillet yield and shape traits have been studied in GIFT generations (Nguyen et al., 2007; Nguyen et al., 2010; Trọng, 2013; Khaw, 2015). To date, improved Nile tilapia strains from the GIFT breeding program have been widely distributed from Asia to many parts of the world (Ponzoni et al., 2011).

\subsubsection{Nile tilapia production in Africa}

Africa holds the global wealth of Nile tilapia genetic resources. This genetic variability represents a great natural potential, but is currently underexploited (Pullin, 1988; Khaw et al., 2009). Poor growth and survival among the currently farmed Nile tilapia populations are some of the key constraints holding back growth of the sector. Breeding strategies to improve Nile tilapia in Africa have been implemented unsystematically, with most tilapia hatcheries producing low quality and inbred fry that are supplied to farmers (Brummett et al., 2004; Brummett and Ponzoni, 2009). Improved lines of tilapia for African aquaculture could be expected to nearly double current growth rates and render economically viable many smaller farms that are struggling to survive (Moehl et al., 2006). This can only be achieved through development and implementation of well-designed breeding programs (Brummett and Ponzoni, 2009).

Appropriate breeding objectives are a prerequisite for the development of any genetic improvement program (Harris, 1970; Ponzoni, 1986). The breeding objective defines the target traits to be improved and assigns an economic value or desired gains weight to each of the traits involved. The economic values and/or 
desired gains are derived from an in-depth analysis of the prevailing production systems, and their social and economic context (Harris, 1970; Ponzoni, 1986). In sub-Saharan Africa, smallholder farmers grow Nile tilapia either using fertilization with organic material alone or with a wide variety of locally available farm resources, making its farming conditions quite diverse (Brummett and Ponzoni, 2009). It can therefore be hypothesized that breeding objectives for farmers differ depending on their diverse farming conditions. This is an issue that has not been addressed until now. In addition, economic assessment of cost and revenues for Nile tilapia based on farming conditions are rare. Estimation of economic values for breeding objective traits to evaluate their economic relevance are still lacking. Developing relevant breeding objectives that will maximize economic returns are a prerequisite for sustainable genetic improvement programs for smallholder production circumstances for Nile tilapia.

In Africa, selective breeding programs of Nile tilapia are based on the development of new improved lines from local strains targeted at improving final harvest weight, such as the Abbassa and Akosombo strains of Nile tilapia (World Fish Center, 2012). These local strains have to exhibit high genetic variation for the traits of interest. However, genetic parameters for breeding goal traits to quantify this variation for Nile tilapia are still lacking. In addition, selection is practiced in breeding stations with good controlled environments, yet the realized responses in the farming environments are still very low (Brummett et al., 2004; Brummett and Ponzoni, 2009). There are also reports that the gains of selection in the breeding programs carried out in good environments were lost when selected breeds were tested in less favorable environments (Macaranas et al., 1997). This could indicate that growth in different culture conditions is subject to genotype by environment interaction ( $\mathrm{G} \times \mathrm{E}$ ). To avoid such interactions, selection should match the low input production system, where farmers grow Nile tilapia using fertilization with organic material alone or with a wide variety of locally available farm resources (Charo-Karisa, 2006).

Brummett and Ponzoni (2009) and Ponzoni et al. (2011) showed that performance of Nile tilapia in Africa can be achieved through genetic improvement, by use of local strains or improved strains. However, improved strains like GIFT tilapia, cannot be used to introgress faster growth in the local strains of most African countries, as GIFT is currently considered an exotic crossbred species, and would pose a risk to the genetic resources of wild tilapia (Gupta et al., 2004; Ansah et al., 
2014). This therefore necessitates the development of local breeding programs based on locally available strains of Nile tilapia.

A major concern for Nile tilapia pond culture systems is the rapid reproduction at the onset of sexual maturity resulting in over-population. This leads to reduction of growth rate and low yields of harvestable size fish. This has prompted the production of all-male tilapia fish to control the reproductive activity and to increase production of Nile tilapia in pond culture. Male tilapias grow faster than females, they have better food conversion ratio and relatively high survival ( Rutten et al., 2005; Tran-Duy et al., 2008; Angienda et al., 2010). All-male populations of tilapia are commonly produced by treating fry with methyl-testosterone hormone (Popma et al., 1990; Popma and Lovshin 1995; Phelps et al., 1993; Fuentes-Silva et al., 2013). Commercial production is therefore substantially different from the selection environment where animals are selected for growth rate in a mixed sex environment. In a population that constitutes only males, the agonistic influences of males on females are removed; and the usual observation of females being smaller than males in mixed sex environments is probably caused by behavioral factors (Schreiber et al. 1998). Rutten et al., 2005 concluded that growth rate is genetically the same trait in males and females. However, there are no estimates of genetic correlations for growth rate between mixed sex and all-male monosex environment.

\subsection{The motivation and objectives of the study}

This study was carried out in Kenya, where aquaculture has a huge potential for expansion, but currently contributes just about $2 \%$ of the total fish produced, with Nile tilapia (Oreochromis niloticus) being the most important cultivated species. Limited supplies of vegetable proteins have led to competition between farm animals and man for these products, thus limiting the intensification of fish farming based on improved local species. For protein deficient countries like Kenya, the solution may lie with the development of Nile tilapia strains, suitable for low-input culture. Nile tilapia are hardy fish that are able to grow in the low-input fish farming systems that are typical for large parts of the country (Musa et al., 2012). In 2010, the Government of Kenya launched an Economic Stimulus Program (ESP) to boost economic growth of the country. One of the targeted areas by ESP was improving fish farming through the renovation of government fish rearing facilities, establishment of research programs to determine best practices for pond culture, initiating intensive training programs for fisheries extension workers and 
construction of fish ponds to farmers (Musa et al., 2012). Based on this, fisheries and aquaculture department within the ministry of agriculture made an inventory of the available local strains and their production characteristics, which resulted in the composition of a base population for a selective breeding program. This national breeding program is located at Sagana Aquaculture Research Station under Kenya Marine and Fisheries Research Institute (KMFRI). The aim is to breed and produce better performing Nile tilapia fingerlings for grow-out.

The overall objective of this study was to design a sustainable low cost breeding program for Nile tilapia that addresses both genetic and economic aspects of smallholder fish production systems in Kenya. The specific objectives of the study therefore were: i) to use a participatory approach to develop a sustainable breeding objective based on farmer's preferences and accounting for economic constraints, ii) to estimate the genetic parameters for traits of economic importance in the mixed sex nucleus, and to investigate the magnitude of $G \times E$ interaction between mixed sex and monosex populations for these traits, iii) to derive the economic values for breeding objective traits for Nile tilapia and assess their relevance and iv) to design an optimized breeding scheme that maximizes genetic and economic response in the prevailing monosex culture conditions.

\subsection{Outline of the thesis}

This thesis consists of six chapters. Chapter 1 presents the general introduction. Chapter 2 investigates if and how interests of groups of farmers with diverse production systems and economic constraints translate in varying preferences for breeding objective traits. Chapter 3 presents estimates of genetic parameters for harvest weight, daily growth coefficient and body shape traits and investigates the magnitude and importance of $\mathrm{G} \times \mathrm{E}$ interaction between mixed sex and monosex populations for these traits. The aim was to examine whether the existing Nile tilapia population has substantial genetic variation that can be exploited through selection for breeding objective traits. Chapter 4 presents a bio-economic model for the derivation of economic values for breeding objective traits of Nile tilapia. The model focusses on the most important traits: growth rate, feed conversion ratio and feed intake, and assesses the economic impact of selection on these traits. In Chapter 5, optimization of a breeding program that maximizes genetic response in the prevailing monosex culture conditions is investigated using deterministic simulation. The aim was to optimize genetic gains for harvest weight, growth and survival traits in monosex culture of all-male fish in the presence of $\mathrm{G} x$ E. Finally, Chapter 6 integrates the findings in Chapters 2 to 5 and discusses the 
practical implementation of a sustainable national breeding program for genetic improvement of Nile tilapia in Kenya.

\section{References}

Angienda, P., Aketch, B., Waindi, E., 2010. Development of all-male fingerlings by heat treatment and the genetic mechanism of heat induced sex determination in Nile Tilapia (Oreochromis niloticus L.). Int. J. Biol. Sci. 6, 38-42.

Ansah, Y.B., Frimpong, E.A., Hallerman, E.M., 2014. Genetically-improved Tilapia strains in Africa: Potential benefits and negative impacts. Sustainability 6, 3697-3721.

Bolivar, R.B., 1998. Estimation of response to within-family selection for growth in Nile tilapia (Oreochromis niloticus) (PhD thesis) Dalhousie University, Halifax, Canada (166pp.).

Brummett, R.E., Angoni, D.E., Pouomogne, V., 2004. On-farm and on-station comparison of wild and domesticated Cameroonian populations of Oreochromis niloticus. Aquaculture 242, 157-164.

Brummett, R.E., Ponzoni, R.W., 2009. Concepts, alternatives, and environmental considerations in the development and use of improved strains of tilapia in African aquaculture. Rev. Fish Sci. 17, 70-77.

Charo-Karisa, H., 2006. Selection for growth of Nile tilapia (Oreochromis niloticus L.) in low-input environments (PhD Thesis) Wageningen Universiteit (169pp.).

Eknath, A.E., Tayamen, M.M., Palada-de Vera, M.S., Danting, J.C., Reyes, R.A., Dionisio, E.E., Capili, J.B., Bolivar, H.L., Abella, T.A., Circa, A.V., 1993. Genetic improvement of farmed tilapias: the growth performance of eight strains of Oreochromis niloticus tested in different farm environments. Aquaculture 111, 171-188.

El-Sayed, A.F.M., 2006. Tilapia culture. CABI.

FAO, 2014. The State of World Fisheries and Aquaculture, 2014. Opportunities and challenges. Rome, (243 pp.).

FAO, 2014b. Global Aquaculture Production, Volume and Value Statistics Database Updated to 2012. Rome, (4pp.).

Fitzsimmons, K., 2016. Tilapia Aquaculture 2016 and where will we be in 2026. 11th Internatonal Symposium for Tilapia Aquaculture (ISTA), World Aquaculture Society-Asian Pacific Conference, 2016, Surabaya, Indonesia, April 26-29, 2016. 
Fryer, G., Iles, T., 1972. The cichlid fishes of the great lakes of Africa: their biology and distribution. Oliver and Boyd, Edinburgh, Scotland (641pp.).

Fuentes-Silva, C., Soto-Zarazúa, G.M., Torres-Pacheco, I., 2013. Male tilapia production techniques: A mini-review. Afr. J. Biotechnol. 12, 5496-5502.

GenoMar Breeding Services, 2016. Superior sustainable brood-stock, DNAverifiable traceability, (9pp.). http://www.longline.co.uk/Documents/CV /documents/Matt\%20Dyck.pdf. Accessed on 23/10/2016.

Gjedrem, T., Robinson, N., Rye, M., 2012. The importance of selective breeding in aquaculture to meet future demands for animal protein: a review. Aquaculture 350, 117-129.

Guerrero, R.D., 1980. Studies on the feeding of Tilapia nilotica in floating cages. Aquaculture 20, 169-175.

Gupta, M.V., Bartley, D.M., Acosta, B.O., 2004. Use of genetically improved and alien species for aquaculture and conservation of aquatic biodiversity in Africa. WorldFish Center, Malaysia (114pp.).

Harris, D.L., 1970. Breeding for efficiency in livestock production: defining the economic objectives. J. Anim.Sci. 30, 860-865.

Jamu, D., Brummett, R., 2004. Opportunities and challenges for African aquaculture. In Gupta, M.V., Bartley, D.M., Acosta B.O. Use of genetically improved and alien species for aquaculture and conservation of aquatic biodiversity in Africa. WorldFish Center, Malaysia, pp. 1-9.

Khaw, H., 2015. Cooperative and uniform fish?: social interactions and variability in live body weight in the GIFT strain (Nile tilapia, Oreochromic niloticus) in Malaysia (PhD Thesis) Wageningen Universiteit (161 pp.).

Khaw, H.L., Bovenhuis, H., Ponzoni, R.W., Rezk, M.A., Charo-Karisa, H., Komen, H., 2009. Genetic analysis of Nile tilapia (Oreochromis niloticus) selection line reared in two input environments. Aquaculture 294, 37-42.

Komen, J., Trong, T.Q., 2014. Nile tilapia genetic improvement: achievements and future directions. In Proceedings of The 10th International Symposium on Tilapia in Aquaculture (ISTA10), Jerusalem, Israel, 6-10 October, 2014 pp. 1-9.

Macaranas, J.M., Mather, P.B., Lal, S.N., Vereivalu, T., Lagibalavu, M., Capra, M.F., 1997. Genotype and environment: A comparative evaluation of four tilapia stocks in Fiji. Aquaculture 150, 11-24.

Moehl, J., Brummett, R., Ponzoni, R., 2006. Genetic management of aquaculture stocks in Sub-Saharan African. CIFA Occasional Paper (FAO), (65pp.).

Musa, S., Aura, C.M., Owiti, G., Nyonje, B., Orina, P., Charo-Karisa, H., 2012. Fish farming enterprise productivity program (FFEPP) as an impetus to 
Oreochromis niloticus (L.) farming in Western Kenya: Lessons to learn. AJAR. 7, 1324-1330.

Nguyen, N.H., Khaw, H.L., Ponzoni, R.W., Hamzah, A., Kamaruzzaman, N., 2007. Can sexual dimorphism and body shape be altered in Nile tilapia (Oreochromis niloticus) by genetic means? Aquaculture 272, S38-S46.

Nguyen, N.H., Ponzoni, R.W., Abu-Bakar, K.R., Hamzah, A., Khaw, H.L., Yee, H.Y., 2010. Correlated response in fillet weight and yield to selection for increased harvest weight in genetically improved farmed tilapia (GIFT strain), Oreochromis niloticus. Aquaculture 305, 1-5.

Phelps, R.P., Arana, E., Argue, B., 1993. Relationship between the external morphology and gonads of androgen treated Oreochromis niloticus. J. Appl. Aquac. 2, 103-108.

Ponzoni, R., 1986. A profit equation for the definition of the breeding objective of Australian Merino sheep. J. Anim. Breed. Genet. 103, 342-357.

Ponzoni, R.W., Nguyen, N.H., Khaw, H.L., Hamzah, A., Bakar, K.R.A.,Yee, H.Y., 2011. Genetic improvement of Nile tilapia (Oreochromis niloticus) with special reference to the work conducted by the WorldFish Center with the GIFT strain. Rev. Aquac. 3, 27-41.

Popma, T.J., Green, B.W., 1990. Aquaculture production manual: sex reversal of tilapia in earthen ponds. Research and Development Series No. 35. International Center for Aquaculture, Alabama Agricultural Experiment Station, Auburn University, AL, USA (15 pp.).

Popma, T.J., Lovshin, L.L., 1995. Worldwide Prospects for Commercial Production of Tilapia. International Center for Aquaculture and Aquatic Environments, Department of Fisheries and Allied Aquacultures, Auburn University, Alabama p. 36849 (42 pp.).

Pullin, R. S. 1988. Tilapia genetic resources for aquaculture. The WorldFish Center Working Papers. Manila, Philippines (115pp.).

Rutten, M.J., Komen, H., Bovenhuis, H., 2005. Longitudinal genetic analysis of Nile tilapia (Oreochromis niloticus L.) body weight using a random regression model. Aquaculture 246, 101-113.

Rye, M., 2012. Current status and prospects for the application of genetic improvement in aquaculture species. Proceedings of the $9^{\text {th }}$ Biennial Symposium of the Brazilian Society of Animal Breeding, João Pessoa, Paraíba, Brazil, June 20-22, 2012 pp.1-10.

Schreiber, S., Focken, U., Becker, K., 1998. Individually reared female Nile tilapia (Oreochromis niloticus) can grow faster than males. J.Appl. Ichthyol. 14, 43-47. 
Tayamen, M.M., 2004. Nationwide dissemination of GETEXCEL tilapia in the Philippines. In: Bolivar, R.B., Mair, G.C., Fitzsimmons, K. (Eds.), New dimensions of farmed tilapia, Proceedings of the Sixth International Symposium on Tilapia in Aquaculture, Manila, the Philippines, pp. 74-88.

Thodesen, J., Rye, M., Wang, Y.-X., Li, S.-J., Bentsen, H.B., Gjedrem, T., 2013. Genetic improvement of tilapias in China: Genetic parameters and selection responses in growth, pond survival and cold-water tolerance of blue tilapia (Oreochromis aureus) after four generations of multi-trait selection. Aquaculture 396, 32-42.

Thodesen, J., Rye, M., Wang, Y.X., Yang, K.S., Bentsen, H.B., Gjedrem, T., 2011. Genetic improvement of tilapias in China: genetic parameters and selection responses in growth of Nile tilapia (Oreochromis niloticus) after six generations of multi-trait selection for growth and fillet yield. Aquaculture 322, 51-64.

Tran-Duy, A., Schrama, J.W., van Dam, A.A., Verreth, J.A., 2008. Effects of oxygen concentration and body weight on maximum feed intake, growth and hematological parameters of Nile tilapia, Oreochromis niloticus. Aquaculture 275, 152-162.

Trọng, T. Q., 2013. Optimisation of selective breeding program for Nile tilapia (Oreochromis niloticus) (PhD Thesis) Wageningen Universiteit (176 pp.).

World Bank, 2013. Fish to 2030. Prospects for Fisheries and Aquaculture. Agriculture and Envi ronmental Services Discussion Paper 03. World Bank report number $83177-$ GLB (102 pp.).

World Fish Center, 2012. Improved breeding of Nile tilapia leads to productivity gains. Press $\quad$ Releases $30 \quad$ November 2012. http://www.worldfishcenter.org/content/improved-breeding-nile-tilapialeads-productivity-gains.

Zimmermann, S., Natividad, J.M., 2004. Comparative pond performance evaluation of GenoMar Supreme TilapiaTM GST1 and GST3 groups. In: Bolivar, R.B., Mair, G.C., Fitzsimmons, K. (Eds.), New dimensions of farmed tilapia, Proceedings of the Sixth International Symposium on Tilapia in Aquaculture, Manila, the Philippines, pp. 89. 


\title{
2
}

\section{Defining a breeding objective for Nile tilapia that takes into account the diversity of smallholder production systems}

\author{
S.K. Omasaki ${ }^{12}$, J.A.M van Arendonk ${ }^{1}$, A.K. Kahi ${ }^{2}$ H. Komen ${ }^{1}$
}

\footnotetext{
${ }^{1}$ Animal Breeding and Genomics Centre, Wageningen University, P. O. Box 338, $6700 \mathrm{AH}$, Wageningen, the Netherlands; ${ }^{2}$ Animal Breeding and Genomics Group, Department of Animal Sciences, Egerton University, P.O Box 536, 20115 Egerton, Kenya
}

J. Anim. Breed. Genet. 133 (2016) 404-413 


\begin{abstract}
In general, livestock and fish farming systems in developing countries tend to be highly diverse in terms of agro-ecological conditions and market orientation. There are no studies that have investigated if and how this diversity translates to varying preferences for breeding objective traits. This is particularly important for breeding programs that are organized on a national level (e.g. government supported nucleus breeding programs). The aim of the present study was to investigate whether Nile tilapia farmers with diverse production systems and economic constraints have different preferences for breeding objective traits. The second objective was to derive a consensus breeding goal, using weighted goal programming that could be used for a national breeding program for Nile tilapia. A survey was conducted among 100 small-holder Nile tilapia famers in Kenya to obtain preference values for traits of economic importance, by using multiple pair wise comparisons. Individual and group preference values were estimated using Analytical Hierarchy Process. Results: low income farmers preferred harvest weight while medium and high income farmers preferred growth rate and survival. Grouping farmers according to market objective (fingerling production or fattening) showed that fingerling producers preferred growth rate and survival while fattening farmers preferred harvest weight, height and thickness. Weighted goal programming was used to obtain consensus preference values and these were used to derive desired gains for a breeding goal of a national breeding program that takes into account the diversity of smallholder production systems.
\end{abstract}

Key words: breeding goal, desired genetic gain, Nile tilapia, participatory approach, smallholder production. 


\subsection{Introduction}

In developing countries, animal production systems are highly diverse in terms of agro-ecological distribution, and level of commercialization (Sölkner et al., 1998; Wurzinger et al., 2006; Gizaw et al., 2010). The transition process towards commercialization generally leads to intensification (increased inputs, increased output) and specialization (reduced number of livelihood activities, specialized enterprises for crop and livestock products) (Poulton et al., 2010). Few, if any, studies have investigated how these transition processes affect the definition of a breeding objective for a program that is organized on a national level (e.g. government supported nucleus breeding programs).

Participatory approaches can be used to define a breeding objective. Participatory approaches involve farmers as active analysts of their own situations whereby they rank and list priorities of resources, constraints and opportunities based on their circumstances (Tano et al., 2003). Participatory approaches typically produce a ranking for a suite of traits. However, such rankings do not reflect how much more one trait is preferred over another trait. Recently, Sae-Lim et al. (2012) showed how Analytical Hierarchy Process (AHP; Saaty, 1980) can be used to translate rankings in preference values and subsequently into desired gains. In this study, AHP was used to investigate whether Nile tilapia farmers in Kenya with different levels of commercialization differ in preference values for breeding objective traits. Nile tilapia (Oreochromis niloticus) are the most farmed tropical fish species worldwide (World Bank, 2013). In Kenya, tilapia farming is largely done by small-scale farmers with different degrees of market orientation. The aim of this study was to investigate if and how interests of groups of farmers with diverse production systems and economic constraints translate to varying preferences for breeding goal traits. The second objective was to derive a consensus breeding goal that could be used for a national breeding program for the Nile tilapia.

\subsection{Materials and methods}

\subsubsection{Sampling and interviews}

A survey of Nile tilapia farmers was conducted using a set of pre-tested structured questionnaires and personal interviews. The survey covered three counties in western Kenya namely Kakamega ( $\left.0^{\circ} 17^{\prime} \mathrm{N}, 34^{\circ} 45^{\prime} \mathrm{E}\right)$, Kisii $\left(0^{\circ} 41^{\prime} \mathrm{S}, 34^{\circ} 46^{\prime} \mathrm{E}\right)$ and Siaya $\left(0^{\circ} 14^{\prime} \mathrm{N}, 34^{\circ} 16^{\prime} \mathrm{E}\right)$, with average annual rainfalls between 800 and $1600 \mathrm{~mm}$, and mean monthly temperatures between $19^{\circ} \mathrm{C}$ and $30^{\circ} \mathrm{C}$. Households targeted were predominantly small-holder farmers who keep fish and harvested at least 
twice in the last 2 years. The target areas were selected in consultation with officers from the Ministry of Agriculture, Livestock and Fisheries and Kenya Marine Fish and Research Institute (KMFRI). In total 100 farmers were interviewed; 34 in Kakamega, 34 in Kisii and 32 in Siaya.

Two questionnaires were used during the interviews. The first questionnaire was intended to collect general information on the farm economy and identify Nile tilapia traits that farmers would like improved. For clarity, all traits were defined, described and explained during the interview (Table 2.1). In the second questionnaire, farmers were asked to perform multiple pair wise comparisons to give the relative importance of the 5 most frequently mentioned traits obtained from the first questionnaire. A total of 10 pair-wise comparison questions [5 $\times(5-$ $1) / 2=10$ pairs] were developed. In each pair wise comparison question, percentage improvements in both traits $(\mathbf{\Delta G} \%)$ were presented and farmers were asked to give a preference on a numerical scale from 1 to 9 , as shown in Figure 2.1. In this figure, the diagonal line represents the decrease in the improvement of growth, when thickness is preferred. For example, if number 9 is selected from the right hand side, this means a farmer would like to have $2.03 \%$ more thicker fish and no genetic improvement on growth (5.6\% faster). To make sure the farmer interpreted the questions correctly it would be explained that $5.6 \%$ faster growing fish means that $1.06 \mathrm{~g} /$ day more would be achieved while $2.03 \%$ thicker means fish will have more flesh/meat and appear more round in shape. In this case pictures and real fish were used to demonstrate the difference.

For each trait, the hypothetical improvement expressed in \% of trait mean was given which equals the change after one generation of phenotypic selection with selection intensity of 1 . For growth rate (GR), table size/harvest weight (HW), thickness $(\mathbf{T})$ and height $(\mathbf{H})$ this was calculated as $i \times h^{2} \times C V$, where $i$ is the intensity of selection, $h^{2}$ is the heritability and $C V$ the coefficient of phenotypic variation. To eliminate the scaling effect, $\sigma_{p}$ was substituted with $\mathrm{CV}\left(\mathrm{CV}=\sigma_{p} / \mu_{p}\right)$ in calculating the response to phenotypic selection, where $\sigma_{p}$ is the phenotypic standard deviation, and $\mu_{p}$ is the phenotypic mean. Parameters were obtained from literature (Table 2.2). For survival (S), genetic change was derived by assuming that selection is changing the underlying liability scale of a trait (Falconer et al., 1996). 
Table 2.1 Definition of traits used in the multiple pair wise comparison questionnaire.

Trait

Definition

\begin{tabular}{|c|c|}
\hline Growth rate & $\begin{array}{l}\text { Growth rate is defined as daily growth coefficient (DGC), which } \\
\text { is a measurement of the growth rate where water temperatures } \\
\text { are assumed to be constant. Fast growing fish takes a shorter } \\
\text { period to obtain a higher body weight at a fixed duration of } \\
\text { rearing period }\end{array}$ \\
\hline Table size & Defined as fish with higher harvest weights. \\
\hline Survival & $\begin{array}{l}\text { Percentage of fish that survive until harvest = fish live at harvest } \\
\text { out of the number of fish initially stocked. }\end{array}$ \\
\hline Late Maturity & $\begin{array}{l}\text { The age at first maturation. Maturation may reduce flesh } \\
\text { quality, the appearance of harvested fish, and may also make } \\
\text { fish aggressive towards other fish }\end{array}$ \\
\hline Feed Conversion Ratio & $\begin{array}{l}\text { The efficiency of a fish in terms of converting feed mass into } \\
\text { increased body weight. The lower FCR, the better the efficiency. }\end{array}$ \\
\hline ur (pink $\epsilon$ & $\begin{array}{l}\text { The color of the fish eye, most consumers in the market prefers } \\
\text { fish with pink eye color, attaching it with sweetness. }\end{array}$ \\
\hline Length & $\begin{array}{l}\text { Measured at maximum horizontal distance from the mouth } \\
\text { until the end of the peduncle. }\end{array}$ \\
\hline Height & $\begin{array}{l}\text { Measured at maximum vertical distance from dorsal to ventral } \\
\text { locations at the mid-side of the fish. }\end{array}$ \\
\hline Thickness & Measured at the maximum thickness. \\
\hline $\begin{array}{l}\text { Parasite } \\
\text { (leech) }\end{array}$ & $\begin{array}{l}\text { The ability of the fish to withstand the infection by leeches in } \\
\text { the ponds }\end{array}$ \\
\hline
\end{tabular}

Table 2.2 Average heritability and coefficient of variation derived from literature and the expected percentage of genetic improvement of the 5 most important traits used in the multiple pair wise comparison.

\begin{tabular}{lcccc}
\hline Trait & $\mathrm{h}^{2}$ & Reference & $\mathrm{CV}$ & $\Delta \mathrm{G} \%$ \\
\hline Harvest weight & 0.38 & 2 & 33 & 12.5 bigger \\
Growth & 0.47 & 1 & 11.9 & 5.6 faster \\
Survival & 0.33 & 3 & - & 4.5 more \\
Height & 0.21 & 1 & 2.3 & 0.5 more \\
Thickness & 0.27 & 1 & 7.5 & 2.03 more \\
\hline $\mathrm{h}^{2}$, heritability; Reference, 1 = Trong et al., 2013, 2 = Charo-Karisa, 2006, 3 = Santos et al., \\
2011; CV, coefficient of variation; $\Delta \mathrm{G} \%$, the expected percentage of genetic improvement.
\end{tabular}




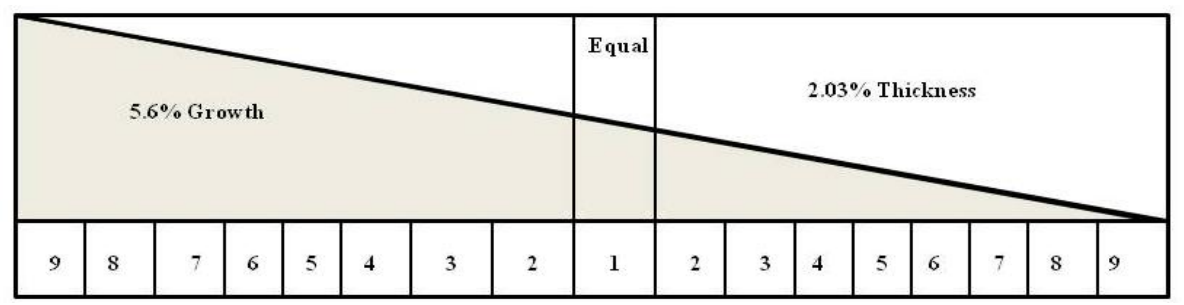

Figure 2.1 Pair wise comparison. Both the intensity of the trait preference (in numeric from 1 to 9) and the percentage of genetic improvement (\%) to be obtained in the traits are captured. One indicates that the two traits are equally important.

\subsubsection{Preferences values for traits}

Estimation of preference values was performed at three different levels; individual, by group (income or market product) and consensus level (across all groups of farmers).

Individual preference value (Ipv). Using analytical hierarchy process (AHP), (Saaty, 1980), the preference values for 100 individual farmers were estimated. The relative importance $\left(a_{j k}\right)$, between the $j^{\text {th }}$ and $k^{\text {th }}$ traits $(j, k=1,2,3,4$ and 5) were expressed using a numeric score 1 to 9 (Figure 2.1). In each entry of the traits $\left(a_{j k}\right)$ in a pair wise comparison, a matrix $(A=5 \times 5)$ was created. In the matrix, the upper elements off diagonal represented the relative importance of the $j^{\text {th }}$ trait to the $k^{\text {th }}$ trait and the lower off diagonal elements contained the reciprocal relative importance of matrix $A$. If the two traits have the same importance, then entry $a_{j k}$ is $1\left(a_{j k} \cdot a_{k j}=1\right)$. From the outcome, the normalized pair wise comparison matrix $A$ was done by making equal to 1 the sum of the entries on each column to obtain individual preference values (Saaty, 1980). From each pair-wise comparison outcome, the consistency ratio (CR) was checked. A CR of less than 0.10 is reliable (Saaty, 1980). When CR was greater than 0.1 , then the same farmers would be revisited and the questionnaire re-administered critically. The individual preference values and corresponding CR were estimated using Super Decisions software (Saaty, 2003).

Group preference value (Gpv). Farmers from the survey were grouped based on their income level and the product they produced. For income, 3 groups of farmers were identified; low, medium and high income farmers. For product, 3 groups of farmers were identified: farmers producing fingerlings, farmers 
producing table-size fish, and farmers producing both fingerlings and table-size fish. Using Weighted Goal Programming (WGP), the individual preference values (Ipv) were combined into group preference values $(G p v)$ according to procedure outlined by Linares and Romero (2002). The objective of WGP is:

$\operatorname{Min} \sum_{k=1}^{5} \sum_{g=1}^{p}\left(m_{i g}+o_{i g}\right)^{\tau}$

subject to

$$
G p v_{k}^{p}+m_{i g}-o_{i g}=I p v_{k}^{c p}
$$

Equation 1

where $k$ is the number of traits, 1 to 5 to be decided upon by $p$ groups within each group; $I p v_{k}^{c p}$ is the individual preference value attached to the $k^{\text {th }}$ trait by the $c^{\text {th }}$ member of the $p^{\text {th }}$ group; $\left(G p v_{k}{ }^{p}\right)$ is the group/combined preference value attached to the $k^{\text {th }}$ trait by the $p^{\text {th }}$ group; and $m_{i g}$ and $o_{i g}$ are the negative and positive deviations for $I p v_{k}^{c p}$ from $G p v_{k}^{p}$ respectively. The metric $\pi$ act as a weight attached to the sum of deviation variables, and was set to 1 . When $\pi=1$, the preferences represents a solution where the sum of individual disagreements are minimized and the corresponding Gpv solution is statistically defined by the median weights. For each group, preference values were normalized so that their sums added up to 1. LINGO computer software was used to perform the weighted goal programming (LINDO Systems, Inc., 1999).

Consensus preference values (Cpv). The final step is aimed at reaching agreement between income groups or producer groups. Agreement is needed when the aim is to develop a harmonized breeding objective that serves all farmers. Using Extended WGP the consensus preference values ( $C p v)$ were elicited from the Gpv. Extended WGP was defined as:

$$
\operatorname{Min}\left[(1-\lambda) S s+\lambda T^{a}\right] \quad \text { with } \quad T^{a}=\sum_{k=1}^{5} \sum_{p=1}^{n}\left(\begin{array}{c}
m_{k p}^{-}+o_{k p}^{-} \\
m_{k=1}
\end{array}\right)
$$

where $\bar{m}_{k p}+\bar{O}_{k p}$ is the sum of the negative and positive variable deviations of the $p^{\text {th }}$ group preference value from the consensus preference value for the $k^{\text {th }}$ trait (1 to 5 traits). Consequently, the summation of these values gives $S s$, which is the disagreement between the $p^{\text {th }}$ group and the consensus preference values. Whereas, $T^{a}$ is the total value obtained by adding all Ss values.

The goals are; 


$$
\begin{array}{ll}
\sum_{k=1}^{5}\left(\begin{array}{c}
- \\
m_{k l}+o_{k l}
\end{array}\right)-S s \leq 0, & \\
\sum_{k=1}^{5}\left(\begin{array}{c}
- \\
m_{k n}+o_{k n}
\end{array}\right)-S s \leq 0 & \text { Equation 2 } \\
C p v_{k}^{p}+\bar{m}_{k p}-\bar{o}_{k p}=G p v_{k}^{p}, k \in\{1 \ldots .5\}, p \in\{1 \ldots . . n\} &
\end{array}
$$

The lambda $(\lambda)$ is the coefficient, which determines the weight on the minority groups. When $\lambda$ equals 0 , then $\pi$ becomes infinity, thus equation 2 defines the consensus preference values by minimizing the disagreement of the most displaced group. For $\lambda=1, \pi$ equals to 1 which defines the consensus preference values by maximizing the average agreement. Equation 2 was solved with LINGO with values of $\lambda$ being varied from 0 to 1 .

\subsubsection{Derivation of desired genetic gains}

Desired genetic gains for the breeding objective traits were derived by multiplying the expected genetic improvement $(\Delta G \%$, Table 2.2$)$ with the consensus preference values for income and product groups (Sae-Lim et al., 2012).

\subsection{Results}

\subsubsection{Fish farming characteristics}

The main characteristics of the farming systems in the three study areas are presented in Table 3. Income range per month for each group was defined as; low (<US\$250), medium (US\$250 - 350) and high income (>US\$350). Of the interviewed farmers, $32 \%$ had low income, $43 \%$ medium income, and $25 \%$ high income. Only medium and high income farmers produced fingerlings, or a combination of fingerlings and table size fish. Low income farmers produced only table size fish. In all income groups, farmers reared fish for own household consumption and to obtain income. Fish sales were more important in the higher income group. Crop sale as a source of income was mainly practiced by low and medium income farmers while livestock sale (50\%) was largely practiced by high income group of farmers.

Fish were reared and owned mainly by individual farmers while only high income farmers (100\%) owned and managed ponds in cooperatives mostly under semi28 
intensive production (Table 2.3). Majority of low income farmers reared their fish for up to 6 months before harvesting. On the other hand, medium and high income farmers reared their fish for up to 8 months. Only farmers from medium and high income groups used commercial feeds. Low income farmers fed their fish with local feeds and farmers across all income groups included kitchen waste in their feeding regime (Table 2.3).

Farmers typically owned 1 to 4 ponds, with the largest number of ponds owned by high income farmers and the smallest number by low income farmers. Low income farmers had smaller ponds than high income farmers. The pond size was directly related to the size of land owned by the farmers. 
Table 2.3 Socio-economic characteristics for $O$. niloticus farmers by income group.

$\%$ distribution of farmers over income groups

\begin{tabular}{|c|c|c|c|c|}
\hline & & & & \\
\hline Variable & Number & Low & Medium & High \\
\hline Respondents per income group & & 32 & 43 & 25 \\
\hline \multicolumn{5}{|l|}{ Respondents per producer group } \\
\hline Fingerlings & 17 & - & 41.2 & 58.8 \\
\hline Table size & 53 & 60.4 & 28.3 & 11.3 \\
\hline Table size and Fingerlings & 30 & - & 70 & 30 \\
\hline \multicolumn{5}{|l|}{ Source of cash income } \\
\hline Fish sale & 63 & 25.4 & 34.9 & 39.7 \\
\hline Crop sale & 24 & 58.3 & 41.7 & - \\
\hline Livestock sale & 35 & 17.1 & 40 & 42.9 \\
\hline \multicolumn{5}{|l|}{ Fish ownership } \\
\hline Individual & 66 & 30.3 & 42.4 & 27.3 \\
\hline Family & 27 & 44.4 & 55.6 & - \\
\hline Cooperative & 7 & - & - & 100 \\
\hline \multicolumn{5}{|l|}{ Rearing period } \\
\hline Up to 6 months & 41 & 63.4 & 26.8 & 9.6 \\
\hline Up to 8 months & 45 & 13.3 & 51.1 & 35.6 \\
\hline > a year & 14 & - & 64.3 & 35.7 \\
\hline \multicolumn{5}{|l|}{ Feeding management } \\
\hline Only commercial feed & 16 & - & 25 & 75 \\
\hline Only Local feeds & 66 & 48.5 & 42.4 & 9.1 \\
\hline Both local and commercial feeds & 18 & - & 61.1 & 38.9 \\
\hline Include kitchen waste & 73 & 43.8 & 39.7 & 16.4 \\
\hline
\end{tabular}

Number, number of farmers; Low, low income farmers; Medium, medium income farmers; High, high income farmers; only commercial feed, formulated feeds with $>30 \%$ crude protein; only local feeds, local feeds with $<26 \%$ crude protein.

Most of the farmers sold their harvested fish fresh and whole both at local and urban markets, with a larger proportion selling at farm gate. High and medium income group of farmers were the major players of fingerling production and sold their fingerlings at a premium price of US\$0.06. The price of table size fish depended on the weight of the fish, height and thickness; on average, thicker fish fetched better prices because thicker fish are believed to have more flesh. Medium and high income farmers generally sold fish with larger height and thickness (Table 2.4). 
Table 2.4 Sale prices for the different product classes of fish and \% distribution of farmers by income group.

\begin{tabular}{|c|c|c|c|c|c|}
\hline \multirow[b]{2}{*}{ product class } & \multirow[b]{2}{*}{$\begin{array}{l}\text { Price } \\
\text { (US\$) }^{a}\end{array}$} & \multirow[b]{2}{*}{$\begin{array}{l}\text { Price } \\
\text { (US\$) }^{\text {b }}\end{array}$} & \multicolumn{3}{|c|}{$\begin{array}{l}\% \quad \text { Distribution } \\
\text { farmers }\end{array}$} \\
\hline & & & Low & Medium & High \\
\hline Fingerlings & $<0.06$ & - & - & 41.2 & 58.8 \\
\hline Table size fish & $1.18-2.35$ & 3.5 & 43.4 & 28.3 & 28.3 \\
\hline with good height & $1.18-2.94$ & 4.1 & - & 37.5 & 62.5 \\
\hline $\begin{array}{l}\sim \text { with good height and } \\
\text { thickness }\end{array}$ & $1.18-3.53$ & 4.7 & - & 31.2 & 68.8 \\
\hline
\end{tabular}

US\$ $\$^{\mathrm{a}}$, US dollars per fish; US\$ $\$^{\mathrm{b}}$, US dollars per kg; Low, low income farmers; Medium, medium income farmers; High, high income farmers.

\subsubsection{Trait ranking}

A number of traits were initially presented to farmers to identify and rank the traits they consider to be important. These traits were: harvest weight, growth, survival, late maturity, feed conversion ratio, eye color (pink eye), parasite resistance (leech) and shape of the fish which was described by height, length and thickness. Based on mean ranking, harvest weight ranked first ( $\mathrm{HW}, 1.32)$, followed by growth rate $(G R, 2.76)$, feed conversion ratio (FCR, 2.98), survival $(S, 3.67)$, thickness ( $T, 4.09)$, late maturity $(L M, 4.45)$, and height $(H, 4.71)$. These traits were subsequently used to set up the pair wise comparisons. Feed conversion ratio and LM were excluded as we could not obtain reliable genetic parameters from literature.

\subsubsection{Preference values for breeding goal traits}

The average individual preference values for $H W, S, G R, T$ and $H$ ranged from 0.046 to 0.33 . The preference values indicated that improvement in $\mathrm{HW}, \mathrm{S}$ and $\mathrm{GR}$ were more preferred than improvement in $\mathrm{T}$ and $\mathrm{H}$. A distinctive difference between high on one hand, and low and medium income farmers on the other hand was observed in preference values for HW and GR (Table 2.5). Group preference values for income groups showed that low and medium income farmers preferred HW followed by GR and S. High income farmers ranked GR as the most preferred trait. Both $\mathrm{H}$ and $\mathrm{T}$ had the lowest preference values irrespective of income group. However, more than half of the farmers (14) from the high income group indicated a preference for $\mathrm{T}$ and $\mathrm{H}$ traits. Fingerling producers preferred $\mathrm{GR}$ and $\mathrm{S}$ more than $\mathrm{HW}, \mathrm{H}$ and $\mathrm{T}$. For the farmers that produce table size fish only, HW was highly preferred, followed by GR and S, while farmers that produced both table size fish and fingerlings preferred $\mathrm{S}$ more than HW and GR (Table 2.5). 
For income group, consensus preference values for GR, HW, S, H and T traits ranged between 0.044 to 0.332 . For product group, the consensus preference values for $\mathrm{GR}, \mathrm{HW}, \mathrm{S}, \mathrm{H}$ and $\mathrm{T}$ traits ranged between 0.041 to 0.314 .

Table 2.5 Group and consensus preference values for income and product groups of farmers for different traits.

\begin{tabular}{lllllrrrrr}
\hline & \multicolumn{3}{c}{ Income groups of farmers } & & \multicolumn{5}{c}{ Product groups of farmers } \\
\cline { 2 - 5 } \cline { 7 - 9 } Trait & Low & Medium & High & Conl & Fingerlings & Table size & FL+TS & ConP \\
\hline GR & 0.264 & 0.303 & 0.380 & 0.311 & & 0.345 & 0.288 & 0.243 & 0.279 \\
HW & 0.355 & 0.361 & 0.312 & 0.332 & & 0.204 & 0.348 & 0.312 & 0.303 \\
S & 0.266 & 0.272 & 0.291 & 0.266 & & 0.345 & 0.251 & 0.324 & 0.314 \\
H & 0.042 & 0.052 & 0.069 & 0.044 & & 0.042 & 0.041 & 0.049 & 0.041 \\
T & 0.065 & 0.084 & 0.098 & 0.086 & & 0.065 & 0.072 & 0.071 & 0.063 \\
Ss & 0.169 & 0.114 & 0.124 & $0.407^{*}$ & & 0.184 & 0.117 & 0.058 & $0.359^{*}$ \\
\hline
\end{tabular}

Low, group preference of low income farmers; Medium, group preference of medium income farmers; High, group preference of high income farmers; Conl, consensus preference values for income group of farmers; Fingerlings, group preference of fingerling producing farmers; Table size, group preference of table size producing farmers; FL+TS, group preference of fingerlings and table size producing farmers; ConP, consensus preference values for product group of farmers; GR, growth rate; HW, harvest weight; $\mathrm{S}$, survival; $\mathrm{H}$, height; T, thickness; Ss, the disagreement values between the $p^{\text {th }}$ group and the consensus preference values; ${ }^{*}$, Ta values, which is the total value obtained by adding all Ss values for income and product group.

The desired genetic gains for traits in the breeding objective are given in Table 2.6. For income group of farmers, the desired gains ranged between 0.02 to 4.15 , while the corresponding desired gains for the product group of farmers ranged between 0.02 to 3.79 .

Table 2.6 Desired genetic gains derived from consensus preference values for income and product groups of farmers and expected percentage of genetic improvement for different traits.

\begin{tabular}{llll}
\hline Trait & $\Delta \mathrm{G} \%$ & ${ }^{*}$ Income group & *Product group \\
\hline Growth & 5.6 & 1.74 & 1.56 \\
Harvest weight & 12.5 & 4.15 & 3.79 \\
Survival & 4.5 & 1.20 & 1.41 \\
Height & 0.5 & 0.02 & 0.02 \\
Thickness & 2.0 & 0.17 & 0.13 \\
\hline \multicolumn{4}{l}{$\Delta$ G\%, expected percentage of genetic improvement; ${ }^{*}$, desired genetic gains. }
\end{tabular}




\subsection{Discussion}

Preference-based methods have proven extremely useful for quantifying the range and perceptions of trait priorities of farmers; especially in situations where production systems are highly diverse and where there are not enough farm economic data to develop economic values of traits (Sölkner et al., 1998; Wurzinger et al., 2006; Gizaw et al., 2010). Analytical Hierarchy Process (AHP; Saaty, 1980) can be used to translate rankings in preference values and subsequently into desired gains which most participatory approaches do not provide for traits under selection (Sae-Lim et al., 2012). The strength of AHP method to estimate preference values for a given set of traits lies in its ability to structure complex and multi-attribute problems hierarchically. In addition, the AHP method provides a unique means of quantifying judgmental consistency (Saaty, 1980; 2003). The AHP method can be combined with any method capable of deriving individual weights in multi-criteria problems by ranking the criteria according to the needs of the farmers leading to more precise decisions on traits preferences (Saaty, 1980; Sae-Lim et al., 2012). However, AHP method has its limitations. Most importantly, it is not suited in situations where more than seven traits are to be analyzed as the number of pair wise comparisons becomes unworkable. In addition, it is not possible to derive economic values for traits preferences to be included in the breeding goal (Sae-Lim et al., 2012). Other methods like PAPRIKA (Potentially All Pairwise RanKings of all possible Alternatives) have been proposed to be useful in such scenarios (Hansen et al., 2009). The advantage of PAPRIKA is that there is no limit to the number of traits to be investigated (Byrne et al., 2012). However, a potential issue with PAPRIKA being a choice-based approach for the derivation of economic values is that participants can confound the economic implications of changes in a trait with the level of genetic variation for the trait (Byrne et al., 2012). In any case, the specification of the survey itself (trait definitions and trait levels) remains the critical aspect in developing preference-based surveys like AHP or PAPRIKA to define breeding objectives. It is particularly important that participants are presented with realistic alternatives with respect to trait variation. Moreover, it is critical that when offered a trade-off, each respondent understands and correctly interprets the definition of each trait, and therefore provides a valid response. To obtain a valid response, unambiguous trait definitions must be included in the survey. 


\subsubsection{Socio-economic characteristics of fish farmers}

Across all surveyed households fish farming played an important role to nutrition. Fish are rich in essential nutrients and households engaged in small-scale fish farming are able to improve their own nutritional intakes by consuming some of the fish they produced. Secondly, all farmers cited fish as a source of income. The income enabled households to access other foods and to improve their overall living standards. However, the amount of fish harvested and revenue collected from fish sales varied largely between farms. Low income farmers mostly practiced subsistence fish farming while both medium and high income farmers ran their fish ponds as a business with the intention of generating income. The variation in income was reflected in distinct differences in the general pond management practices by farmers including their feeding strategies and the prevailing time of harvest. The income from other income-generating activities (e.g. crops and livestock sale) was also paramount and needed to sustain fish farming. This combination of agriculture and aquaculture was also found in Malawi and other developing countries by Aiga et al. ( 2009) and Kawarazuka and Béné (2010).

Farmers fed their fish diverse feeds, from local to commercial feeds. Majority of farmers were feeding local feeds and all farmers included kitchen waste in their feeding regime. In addition, most high income farmers also fed fish with commercial feeds. Feeds manufactured for fish by the private sector were available, but most farmers indicated that the prices were too high, hence only high income farmers could afford to buy commercial feeds. The current study revealed that most farmers (66\%) fed a variety of feeds, mainly local feeds with less than $26 \%$ crude protein. In addition, all respondents frequently fertilized their ponds for natural zoo- and phyto-plankton growth that fish naturally fed on. This is in agreement with the findings of Charo-Karisa (2006) who stated that resource constrained farmers, who reared their fish in stagnant outdoor ponds in the tropics, mainly rely on pond fertilization for natural feeds production and feed supplementation.

\subsubsection{Preference values}

Performing a multiple pair wise comparison exercise is demanding for the interviewed farmers and can lead to inconsistencies in the answers. It is therefore recommended that the number of traits to be evaluated should be limited to a maximum of 7 (Saaty, 1980; Sae-Lim et al., 2012). In this study, we used only 5 
traits, which is well within the recommended range. Analysis revealed that only few (11) farmers had a poor consistency ratio. Those that had a consistency ratio of more than 0.10 were re-visited and the questionnaire was re-administered making sure that the questions were carefully elaborated and explained to farmers.

Preference values calculated by income group showed that low and medium income farmers preferred harvest weight followed by growth rate and survival, respectively. Majority (75\%) of the interviewed farmers were low and medium income farmers, who market live fish; heavy fish at harvest will fetch better market prices. On the other hand, high income farmers ranked growth rate as the most important trait. Most high income farmers on average had better feeding strategies including commercial feeds and better technical skills for fish farming. Growth rate during grow out period is critical to farmers because the cost of feeds is high during this period (Besson et al., 2014). High income farmers use longer grow-out periods than low-income farmers. This is because they use growth rate to optimize harvest time depending on market prices and feed costs.

Grouping farmers according to production showed that fingerling producers preferred growth rate and survival. Majority of farmers in this group had a high income, were more knowledgeable and more resource endowed. Sevilleja (2001) reported that the production and management of fingerlings generally requires more resources, skills and technology than rearing grow out fish, which is in agreement with the findings from this study. Fast growing fingerlings with good survival rate will fetch better prices. On the other hand, fattening farmers producing table size fish emphasized on harvest weight and growth rate as the traits of interest. Heavy fish at harvest will fetch better market prices at the end of the production cycle for these farmers. For farmers producing both fingerlings and table size fish, survival was highly preferred. In this study, farmers cited predation as the cause of increased mortalities for both fingerlings and grow out fish. Survival for fingerlings and overall fish survival to harvest is important to achieve optimum profit in a farm. This is in agreement with Ponzoni et al. (2007) who reported that growth and survival are the main criteria for a farmer to receive economic returns. In addition, Bennison et al. (1997) reported the importance of survival of animals in relation to milk and meat production in a production system where farmers might aim at maximizing on the numbers even if the individual productivity is low, to 
achieve high profits. Selection for overall survival improves resistance against multiple mortality factors (Vehviläinen et al., 2008).

The relevance of body shape in marketing fish is often important to both consumers and producers (Blonk et al., 2010; Trong et al., 2013). In this study, different body measurements (length, height and thickness) were used to describe fish shape. From the results, height and thickness were ranked as less important compared to harvest weight and growth rate by all groups. Though ranked as less important, better shaped fish fetched better prices (Table 2.6), which explains why some high income farmers showed higher preferences for shape. Taken together, our results show that high income farmers have a different market orientation, which translates in different management strategies and different preferences for breeding goal traits.

\subsubsection{Implications for a breeding program}

Feed conversion ratio and late maturity were mentioned by farmers to be among the most important traits. Feed is one of the major costs of fish production to many fish farmers, especially during grow out time and improved FCR is important to reduce cost and increase farm profit (Besson et al., 2014). However, FCR was removed from further analysis, first because there are no reliable genetic parameters for this trait. Secondly, in many livestock species growth rate is favorably correlated to increased feed conversion efficiency (Quillet et al., 2007; Ponzoni et al., 2007).

Late maturation is a preferred trait because early maturation during grow-out period spoils flesh quality; mature males become more aggressive against other fish, resulting in wounds, fin erosion, and poor appearance. In addition, early maturation will enhance early spawning thus resulting in stunted growth. Due to lack of reliable genetic parameters for this trait, it was excluded from the study. Studies on the correlation between growth rate and early maturation in tilapia have been inconclusive. Selection for improved growth may increase the frequency of early maturing females, but not males (Longalong et al., 1999). Results from other studies (Kronert et al., 1989; Charo-Karisa, 2006) show zero correlations between harvest weight or growth rate and maturation. In this case, inclusion of late maturation in the breeding goal would only reduce the response to selection for growth traits. Clearly this is an issue that warrants further research. 
Socio-economic factors have an effect on animal and farm management, decision making and the general perception of breeds by farmers (Kosgey et al., 2006). These factors, therefore, need to be considered in the design and implementation of a breeding program. Kosgey (2004) pointed out that without a good understanding of these factors, it would be very difficult for farmers to fully participate and cooperate in a breeding program.

Based on the results obtained in this study, two distinct breeding objectives can be defined. The majority of farmers (75\%) in income group were between low and medium income; a breeding goal for this group should focus on harvest weight and less on growth rate. This breeding goal will satisfy mainly grow out farmers who rear fish to harvest.

Secondly, a breeding goal can be defined based on market orientation with farmers who are either fingerling producers, table size fish producers or fingerlings and table size producers. One of the key constraints that all farmers raised was poor quality fingerlings. There should be a sufficient supply of good quality fingerlings that grow fast and with high survival, to meet the farmers demand, especially for low income farmers. Current practice shows that many (medium and high income) farmers buy their own broodstock to produce fingerlings. Our results show that a breeding goal that takes into account the differences in types of farmers and the product they market (fry or table size fish) is important. The consensus breeding goal for product group emphasizes survival 15\% more than the income oriented breeding goal that mainly serves low and medium income grow-out farmers. Similar results were obtained by Sae-lim et al. (2012), who observed large differences in preferences between fingerling, table size and large fish producers of rainbow trout. However, dividing a breeding program to meet different groups of farmers comes with a cost since more than one breeding program would need to be established. This indicates that consensus is more important for fish farmers who have different product objectives. In these situations, extended WGP is a valuable tool to minimize the disagreement between groups. Extended WGP takes both minority opinion and overall disagreement into account. The consensus values obtained for trait preferences for these groups of farmers represent an optimal point where all farmers were equally satisfied (Table 2.5). Further analysis need to reveal whether the differences between income and product groups of farmer's 
preferences (Table 2.5) are large enough to justify different breeding programs for different groups of producers.

\subsection{Conclusions}

Understanding farmers' production practices and including farmer preferences in the breeding strategy is essential for the design of sustainable breeding programs. Using a participatory approach, we have shown that farmers' preferences for traits differed significantly depending on income and market orientation. In developing breeding objectives, it is paramount to consider not only traits that respond to market trends, but also traits that farmers judge important from their production system perspective. In this study we show how to develop sustainable breeding goals for 0 . niloticus based on income or market orientation of farmers. Through estimation of consensus preference values, farmers' diverse backgrounds and preferences for traits can be taken into account leading to harmonized breeding goals.

\section{Acknowledgements}

This work is part of the first author's sandwich PhD program funded by Koepon Foundation, their support is acknowledged. We thank fish farmers in Kenya for provision of information. We thank Panya Sae-Lim for his help in the analysis.

\section{References}

Aiga, H., Matsuoka, S., Kuroiwa, C., Yamamoto, S., 2009. Malnutrition among children in rural Malawian fish-farming households. Trans. R. Soc. Trop. Med. Hyg. 103, 827-833.

Bennison, J., Barton, D., Jaitner, J., 1997. The production objectives and feeding strategies of ruminant livestock owners in The Gambia: implications for policy makers. Agric. Sys. 55, 425-444.

Besson, M., Komen, H., Aubin, J., de Boer, I.J.M., Poelman, M., Quillet, E., Vancoillie, C., ๆ Vandeputte, M., van Arendonk, J.A.M., 2014. Economic values of growth and feed efficiency for fish farming in recirculating aquaculture system with density and nitrogen output limitations: a case study with African catfish (Clarias gariepinus). J. Anim. Sci. 92, 5394-5405.

Blonk, R.J.W., Komen, J., Tenghe, A., Kamstra, A., van Arendonk, J.A.M., 2010. Heritability of shape in common sole, Solea solea, estimated from image analysis data. Aquaculture 307, 6-11. 
Byrne, T.J., Amer, P.R., Fennessy, P.F., Hansen, P., Wickham, B.W., 2012. A preference-based approach to deriving breeding objectives: applied to sheep breeding. Animal 6, 778-788.

Charo-Karisa, H., 2006. Selection for growth of Nile tilapia (Oreochromis niloticus L.) in Low-input environments (PhD Thesis) Wageningen Universiteit (169 pp.).

Falconer, D.S., Mackay, T.F., Frankham, R., 1996. Introduction to Quantitative Genetics. 4th edn. Longman Group Ltd., Essex, UK (464 pp.).

Gizaw, S., Komen, H., van Arendonk, J.A., 2010. Participatory definition of breeding objectives and selection indexes for sheep breeding in traditional systems. Livest. Sci. 128, 67-74.

Hansen, P., Ombler, F., 2009. A New Method for Scoring Additive Multi-attribute Value Models Using Pairwise Rankings of Alternatives. JMCDA 15, 87-107.

Kawarazuka, N., Béné, C., 2010. Linking small-scale fisheries and aquaculture to household nutritional security: an overview. Food Sec. 2, 343-357.

Kosgey, I.S., 2004. Breeding objectives and breeding strategies for small ruminants in the tropics (PhD Thesis) Wageningen Universiteit (272 pp.).

Kosgey, I.S., Baker, R.L., Udo, H.M.J., van Arendonk, J.A.M., 2006. Successes and failures of small ruminant breeding programmes in the tropics: a review. Small Ruminant Res, 61, 13-28.

Kronert, U., Hörsten-Schwark, G., Langholz, H.J., 1989. Prospects of selecting for late maturity in Tilapia (Oreochromis niloticus). I: family studies under laboratory conditions. Aquaculture 77, 113-121.

Linares, P., Romero, C., 2002. Aggregation of preferences in an environmental economics context: a goal-programming approach. Omega 30, 89-95.

LINDO Systems Inc., 1999. LINGO User's Guide, LINDO Systems Inc., Chicago, USA (172 pp.).

Longalong, F.M., Eknath, A.E., Bentsen, H.B., 1999. Response to bi-directional selection for frequency of early maturing females in Nile tilapia (Oreochromis niloticus). Aquaculture 178, 13-25.

Ponzoni, R.W., Nguyen, N.H., Khaw, H.L., 2007. Investment appraisal of genetic improvement programs in Nile tilapia (Oreochromis niloticus). Aquaculture 269, 187-199.

Poulton, C., Dorward, A., Kydd, J., 2010. The Future of Small Farms: New Directions for Services, Institutions, and Intermediation. World Dev. 38, 1413-1428. 
Quillet, E., Le Guillou, S., Aubin, J., Labbé, L., Fauconneau, B., Médale, F., 2007. Response of a lean muscle and a fat muscle rainbow trout (Oncorhynchus mykiss) line on growth, nutrient utilization, body composition and carcass traits when fed two different diets. Aquaculture 269, 220-231.

Saaty, T.L., 1980. The analytic hierarchy process: planning, priority setting, resources allocation. McGraw-Hill, New York, USA (283 pp.).

Saaty, T.L., 2003. Decision making in complex enviroments; The analytic hierarchy process (AHP) for decision making and the analytic network process (ANP) for decision making with independence and feedback. Super decisions. Creative decisions foundations in Pittsburgh, Pennsylvania, USA (121 pp.).

Sae-Lim, P., Komen, H., Kause, A., Van Arendonk, J., Barfoot, A., Martin, K., Parsons, J., 2012. Defining desired genetic gains for rainbow trout breeding objective using analytic hierarchy process. J. Anim. Sci. 90, 1766-1776.

Santos, A.I., Ribeiro, R.P., Vargas, L., Mora, F., Alexandre Filho, L., Fornari, D. C., Oliveira, S.N.d., 2011. Bayesian genetic parameters for body weight and survival of Nile tilapia farmed in Brazil. Pesqui. Agropecu. Bras. 46, 33-43.

Sevilleja, R., 2001. Adoption and economics of tilapia farming technology in the Philippines. https://ir.library.oregonstate.edu/xmlui/bitstream/handle/ 1957/30433/012.pdf?sequence=1. Accessed on 15 May, 2015 (8 pp.).

Sölkner, J., Nakimbugwe, H., Valle Zarate, A., 1998. Analysis of determinants for success and failure of village breeding programmes. Proceedings of the 6th World Congress on Genetics Applied to Livestock Production. Armidale, Australia, 12-16 January 1998.

Tano, K., Kamuanga, M., Faminow, M.D., Swallow, B., 2003. Using conjoint analysis to estimate farmer's preferences for cattle traits in West Africa. Ecol. Econ. 45, 393-407.

Trọng, T.Q., Mulder, H.A., van Arendonk, J.A., Komen, H., 2013. Heritability and genotype by environment interaction estimates for harvest weight, growth rate, and shape of Nile tilapia (Oreochromis niloticus) grown in river cage and VAC in Vietnam. Aquaculture 384, 119-127.

Vehviläinen, H., Kause, A., Quinton, C., Koskinen, H., Paananen, T., 2008. Survival of the currently fittest: genetics of rainbow trout survival across time and space. Genetics, 180, 507-516.

World Bank, 2013. Fish to 2030. Prospects for Fisheries and Aquaculture. Agriculture and Environmental Services Discussion Paper 03. World Bank Report, number 83177-GLB (102 pp.). 
Wurzinger, M., Ndumu, D., Baumung, R., Drucker, A., Okeyo, A., Semambo, D., Byamungu, N., Sölkner, J., 2006. Comparison of production systems and selection criteria of Ankole cattle by breeders in Burundi, Rwanda, Tanzania and Uganda. Trop. Anim. Health Prod. 38, 571-581. 


\section{Genotype by environment interaction for harvest weight, growth rate and shape between monosex and mixed sex Nile tilapia (Oreochromis niloticus)}

Omasaki S.K. ${ }^{a, d}$, van Arendonk J.A.M. ${ }^{b}$, Charo-Karisa H. ${ }^{c}$, Kahi A.K. ${ }^{d}$, Komen H. $^{a^{*}}$

\footnotetext{
${ }^{a}$ Animal Breeding and Genomics Centre, Wageningen University, P. O. Box 338, $6700 \mathrm{AH}$ Wageningen, The Netherlands, ${ }^{\mathrm{b}}$ Hendrix Genetics Research, Technology and Services, P.O. Box 114, 5830 AC Boxmeer, The Netherlands, 'State Department of Fisheries, P.O Box 58187, Nairobi-00200, Kenya, 'Animal Breeding and Genomics Group, Department of Animal Sciences, Egerton University, P.O Box 536, Egerton20115, Kenya
} Aquaculture 458, 75-81 


\begin{abstract}
In Kenya, Nile tilapia (Oreochromis niloticus) is mostly grown in ponds. To avoid excessive reproduction and stunted growth, fingerlings are treated with methyltestosterone to make all-male populations (monosex). For a national breeding program that aims to provide genetically improved broodstock to hatcheries that supply monosex fry to smallholder pond farmers, it is important to assess the genetic correlation ( $\mathrm{rg}$ ) for traits between the mixed sex breeding candidates from the breeding nucleus and monosex production fish. The purpose of the study was to estimate genetic parameters for harvest weight (HW), daily growth coefficient (DGC) and body shape and investigate genotype by environment interaction (GxE) for these traits between mixed sex and monosex populations. Forty-eight sires and 76 dams from the $F_{2}$ generation of a local 0 . niloticus strain, kept at Sagana Aquaculture Research Station, Kenya were used to produce 76 full-sib families. Mixed sex fry (3 days old) from each full sib family were divided into two groups of 50 individuals each. One group (monosex) was fed a diet treated with methyltestosterone to induce sex reversal while the other group (mixed sex) was reared on a control diet. After hapa rearing, tagging and weighing, fish were randomly divided and stocked in six earthen ponds, three for mixed sex and three for monosex fish. After 5 months, fish were harvested, photographed and weighed. Genetic parameter estimates for HW, DGC, and shape were obtained on 2105 fish. Heritability estimates for HW, DGC and shape were $0.21 \pm 0.03,0.26 \pm 0.04$ and $0.12 \pm 0.03$ for mixed sex respectively. Genetic correlations for HW between monosex and mixed sex was $0.74 \pm 0.14$, suggesting low GxE. The corresponding rg for DGC and shape were lower; $0.59 \pm 0.10$, and $-0.19 \pm 0.11$, respectively, denoting presence of GxE. It is concluded that GxE between the mixed sex nucleus and monosex production fish is important, and that a breeding program for Nile tilapia needs to include production performance from monosex siblings.
\end{abstract}

Key words: Nile tilapia, harvest weight, growth rate, monosex, genotype by environment interaction, Kenya. 


\subsection{Introduction}

Worldwide, Nile tilapia (Oreochromis niloticus), and its hybrids are the most cultivated and widely farmed fish species, ranking second only after carps (CharoKarisa et al., 2006). In 2013, the production of Nile tilapia was estimated to be over 4.5 million tons (World Bank, 2013). Culture of tilapia primarily takes place in cages and ponds (Tsadik and Bart, 2007). A major concern for tilapia pond culture systems is the reduction of growth rate at the onset of sexual maturity and excessive reproduction leading to overpopulation (Damien et al., 2003). Monosex tilapia culture that constitutes males only can be employed to control reproductive activity, to attenuate growth inhibiting effects of interactions between the sexes and to increase production because males grow faster than the female in these species (Pham et al., 1998; Phelps and Popma, 2000; Damien et al., 2003). As a consequence of these effects, the economic feed conversions are generally more favourable in monosex male populations (Lone and Ridha, 1993).

Selective breeding remains the main driving force for development of resource efficient, sustainable and increased productivity in any livestock species. For most breeding programmes, selection of breeding candidates takes place in a wellcontrolled "nucleus" environment whereas the rearing of production individuals takes place in more heterogeneous environments. Genotype by environment interaction (GxE) can occur due to differences in the sensitivity of individuals to the nucleus and production environments. In the presence of GxE, re-ranking of individuals and heterogeneity of genetic variance makes genetic improvement obtained by selecting individuals in one environment to differ with other environments (Lynch and Walsh, 1998; Kolmodin et al., 2002; Sae-Lim et al., 2014).

The magnitude and importance of GxE in aquaculture varies depending on the production environments. In Nile tilapia, most GxE studies have focussed on comparison of production systems such as ponds and cages, using harvest weight as the trait of interest (Khaw et al., 2009; Bentsen et al., 2012). Results so far show that GxE is probably not biologically important as indicated by relatively high genetic correlations ranging from $0.73-0.99$ (Eknath et al., 2007; Thodesen et al., 2011; Trọng et al., 2013; Khaw, 2015). Surprisingly, there are no estimates of genetic correlations between monosex and mixed sex Nile tilapia.

In Kenya, Nile tilapia farming is practiced by small scale farmers and is largely characterized by low inputs and diverse farming conditions in terms of income level 
and market objective (Omasaki et al., 2016). The predominant production system is earthen ponds using monosex male tilapia. For a national breeding program that aims to provide genetically improved Nile tilapia brood-stock to hatcheries that supply monosex fry to smallholder pond farmers, genetic parameters for monosex and mixed sex are needed. The purpose of this study therefore, was first, to estimate the genetic parameters for harvest weight, daily growth coefficient and body shape traits in the mixed sex nucleus, and secondly; to investigate the magnitude of genotype by environment interaction between mixed sex and monosex populations for these traits.

\subsection{Materials and methods}

\subsubsection{The Location of the breeding program}

Selective breeding program for O. niloticus in Kenya is conducted at Sagana Aquaculture Research Station (National Breeding Centre for Kenya Freshwater Aquaculture). It was initiated in 2011 from a base population of locally available strains. Selection target is to improve harvest weight in low-input production ponds.

\subsubsection{Selection of breeding candidates}

Fifty males and 150 females from the 2 nd generation were selected to become parents. Selection was based on their estimated breeding values for harvest weight. The selected individuals were conditioned in hapas $(4 \times 2 \times 1 \mathrm{~m})$ separately by sex for one month. They were fed twice a day on a Kenyan local floating pelleted feed with $26 \%$ crude protein, at a feeding rate of $3 \%$ of body weight.

\subsubsection{Production of fingerlings}

The production of fingerlings took place from 22nd November 2013 to 28th February 2014. An earthen pond (1800 m2) equipped with fifty breeding hapas $(2 \times 1.5 \times 1 \mathrm{~m})$ was used for fry production. Three female fish were placed with one male fish in each hapa. Inspection of the breeding hapas was conducted after every five days to collect swim up fry and fertilized eggs. Every time a female fish spawned, it was immediately removed from the breeding hapa. Collected fertilized eggs were then taken to the hatchery and incubated until hatching. After hatching, fry was transferred to hapas $(1 \times 1 \times 1 \mathrm{~m})$. Eggs and fry that died were removed from the hapas on a daily basis. In total, 76 full-sib families from 48 sires and 76 dams were produced. 


\subsubsection{Rearing of fingerlings and tagging}

A hundred individuals per family were collected from three day old mixed sex juveniles of Nile tilapia and divided in two equal groups of 50 individuals. Each group was placed in a hapa $(1 \times 1 \times 1 \mathrm{~m}$, mesh size $1 \mathrm{~mm})$ suspended in a $1800 \mathrm{~m} 2$ earthen pond. One group was fed for 30 days with a diet (Skretting: 35\% CP, 9 \% fat) containing $60 \mathrm{mg} \mathrm{17 \alpha}$ methyltestosterone per kg feed (17 $\alpha$ MT; Sigma-Aldrich company, Netherlands) to induce sex reversal; the other group was reared on a control diet (Skretting: 35\% CP, $9 \%$ fat).

After a rearing period of 3 months, 20 fingerlings, randomly chosen from each hapa-family, were anaesthetized using tricaine methane sulphonate (MS222) at a concentration of $100 \mathrm{mg} / \mathrm{L}$, weighed and tagged using Passive Integrated Transponder (PIT) tags (Pocket RFID readers chips, Dorset Identification, Netherland). All full sib individuals of the same family and treatment group were tagged at the same time and returned to the hapas before stocking. Due to differences in egg collection dates, fingerlings were tagged when they were $94-$ 177 days $(8.85-73.56 \mathrm{~g}$ ) old. In total 3014 fingerlings were tagged (Table 3.1).

\subsubsection{Grow-out and pond management}

Before stocking, tagged fingerlings from each family were removed from the hapas and scanned using an electronic scanner to check the presence of the tags. Body weights and total body lengths were taken and recorded for all fingerlings before stocking. Each full sib treatment group of fingerlings was then randomly divided into three groups. Each group was assigned to one of three $150 \mathrm{~m} 2$ ponds. For monosex fingerlings, 3 ponds $A, B$ and $C$ were used while ponds $D, E$ and $F$ were used for mixed sex fingerlings. In total, a range of 454-524 fish were stocked in each pond at an average stocking density of 3 fish per $\mathrm{m} 2$. All the grow-out earthen ponds used were located at Sagana Aquaculture Research Station. During the growout period, water temperature stayed relatively constant at $25 \sim 27^{\circ} \mathrm{C}$ in all the ponds. Fish that died within the first week of stocking were replaced with newly tagged individuals from the same family. Fish were fed twice a day on a commercial floating pelleted feed (Skretting: 35\% CP, $9 \%$ fat) following the recommendations of the manufacturer.

\subsubsection{Records}

Fish were harvested after approximately 5 months of growth, using the seine net. They were first sedated using tricaine methane sulphonate (MS222) at a 
concentration of $100 \mathrm{mg} / \mathrm{L}$. Sex was assigned by visually examining the urogenital papilla of the fish. Harvest body weight (HW) in grams and digital pictures (lateral view) were taken and recorded as follows: each fish was scanned using an electronic scanner and put in a measuring board placed underneath a camera, which was suspended at a fixed height above the fish. A piece of paper was then placed on the fish with a unique number, identifying the pond $(A, B, C, D, E, F)$ and the fish (1-524) correspondingly. ImageJ software (1.47 for windows (Rasband, 2008) was used to measure standard length (L), body height $(H)$ an ellipticity (Ec) from the picture taken. Length $(L)$ was measured as the total distance from snout of the fish to the caudal peduncle, and $\mathrm{H}$ was measured as the maximum vertical distance. The Ec was calculated as $(\mathrm{L}-\mathrm{H}) /(\mathrm{L}+\mathrm{H})$ (Blonk et al., 2010).

Daily growth coefficient (DGC) (Dabrowski et al., 1986) was used to calculate growth rate:

$$
D G C=\frac{\sqrt[3]{H W}-\sqrt[3]{S B W}}{\text { Time }} x 100
$$

Equation 1

where SBW is body weight at stocking, HW is harvest body weight and time is the grow out period (in days) between stocking and harvest.

\subsubsection{Data Analysis}

\subsubsection{Descriptive statistics}

In total, data for 2105 individuals from the 76 families were recorded (Table 3.1). Descriptive statistics and checking of data anomalies was carried out using SAS (SAS Institute Inc., 1997) for HW, DGC, L, H and Ec traits. Due to non-normal distribution of residuals, harvest body weight and total length were log transformed. PROC GLM was used to test for significant fixed effects to be included in the model.

\subsubsection{Phenotypic and genetic parameter estimation in the mixed sex group}

Estimation of phenotypic and genetic parameters was performed using ASReml version 3 (Gilmour et al., 2009). For HW, L, H and Ec traits, a univariate model was used:

Model 1:

$Y_{i j k l m n}=\mu+S c_{i}+$ Pond $_{j}+(\operatorname{Sex} \times \mathrm{Hapa})_{k}+(\operatorname{Age}(\operatorname{Sex}))_{1}+\left(\operatorname{Age}^{2}(\operatorname{Sex})\right)_{m}+A_{n}+E_{i j k l m n}$

where $Y_{j k / m n}$ is a vector of the observed individual body traits ( $\mathrm{HW}, \mathrm{L}, \mathrm{H}$ and $\mathrm{Ec}$ ) for the $n^{\text {th }}$ individual fish, $\mu$ is the overall mean, $S c_{i}$ is the fixed effect of 
spawning/collection date ( $i=1$ to 11$)$, which translates to 11 different collection dates, Pond $_{j}$ is the fixed effect of $j^{\text {th }}$ pond ( $j=1$ to 3$),(\text { Sex } \times \text { Hapa) })_{k}$ is the fixed effect of $k^{\text {th }}$ combination of sex ( 2 sexes) and hapas $(1, \ldots 76),(\operatorname{Age}(\operatorname{Sex}))$, is a regression coefficient of fixed effect age, calculated as the total number of days from hatching/date of egg collection to harvest, nested within sex $l,\left(\operatorname{Age}^{2}(\operatorname{Sex})\right)_{m}$ is a regression coefficient of fixed effect age squared nested within sex $l$. The fixed effect age and age squared were included in the model as covariates to correct for different measurement or weighing dates within environment. $A_{n}$ is the random additive genetic effect of the $n^{\text {th }}$ individual fish with $\sim N\left(0, A \sigma^{2}{ }_{a}\right)$, where $A$ is the additive genetic relationship matrix among the recorded fish with the additive genetic variance $\sigma^{2}$ and $E_{i j k l m n}$ is the random error term associated with $\sim \mathrm{N}\left(0,1 \sigma^{2}{ }_{e}\right)$ , where $\mathbf{I}$ is the identity matrix and $\boldsymbol{\sigma}^{2}{ }_{\mathrm{e}}$ is the residual variance.

For DGC, the following model was used;

Model 2:

$Y_{i j k l m n}=\mu+S c_{i}+$ Pond $_{j}+(\operatorname{Sex} \times \text { Hapa })_{k}+(S A(\operatorname{Sex}))_{l}+\left(S A^{2}(\operatorname{Sex})\right)_{m}+A_{n}+E_{i j k l m n}$

where $S A$ is the stocking age, $S A^{2}$ is the stocking age squared and the other fixed effects are as described above. DGC already accounts for growing time from stocking to harvest, see equation 1 . In all the models, an effort to include common environmental effect for full sibs $\left(c^{2}\right)$ was not successful. When $c^{2}$ was added to the model, either the estimates did not converge or if they did converge, the covariances of the traits were absorbed by the $c^{2}$ effects.

Phenotypic $\left(r_{p}\right)$ and genetic correlation $\left(r_{A}\right)$ between traits within mixed sex environment were estimated using bivariate models. For $\mathrm{HW}, \mathrm{L}, \mathrm{H}$ and $\mathrm{Ec}$ traits, the same fixed effects fitted above in model 1 were applied while for DGC the fixed effect in model 2 were fitted. The animal effects were distributed as $N(\mathbf{0}, \mathbf{A} \otimes \mathbf{G})$, with the additive genetic variance-covariance matrix $(\mathbf{G})$ is $\left[\begin{array}{cc}\sigma_{A, 1}^{2} & r_{A, 12} \sigma_{A, 1} \sigma_{A, 2} \\ r_{A, 12} \sigma_{A, 1} \sigma_{A, 2} & \sigma_{A, 2}^{2}\end{array}\right]$ where $\sigma_{A, 1}^{2} \sigma_{A, 2}^{2}$ is the additive genetic variance of trait 1 (trait 2), $r_{A, 12}$ is the additive genetic correlation between trait 1 and trait 2 . The residuals were distributed as $\mathbf{N}(\mathbf{0}, \mathbf{A} \otimes \mathbf{R})$ with residual variance 
covariance matrix (R) is $\left[\begin{array}{cc}\sigma_{e, 1}^{2} & r_{e, 12} \sigma_{e, 1} \sigma_{e, 2} \\ r_{e, 12} \sigma_{e, 1} \sigma_{e, 2} & \sigma_{e, 2}^{2}\end{array}\right]$ where $\sigma_{e, 1}^{2}\left(\sigma_{e, 2}^{2}\right)$ is the residual variance of trait 1 (trait 2), and $r_{e, 12}$ is the residual correlation between trait 1 and trait 2.

Heritability was computed as the ratio of additive genetic variance and phenotypic variance; $h^{2}=\frac{\sigma_{A}^{2}}{\sigma_{P}^{2}}$, where $h^{2}$ is heritability, $\sigma_{A}^{2}$ is the additive genetic variance and $\sigma_{P}^{2}$ is the phenotypic variance

Genotype by environment interaction for $H W, D G C, L, H$ and $E_{c}$ traits were quantified by estimating genetic correlations $\left(r_{A}\right)$ for these traits between mixed sex and monosex groups using bivariate models. For this models, the additive genetic variance-covariance matrix is $\left[\begin{array}{cc}\sigma_{A, M X S}^{2} & r_{A, M X S, M N S} \sigma_{A, M X S} \sigma_{A, M N S} \\ r_{A . M X S, M N S} \sigma_{A, M X S} \sigma_{A, M N S} & \sigma^{2}{ }_{A, M N S}\end{array}\right]$ where $\sigma^{2}{ }_{A, M X S}$ is the additive genetic variance for the traits in mixed sex fish, $\sigma_{A, M N S}^{2}$ is the additive genetic variance for the traits in monosex fish, $r_{A, M X S, M N S}$ is the additive genetic correlation between mixed and monosex fish. The error (enviromental) covariance between the traits in two test enviroments was set to zero because individual fish cannot produce records simultaneously in more than one enviroment. Therefore, the residual variance co-variance matrix is $\left[\begin{array}{cc}\sigma_{e, M X S}^{2} & 0 \\ 0 & \sigma_{e, M N S}^{2}\end{array}\right]$ where $\sigma_{e, M X S}^{2}$ is the residual variance for the trait in mixed sex and $\sigma_{e, M N S}^{2}$ is the residual variance for the trait in monosex fish.

\subsection{Results}

\subsubsection{General descriptive statistics}

The recorded number of fish at stocking and harvest, age at stocking, sex ratio, and survival rate are shown in Table 3.1. Mean values and coefficient of variation (CV) for stocking and harvest body weight for both monosex and mixed sex fish are shown in Table 3.2. Mean stocking age for mixed sex was a little higher (144.5 days) than for monosex (138.5 days). Monosex groups had a high percentage (>94\%) of males compared to the mixed sex groups (Table 3.1). Generally, survival till harvest 
across the treatments ranged between 55.9 - 81.5\%, with mixed sex fish recording lower survival rates compared to monosex fish across all the ponds.

Mean stocking body weight for monosex fish was higher than for mixed sex fish. The CV for stocking body weight ranged between $45.6-60.9 \%$ for monosex and $33.2-51.8 \%$ for mixed sex (Table 3.2). Mean harvest body weight ranged between $92.8-111.5 \mathrm{~g}$ and $118.3-124.6 \mathrm{~g}$ for mixed sex and monosex groups respectively. Mean harvest weights for male fish were higher for both monosex and mixed sex fish than for female fish. Generally, the CV for harvest body weight was lower compared to CV for stocking weights in both treatments, ranging between 26.8 $34 \%$ across all the ponds. CV ranged from moderate to high across the two treatments; males had lower CV than females in general; monosex groups had lower CV (average 28.8) than mixed sex (average 30.3) (Table 3.2). Mean DGC was high in monosex groups than mixed sex.

Table 3.1 Stocking age, number of fish at stocking and harvest, sex ratio at harvest and mean survival (\%) at harvest for both monosex and mixed sex fish.

\begin{tabular}{|c|c|c|c|c|c|c|}
\hline Treatment & Pond & $\begin{array}{l}\text { Stocking } \\
\text { age }\end{array}$ & $\begin{array}{l}\text { Number } \\
\text { stocked }\end{array}$ & $\begin{array}{l}\text { Number } \\
\text { harvested }\end{array}$ & $\begin{array}{l}\% \text { of } \\
\text { males }\end{array}$ & $\begin{array}{l}\text { Survival } \\
\text { (\%) }\end{array}$ \\
\hline \multirow[t]{4}{*}{ Mono-sex } & & $97-180$ & & & & \\
\hline & A & & 454 & 350 & 94.0 & 77.1 \\
\hline & B & & 525 & 428 & 94.5 & 81.5 \\
\hline & $\mathrm{C}$ & & 524 & 404 & 95.3 & 77.1 \\
\hline \multirow[t]{5}{*}{ Mixed sex } & & 103 & & & & \\
\hline & & 186 & & & & \\
\hline & $D$ & & 456 & 283 & 48.8 & 62.1 \\
\hline & $E$ & & 531 & 347 & 46.9 & 65.4 \\
\hline & $\mathrm{F}$ & & 524 & 293 & 47.1 & 55.9 \\
\hline
\end{tabular}


Table 3.2 Mean stocking and harvest weights (g), coefficient of variation (CV, \%) for stocking body weight and body weight at harvest and mean daily growth rate (DGC) and weights (g) for recorded sex at harvest for both mono and mixed sex.

\begin{tabular}{|c|c|c|c|c|c|c|c|c|c|c|}
\hline \multirow[b]{2}{*}{ Treatment } & \multirow[b]{2}{*}{ Pond } & \multicolumn{2}{|c|}{$\begin{array}{c}\text { Stocking } \\
\text { weight }\end{array}$} & \multicolumn{2}{|c|}{$\begin{array}{l}\text { Harvest } \\
\text { weight }\end{array}$} & \multicolumn{2}{|c|}{ Mean harvest weights } & \multicolumn{2}{|c|}{$\mathrm{CV}$} & \multirow[t]{2}{*}{ DGC } \\
\hline & & Mean & $\mathrm{CV}$ & Mean & $\mathrm{CV}$ & Males & Females & Males & Females & \\
\hline \multicolumn{11}{|l|}{ Mono-sex } \\
\hline & $A$ & 17.8 & 60.9 & 124.6 & 33.1 & 141.7 & 68.1 & 26.0 & 34.2 & 1.52 \\
\hline & B & 16.4 & 49.7 & 118.3 & 34.0 & 140.0 & 69.9 & 31.3 & 40.0 & 1.49 \\
\hline & $\mathrm{C}$ & 14.5 & 45.6 & 118.8 & 33.3 & 137.7 & 72.9 & 29.1 & 32.3 & 1.55 \\
\hline \multicolumn{11}{|l|}{ Mixed sex } \\
\hline & $\mathrm{D}$ & 15.8 & 51.8 & 92.8 & 26.8 & 106.8 & 82.8 & 33.4 & 37.1 & 1.29 \\
\hline & $E$ & 13.1 & 43.5 & 96.3 & 32.2 & 116.0 & 82.4 & 30.0 & 42.5 & 1.4 \\
\hline & $\mathrm{F}$ & 10.8 & 33.2 & 111.5 & 30.7 & 135.1 & 90.0 & 27.4 & 39.1 & 1.6 \\
\hline
\end{tabular}




\subsubsection{Estimation of phenotypic and genetic parameters}

Genetic parameters for the mixed sex group are presented in Table 3.3. Heritability estimates for HW and DGC were moderate, 0.21 and 0.26 respectively. Heritability estimates for body measurements $(L$ and $H)$ were 0.18 and 0.15 respectively, while for $E_{c}$, the heritability estimate was 0.12 .

The phenotypic correlation $\left(r_{p}\right)$ between HW and DGC was moderate (0.76) while the genetic correlation $\left(r_{A}\right)$ was high (0.90). The $r_{p}$ between $\mathrm{HW}$ and body measurements ( $\mathrm{L}$ and $\mathrm{H}$ ) were 0.64 and 0.41 respectively, while their corresponding $r_{A}$ were relatively high, 0.89 and 0.94 . Phenotypic correlations between DGC and $L$ and $\mathrm{H}$ were 0.51 and 0.59 respectively; the corresponding genetic correlations $r_{A}$ were 0.69 and 0.78 . The $r_{p}$ and $r_{A}$ between harvest weight and $\mathrm{E}_{c}$ were positive, 0.38 and 0.09 respectively (Table 3.3 ).

Table 3.3 Heritability (bold), phenotypic (above diagonal), genetic correlations (below diagonal) and the standard errors between traits in mixed sex breeding nucleus fish.

\begin{tabular}{llllll}
\hline Trait & $\mathrm{HW}$ & $\mathrm{DGC}$ & $\mathrm{L}$ & $\mathrm{H}$ & $\mathrm{E}_{\mathrm{c}}$ \\
\hline $\mathrm{HW}$ & $\mathbf{0 . 2 1} \pm \mathbf{0 . 0 3}$ & $0.76 \pm 0.06$ & $0.64 \pm 0.10$ & $0.41 \pm 0.08$ & $0.09 \pm 0.02$ \\
DGC & $0.90 \pm 0.12$ & $\mathbf{0 . 2 6} \pm \mathbf{0 . 0 4}$ & $0.59 \pm 0.07$ & $0.51 \pm 0.05$ & $0.13 \pm 0.02$ \\
$\mathrm{~L}$ & $0.94+0.08$ & $0.69 \pm 0.11$ & $\mathbf{0 . 1 8} \pm \mathbf{0 . 0 5}$ & $0.65 \pm 0.04$ & $0.16 \pm 0.03$ \\
$\mathrm{H}$ & $0.89 \pm 0.10$ & $0.78 \pm 0.09$ & $0.90 \pm 0.05$ & $\mathbf{0 . 1 5} \pm \mathbf{0 . 0 5}$ & $-0.39 \pm 0.05$ \\
$\mathrm{E}_{\mathrm{c}}$ & $0.38 \pm 0.13$ & $0.19 \pm 0.20$ & $0.37 \pm 0.14$ & $0.18 \pm 0.22$ & $\mathbf{0 . 1 2} \pm \mathbf{0 . 0 3}$ \\
\hline
\end{tabular}

$\mathrm{HW}=$ harvest weight, $\mathrm{DGC}=$ daily growth coefficient, $\mathrm{L}=$ length, $\mathrm{H}=$ height and $\mathrm{Ec}=$ ellipse.

\subsubsection{Genetic correlations between treatment groups}

Genetic correlations between monosex and mixed sex treatments are given in Table 3.4. The genetic correlations for $\mathrm{HW}$ and $\mathrm{L}$ between mixed sex and monosex fish were 0.74 and 0.77 respectively, suggesting a low degree of genotype by environment interaction. On the other hand, the genetic correlations for DGC, $\mathrm{H}$ and $E_{c}$ were low; $0.59,0.46$ and -0.19 respectively, denoting the presence of significant genotype by environment interaction (Table 3.4). The estimated $\sigma_{A}^{2}$ and $\sigma_{P}^{2}$ variances were higher in monosex groups than in mixed sex groups for all the traits. Variances for HW and DGC in monosex were double the variances in mixed sex group, while for $L, H$ and $E_{c}$, the variances were comparable (Table 3.4). 
Table 3.4 Genetic parameters and genetic correlations with standard errors for harvest weight (HW), daily growth coefficient (DGC), length (L), height $(H)$ and ellipse $\left(E_{c}\right)$ traits between mixed sex (Mxs) and monosex (Mns) fish.

\begin{tabular}{|c|c|c|c|c|c|c|c|c|c|c|}
\hline \multirow[b]{2}{*}{ Parameter } & \multicolumn{10}{|c|}{ Traits } \\
\hline & Mxs & Mns & Mxs & Mns & Mxs & Mns & Mxs & Mns & Mxs & Mns \\
\hline \multicolumn{11}{|l|}{$\boldsymbol{\sigma}_{\mathrm{a}}^{2}$} \\
\hline & 188.25 & 390.84 & 0.07 & 0.17 & 0.71 & 0.74 & 0.17 & 0.15 & 0.005 & 0.004 \\
\hline$\sigma_{p}^{2}$ & 896.42 & 1628.50 & 0.27 & 0.53 & 3.93 & 4.62 & 1.13 & 1.24 & 0.04 & 0.06 \\
\hline$r_{g}$ & \multicolumn{2}{|c|}{$0.74 \pm 0.14$} & \multicolumn{2}{|c|}{$0.59 \pm 0.10$} & \multicolumn{2}{|c|}{$0.77 \pm 0.09$} & \multicolumn{2}{|c|}{$0.46 \pm 0.09$} & \multicolumn{2}{|c|}{$-0.19 \pm 0.11$} \\
\hline
\end{tabular}

$\sigma_{a}^{2}=$ genetic variance, $\sigma_{p}^{2}=$ phenotypic variances, $r_{g}=$ genetic correlations. 


\subsection{Discussion}

\subsubsection{Experimental conditions}

Production of fry took place for over a period of 98 days, which is quite long. This is a major problem in Nile tilapia genetic experiments where the aim is to produce sufficient numbers of full and half-sib families while restricting the common environmental rearing period. Similarly long spawning periods have been reported (Ponzoni et al., 2011; Trong et al., 2013; Khaw, 2015). The stocking density was 0.75 $\mathrm{fish} / \mathrm{m} 2$, which is quite low compared to other experiments conducted in Nile tilapia e.g., 1.5 - 10 fish/m2 (Hughes and Behrends, 1983; Trong et al., 2013). In commercial Nile tilapia seed production, group mating is used with a sex ratio of 2 females to 1 male, 3 females to 1 male or even 4 females to 1 male (Fessehaye et al., 2006; Trong et al., 2013). In genetic studies with Nile tilapia, it is recommended to mate a single male with a single female in a hapa (WorldFish, 2004). In practice this often leads to aggressive behaviour of males and failure to spawn. Studies by Trong et al. (2013) have shown that spawning is much more optimal when 3-5 females are stocked with a single male, and males are frequently exchanged (e.g. every 4 days). In our study, a sex ratio of 3 females to 1 male was used which is within the range recommended by Trong. We therefore do not think that stocking density or sex ratio had an effect on spawning success in our study. However, biologically, spawning success in tilapia will depend on many factors e.g., temperature, photoperiod and social interaction (Coward and Bromage, 2000). The water temperature at Sagana was $20-24{ }^{\circ} \mathrm{C}$ during the reproduction period, which is lower than the optimal temperature for spawning $\left(25^{\circ} \mathrm{C}\right.$; Popma and Lovshin, 1995). This may have had several negative consequences for both the spawning period and the overall rearing period of fingerlings, thus affecting both tagging and stocking age.

Maluwa et al. (2006) reported that rearing fish from stocking to harvest should exceed the initial rearing period of fry production to tagging, if the magnitude of $c^{2}$ has to be reduced. In our study, grow out period lasted for only 5 months, which is relatively short compared to the period of fry production to tagging. This might have increased the $c^{2}$ and in turn inflate the heritability estimates. To solve this problem, we fitted spawning date and hapa in the model as fixed effects, which were found highly significant $(P<0.05)$, confirming that correction for spawning/collection time and hapa will lead to more precise estimation of genetic parameters. 
Models for estimating genetic parameters in Nile tilapia generally include common environmental effect for full sibs $\left(c^{2}\right)$. However, in our study, efforts to include $c^{2}$ for full sibs in all the models were not successful. When $c^{2}$ was added to the model, either the estimates did not converge or if they did converge, trait covariances were absorbed by the $c^{2}$ effects (Maluwa et al., 2006). This is because separating $c^{2}$ from genetic effects was a problem due to the low number of female fish mated to each male fish, and the effect of spawning date which was partly confounded with the $c^{2}$ because in many incidences only one female spawned at a given time.

\subsubsection{Sex reversal}

To achieve more productivity in growing tilapia, one should avoid unwanted spawning and prevent stunting by employing monosex culture that constitutes males only. This is because males have a higher growth rate as compared to females. In this study, we observed a high male percentage compared to females in monosex fish. These results are similar to other findings (Phelps et al., 1992; Okoko, 1996; Pham et al., 1998; Phelps and Popma 2000; Damien et al., 2003) implying that $17 \alpha$ methyl testosterone hormone is an effective androgen in sex reversal. However, our findings of male: female sex ratios in monosex fish were slightly lower compared to other studies 94 vs 99\% (Bocek et al., 1992; Phelps et al., 1992; 1993; Pham et al., 1998; Phelps and Popma 2000; Damien et al., 2003). Sex was determined by visual examination of the urogenital papilla, which could have biased the results. However, sex ratios, based on gonadal sex, in samples of monosex fry produced by Sagana Aquaculture Research Station in Kenya over a longer period of time are in range with the current observations (Table 3.5). 
Table 3.5 Sex ratios in samples of monosex fry produced by Sagana for gonad examination.

\begin{tabular}{|c|c|c|c|c|c|}
\hline $\begin{array}{l}\text { Name of the fish Farm/ } \\
\text { Multiplication centre }\end{array}$ & $\begin{array}{l}\text { Fish } \\
\text { sampled }\end{array}$ & Males & Females & Deformed & $\begin{array}{l}\% \\
\text { reversal }\end{array}$ \\
\hline $\begin{array}{l}\text { Nyabururu Girls Boarding } \\
\text { Primary school fish farm }\end{array}$ & 190 & 187 & 2 & 1 & 98 \\
\hline $\begin{array}{l}\text { Mr Abel Nyakundi's fish } \\
\text { farm }\end{array}$ & 92 & 86 & 4 & 2 & 93 \\
\hline Mr. Nyangweso's fish farm & 56 & 51 & 5 & 0 & 91 \\
\hline KMFRI Kegati & 134 & 126 & 6 & 2 & 94 \\
\hline Mr. Nyarumba fish farm & 127 & 121 & 4 & 2 & 95 \\
\hline $\begin{array}{l}\text { Kisii Fish multiplication } \\
\text { centre }\end{array}$ & 152 & 134 & 15 & 3 & 88 \\
\hline $\begin{array}{l}\text { Rigoma secondary school } \\
\text { fish farm }\end{array}$ & 67 & 64 & 2 & 1 & 96 \\
\hline Average & & & & & 94 \\
\hline
\end{tabular}

KMFRI = Kenya Marine Fish and Research Institute.

A relatively high growth rate in monosex fish (1.52) compared to the mixed sex fish (1.43) was observed in this study (Table 3.2). Furthermore, coefficient of variation in harvest weight was higher in mixed sex groups than in monosex groups. This confirms other findings that in pond culture, males are more desirable for aquaculture as they grow faster than females (Popma and Green, 1990; Phelps and Popma, 2000; Rutten et al., 2005). Studies that compared mixed groups with monosex groups in cages, suspended in ponds, did not find a difference in growth rate (Norhidayat et al., 2009). The main reason for this difference is that Nile tilapia apparently do not breed in cages. Most of the feed protein consumed by mature females is not spent towards growth. According to Lone and Ridha (1993), female fish use most of their feed protein for production of eggs and little is converted to flesh, which is why males are relatively big as compared to females. Moreover, during incubation or caring period for the fry, females do not eat properly. In a population where males constitute a greater percentage, the feed conversions are therefore more favourable. In addition, Schreiber et al. (1998) reported that $O$. niloticus females grew significantly larger than males when reared individually and the agonistic influences of males on females are removed. The authors concluded that the usual observation of females being smaller than males in mixed sex 
environments is probably caused by behavioural factors. These conclusions are in line with those of Rutten et al. (2005) who concluded that male and female growth is genetically the same trait.

A significant variation in survival rates has been reported in Nile tilapia, reared in fertilized ponds with or without feed supplementation, ranging from 26 to $91.6 \%$ (Abdalla et al., 1996; Charo-Karisa, 2006; Luan et al., 2008; Thodesen et al., 2011), indicating that survival is an important trait to consider in fish farming. In our study, the mean survival rate was $69.9 \%$ across all the ponds, with mixed sex generally recording lower survival rates compared to monosex fish. The survival rates recorded in our study are within the upper range of the reported studies above. Charo-Karisa et al. (2006) indicated that survival rates in the ponds can be a result of pond and initial stocking weights effects. On the other hand, though all the ponds were covered with nets to protect fish from birds, the predation of fish by African otter (Aonyx capensis) was a challenge, which certainly contributed to increased mortality.

In this study, higher CV were observed for stocking weight than for harvest weight, with monosex fish recording higher CV than mixed sex fish; an indication that young fish have higher variable weights than mature fish (Table 3.2). This is in agreement with earlier observations made by (Gjedrem, 1983; Charo-Karisa, 2006; Khaw, 2015). High CV indicates the presence of competition for feed, which may lead to variation in body size and creation of dominance hierarchy in the ponds, especially when feeding is conducted from a central point. Khaw (2015) indicated that low CV suggests a low competition and a good social environment. On the other hand, experiments conducted in laying hens involving competition effects, indicated that competition is an important environmental factor leading to GXE interaction (Van der Werf, 2009). The higher variation in CV in stocking weights than harvest weights in our study might have been caused by feeding competition in hapas, which could have been more severe than in ponds where tilapia can feed on a variety of natural food sources next to pellets.

\subsubsection{Genetic parameters in mixed sex fish (breeding nucleus)}

Heritability $\left(\mathrm{h}^{2}\right)$ estimates for harvest body weight in our study are within the range of those reported earlier, $0.11-0.60$ by (Bolivar and Newkirk, 2002; Charo-Karisa et al., 2006; Luan et al., 2008; Trọng et al., 2013; Khaw, 2015) but much lower than 
the estimates for low input earthen ponds reported by (Charo-Karisa et al., 2006; Khaw et al., 2009). However, moderate estimate of 0.2 was obtained in fertilized ponds with no supplementation (Eknath et al., 1995). The $h^{2}$ obtained in this study for harvest weight and growth rate indicates the presence of additive genetic variance that can be exploited through selection in the present population of Nile tilapia under low input system.

Moderate $\mathrm{h}^{2}$ for DGC was obtained in this study (0.26) which is below the range of values reported for the GIFT strain in Vietnam (Trọng et al., 2013). In aquaculture, growth rate estimation based on DGC is recommended because it is much more independent of stocking body weight than weight gain and specific growth rate. Furthermore, DGC accounts for growing time from stocking to harvest, and high growth rate during grow-out period is paramount to many farmers or producers because it is associated with higher feed efficiency, especially at more restricted feeding regimes (Henryon et al., 2002). Fast growing fish will attain market weight early, reducing the overall operational costs because increased growth rate leads to shorter production cycles.

In this study, $\mathrm{h}^{2}$ estimates for both $\mathrm{L}$ and $\mathrm{H}$ were within the range reported earlier on O. niloticus studies, 0.16 - 0.6 (Basiao et al., 2005; Rutten et al., 2005; CharoKarisa et al., 2007; Khaw, 2015). Body measurements traits are useful when weight measurements are unreliable as is often the case when weighing fish in field conditions. Body dimensions are important when market prices favour bettershaped fish, as is the case for Nile tilapia in Kenya (Omasaki et al., 2016). We used ellipticity to describe shape in fish in relation to length, height and thickness. Our $\mathrm{h}^{2}$ estimate of 0.12 for ellipticity $(\mathrm{L}-\mathrm{H})$ and its correlation with $\mathrm{HW}\left(\mathrm{r}_{\mathrm{g}} \mathbf{0 . 3 8}\right)$ in the present study were in good agreement with the findings by Trong et al. (2013). They show that selection for harvest weight will increase the decrease ratio of $L$ to $\mathrm{H}$, making fish relatively more "round" (side view).

In our study, the genetic correlations between HW and DGC were relatively high and in agreement with earlier reported results by other authors; 0.71 - 0.92 in trout (Le Boucher et al., 2011; Sae Lim, 2013). This high genetic correlation indicates the possibility of improving harvest weight by selection on growth rate, since the two traits are complementary. More important is the possibility that growth rate is probably favourably correlated to increased feed conversion efficiency (Henryon et al., 2002; Quillet et al., 2007). Feed cost is a major concern to many fish farmers, 
especially during grow out time, and therefore improvement on growth should reduce the overall production cost.

High correlations between HW and the corresponding body measurements in the present study agree with other findings (Rutten et al., 2005b; Charo-Karisa et al., 2007; Blonk et al., 2010; Trong et al., 2013). Falconer et al. (1996), indicated that for traits with high genetic correlations, indirect selection can be performed. In the present study, we used pictures to measure body dimensions. This can be a good alternative opportunity for field work for developing countries like Kenya, where digital recording can be done with (widely available) smartphones. Body measurements can be derived from these pictures later on and used to predict final body weight.

\subsubsection{Genotype by environment interaction}

High genetic correlations for harvest body weight, ranging from $0.73-0.99$ in Nile tilapia (GIFT strain) cultured in different enviroments have been reported (Eknath et al., 2007; Khaw et al., 2009; Bentsen et al., 2012; Trong et al., 2013). In other cultured fish species, the same trend has been reported; 0.82 in large rainbow trout (Oncorhynchus mykiss) (Kause et al., 2003), $0.63-0.95$ in Oreochromis shiranus, (Maluwa et al., 2006) and $0.81-0.86$ in European sea bass (Dicentrarchus labrax) (Dupont-Nivet et al., 2010). Our estimate of genetic correlation for harvest body weight between mixed sex breeding nucleus and monosex fish was also high (0.74), suggesting little re-ranking due to GxE.

A significant GxE interaction was observed for DGC, as indicated by a moderate genetic correlation of 0.59 . Genetic correlations ranged from 0.21 to 0.61 in sea bass (Dicentrarchus labrax) (Saillant et al., 2006; Dupont-Nivet et al., 2010). Sae-Lim (2013) reported a strong GxE interaction for thermal growth coefficient (TGC) in rainbow trout reared in three different environments, with genetic correlations ranging between 0.31 and 0.42 . Our results however, differed from Trong et al. (2013), who reported genetic correlation between 0.77 and 0.95 for DGC in GIFT tilapia raised in different test environments in Vietnam. In general GxE estimates for growth rate are lower than that for harvest weight. This is because DGC only accounts for grow out period from stocking to harvest; measured at different ages between the two environments, while harvest body weight is a cumulative result of growth from spawning to harvest and there is a prolonged common rearing period prior to the testing in the two enviroments. Re-ranking of individuals in TGC/DGC is 
expected to increase more with time than in harvest body weight (Rutten et al., 2005b).

We found little evidence for GxE interaction for body length. This is in agreement with other studies on this trait in Nile tilapia (Trong et al., 2013; Khaw, 2015) and Atlantic cod (Gadus morhua) (Kolstad et al., 2006). On the other hand, a significant GxE interaction for height and ellipse was observed, which is in agreement with the findings of Trong et al. (2013). The low genetic correlation for ellipse (-0.19) between the two enviroments suggests that the genetic expression of shape of fish is altered by hormone treatment.

There was no heterogeneity in the amount of additive genetic and phenotypic variance for all the traits estimated in the two environments (Table 3.4). This implies that all male fish and mixed sex fish express body traits in the same way in response to selection. It also suggests that there were little or no differences in the sensitivity to the environment between monosex and mixed sex groups.

\subsubsection{Implication for a breeding program}

In the presence of GxE interaction, re-ranking of individuals occurs; superior individuals in one environment will be inferior in other environments. In this case, the question on how to optimize the breeding program to respond to multiple environment requirements is critical. In our study, a moderate GxE for daily growth coefficient, height and ellipticity traits was observed. Mulder and Bijma (2005) pointed out that when GxE interaction occurs in a breeding program, the reduction in genetic gain mainly occurs due to inaccurate selection of breeding candidates. The explicit use of sibling information to select individuals with highest breeding values from the nucleus to perform better in another environment in order to optimize a breeding program was addressed by (Mulder and Bijma, 2005). Sib selection programs enable effective selection for traits that can be recorded through killing of an animal e.g., carcass traits and traits that are difficult to measure such as diseases. In addition, they provide increased selection accuracy for traits of medium and low heritability. Based on the findings in the present study, we recommend that breeding programs for Nile tilapia incorporate sib information from production environments when production is based on monosex fish. Incorporating more information into selection index will also result in a more accurate estimation of breeding values. 


\subsection{Conclusions}

We conclude that a substantial additive genetic effect for harvest weight, growth rate and shape traits were observed that can be exploited under low input system if a breeding program is well designed. Our results show that selection for fast growth will produce thicker fish which will reach market weight earlier. We found high genetic correlations for HW trait between mixed sex and monosex groups suggesting low GxE. A significant GxE for daily growth rate and ellipticity traits between mixed sex and monosex groups was observed as indicated by low genetic correlations. We recommend that breeding programs that serve hatcheries which produce monosex fry should include information from sex reversed male sibling individuals to be combined with individual information from the breeding nucleus into a selection index to minimize the magnitude of GxE.

\section{Acknowledgements}

This study is part of the first author's sandwich PhD study, funded by Koepon Foundation, their support is acknowledged. We would like to thank staff of Sagana Aquaculture Research Station Kenya, for providing the experimental fish, facilities and helping with the experiment.

\section{References}

Abdalla, A.A., McNabb, C.D., Batterson, T.R., 1996. Ammonia dynamics in fertilized fish ponds stocked with Nile Tilapia. Progressive. Fish Cult. 58, 117-123.

Basiao, Z.U., Arago, A.L., Doyle, R.W., 2005. A farmer-oriented Nile tilapia (Oreochromis niloticus L.), breed improvement in the Philippines. Aquac. Res. 36, 113-119.

Bentsen, H.B., Gjerde, B., Nguyen, N.H., Rye, M., Ponzoni, R.W., de Vera, M.S. P., Bolivar, H.L., Velasco, R.R., Danting, J.C., Dionisio, E.E., 2012. Genetic improvement of farmed tilapias: Genetic parameters for body weight at harvest in Nile tilapia (Oreochromis niloticus) during five generations of testing in multiple environments. Aquaculture 338, 56-65.

Blonk, R.J.W., Komen, J., Tenghe, A., Kamstra, A., Van Arendonk, J.A.M., 2010. Heritability of shape in common sole, Solea solea, estimated from image analysis data. Aquaculture 307, 6-11.

Bocek, A., Phelps, R.P., Popma, T.J., 1992. Effect of feeding frequency on sex reversal and growth on Nile tilapia (Oreochromis niloticus). J. Appl. Aquac. 1, 97-103. 
Bolivar, R.B., Newkirk, G.F., 2002. Response to within family selection for body weight in Nile tilapia (Oreochromis niloticus) using a single-trait animal model. Aquaculture 204, 371-381.

Charo-Karisa, H., 2006. Selection for growth of Nile tilapia (Oreochromis niloticus L.) in Low-input environments (PhD Thesis) Wageningen Universiteit (169 pp.).

Charo-Karisa, H., Bovenhuis, H., Rezk, M.A., Ponzoni, R.W., Van Arendonk, J.A.M., Komen, H., 2007. Phenotypic and genetic parameters for body measurements, reproductive traits and gut length of Nile tilapia (Oreochromis niloticus) selected for growth in low-input earthen ponds. Aquaculture 273, 15-23.

Charo-Karisa, H., Komen, J., Rezk, M.A., Ponzoni, R.W., van Arendonk, J.A.M., Bovenhuis, H., 2006. Heritability estimates and response to selection for growth of Nile tilapia (Oreochromis niloticus) in low-input earthen ponds. Aquaculture 261, 479-486.

Coward, K., Bromage, N., 2000. Reproductive physiology of female tilapia broodstock. Rev. Fish Biol. Fish. 10, 1-25.

Dabrowski, K., Murai, T., Becker, K., 1986. Physiological and Nutritional Aspects of Intensive Feeding of Carp. In: Billard, R., Marcel, J. (Eds.), Aquaculture of Cyprinids. INRA, Paris, pp. 55-70.

Damien, D., Eddy, G., Marie, C.H., Charles, M., Pierre, B., Jean, F.B., 2003. Production of a high percentage of male offspring with a natural androgen, 11h-hydroxyandrostenedione (11hOHA4), in Florida red tilapia. Aquaculture 216, 55-65.

Dupont-Nivet, M., Karahan-Nomm, B., Vergnet, A., Merdy, O., Haffray, P., Chavanne, H., Chatain, B., Vandeputte, M., 2010. Genotype by environment interactions for growth in European seabass (Dicentrarchus labrax) are large when growth rate rather than weight is considered. Aquaculture 306, 365-368.

Eknath, A.E., Reyes, R.A., Bolivar, H.L., De Vera, M.P., Danting, J.C., Dionisio, E.E., Longalong, F.M., 1995. Genetic improvement of farmed tilapias: estimation of genetic variation and heritability for age and size at first spawning in Nile tilapia (Oreochromis niloticus). Aquaculture 137, 279-280.

Eknath, A.E., Bentsen, H.B., Ponzoni, R.W., Rye, M., Nguyen, N.H., Thodesen, J., Gjerde, B., 2007. Genetic improvement of farmed tilapias: composition and genetic parameters of a synthetic base population of Oreochromis niloticus for selective breeding. Aquaculture 273, 1-14. 
Falconer, D.S., Mackay, T.F., Frankham, R., 1996. Introduction to Quantitative Genetics (4th edn). Longman Group Ltd., Essex, UK (464 pp.).

Fessehaye, Y., El-bialy, Z., Rezk, M.A., Crooijmans, R., Bovenhuis, H., Komen, H., 2006. Mating systems and male reproductive success in Nile tilapia (Oreochromis niloticus) in breeding hapas: A microsatellite analysis. Aquaculture 256, 148-158.

Gilmour, A.R., Gogel, B., Cullis, B., Thompson, R., 2009. ASReml user guide release 3.0. VSN International Ltd, Hemel Hempstead, UK.

Gjedrem, T., 1983. Genetic variation in quantitative traits and selective breeding in fish and shellfish. Aquaculture 33, 51-72.

Henryon, M., Jokumsen, A., Berg, P., Lund, I., Pedersen, P.B., Olesen, N.J., Slierendrecht, W.J., 2002. Genetic variation for growth rate, feed conversion efficiency, and disease resistance exists within a farmed population of rainbow trout. Aquaculture 209, 59-76.

Hughes, D.G., Behrends, L.L., 1983. Mass production of Tilapia nilotica seed in suspended net enclosures. in: Fishelson, L.,Yaron, Z. (Ed.), International Symposium on Tilapia in Aquaculture, Tel Aviv University, Tel Aviv, Israel, pp. 394-401.

Kause, A., Ritola, O., Paananen, T., Mäntysaari, E., Eskelinen, U., 2003. Selection against early maturity in large rainbow trout (Oncorhynchus mykiss): the quantitative genetics of sexual dimorphism and genotype-by-environment interactions. Aquaculture 228, 53-68.

Khaw, H., 2015. Cooperative and uniform fish?: social interactions and variability in live body weight in the GIFT strain (Nile tilapia, Oreochromic niloticus) in Malaysia (PhD Thesis) Wageningen Universiteit (161 pp.).

Khaw, H. L., Bovenhuis, H., Ponzoni, R.W., Rezk, M.A., Charo-Karisa, H., Komen, H., 2009. Genetic analysis of Nile tilapia (Oreochromis niloticus) selection line reared in two input environments. Aquaculture 294, 37-42.

Kolmodin, R., Strandberg, E., Madsen, P., Jensen, J., Jorjani, H., 2002. Genotype by environment interaction in Nordic dairy cattle studied using reaction norms. Acta Agric. Scand. Sect. A Anim. Sci. 52, 11-24.

Kolstad, K., Thorland, I., Refstie, T., Gjerde, B., 2006. Genetic variation and genotype by location interaction in body weight, spinal deformity and sexual maturity in Atlantic cod (Gadus morhua) reared at different locations off Norway. Aquaculture 259, 66-73.

Le Boucher, R., Quillet, E., Vandeputte, M., Lecalvez, J.M., Goardon, L., Chatain, B., Médale, F., Dupont-Nivet, M., 2011. Plant-based diet in rainbow trout (Oncorhynchus mykiss Walbaum): Are there genotype-diet interactions for 
main production traits when fish are fed marine vs. plant-based diets from the first meal?. Aquaculture 321, 41-48.

Lone, K.P., Ridha, M.T., 1993. Sex reversal and growth of Oreochromis spilurus (Gunther) in brackish and sea water by feeding $17 \alpha$-methyltestosterone. Aquac. Fish. Manag. 24, 593-602.

Luan, T.D., Olesen, I., Ødegård, J., Kolstad, K., Dan, N.C., 2008. Genotype by Environment Interaction for Harvest Body Weight and Survival of Nile tilapia (Oreochromis niloticus) in Brackish and Fresh Water Ponds. In Proceedings from the Eight International Symposium on Tilapia Aquaculture, Vol. 1. ag.arizona.edu, Cairo, pp. 231-240.

Lynch, M., Walsh, B., 1998. Genetics and Analysis of Quantitative Traits. Sinauer Associates, Inc., U.S.A. pp. 980.

Maluwa, A.O., Gjerde, B., Ponzoni, R.W., 2006. Genetic parameters and genotype by environment interaction for body weight of Oreochromis shiranus. Aquaculture 259, 47-55.

Mulder, H., Bijma, P., 2005. Effects of genotypex environment interaction on genetic gain in breeding programs. J. Anim. Sci. 83, 49-61.

Norhidayat, K., Nguyen, H.N., Hamzah, A., Ponzoni, R.W., 2009. Growth performance of mixed sex, hormonally sex reversed and progeny of $\mathrm{YY}$ male tilapia of the GIFT strain, (Oreochromis niloticus). Aquac. Res. 40, 720-728.

Okoko, M., 1996. Effect of $17 \alpha$ - methyltestosterone concentrations on the sex ratio, and gonadal development of Nile tilapia Oreochromis niloticus (Master's Thesis) Auburn University, AL, USA (234 pp.).

Omasaki, S.K., van Arendonk, J.A.M., Kahi, A.K., Komen, H., 2016. Defining a breeding objective for Nile tilapia that takes into account the diversity of smallholder production systems. J. Anim. Breed.Genet. 133, (2016) 404413.

Pham, A.T., David C.L., Graham, C.M., 1998. Genotypic effects on comparative growth performance of all-male tilapia (Oreochromis niloticus L.). Aquaculture 159, 293-302.

Phelps, R.P., Popma, T.J., 2000. Sex reversal of tilapia. In: B.A. Costa-Pierce, J.E. Rakocy (Eds.), Tilapia Aquaculture in the Americas, Vol. 2. The World Aquaculture Society, Baton Rouge, Louisiana, USA, pp. 34-59.

Phelps R.P., Cole, W., Katz, T., 1992. Effect of fluoxymesterone on sex ratio and growth of Nile tilapia (Oreochromis niloticus L.). Aquac. Res. 23, 405-410. 
Phelps, R.P., Arana, E., Argue, B., 1993. Relationship between the external morphology and gonads of androgen treated Oreochromis niloticus. J. Appl. Aquac. 2, 103-108.

Ponzoni, R.W., Nguyen, N.H., Khaw, H.L., Hamzah, A., Bakar, K.R.A., Yee, H.Y., 2011. Genetic improvement of Nile tilapia (Oreochromis niloticus) with special reference to the work conducted by the WorldFish Center with the GIFT strain. Rev. Aquac. 3, 27-41.

Popma, T.J., Green, B.W., 1990. Aquaculture production manual: sex reversal of tilapia in earthen ponds. Research and Development Series No. 35. International Center for Aquaculture, Alabama Agricultural Experiment Station, Auburn University, AL, USA (15 pp.).

Popma, T.J., Lovshin, L.L., 1995. Worldwide Prospects for Commercial Production of Tilapia. International Center for Aquaculture and Aquatic Environments, Department of Fisheries and Allied Aquacultures, Auburn University, Alabama p. 36849 (42 pp.).

Quillet, E., Le Guillou, S., Aubin, J., Labbé, L., Fauconneau, B., Médale, F., 2007. Response of a lean muscle and a fat muscle rainbow trout (Oncorhynchus mykiss) line on growth, nutrient utilization, body composition and carcass traits when fed two different diets. Aquaculture 269, 220-231.

Rasband, W.S., 2008. ImageJ. U.S. National Institutes of Health, Bethesda, Maryland, USA.

Rutten, M.J., Bovenhuis, H., Komen, H., 2005. Genetic parameters for fillet traits and body measurements in Nile tilapia (Oreochromis niloticus L.). Aquaculture 246, 125-132.

Rutten, M.J., Komen, H., Bovenhuis, H., 2005b. Longitudinal genetic analysis of Nile tilapia (Oreochromis niloticus L.) body weight using a random regression model. Aquaculture 246, 101-113.

Sae-Lim, P., 2013. One size fits all?. Optimization of Rainbow Trout Breeding Program Under Diverse Producer Preferences and Genotype-byenviroment Interaction (PhD Thesis) Wageningen Universiteit (200 pp.).

Sae-Lim, P., Komen, J., Kause, A., Mulder, H.A., 2014. Identifying environmental variables explaining genotype-by-environment interaction for body weight of rainbow trout (Onchorynchus mykiss): reaction norm and factor analytic models. Genet. Sel. Evol. 46,16. 10.1186/1297-9686-46-16.

Saillant, E., Dupont-Nivet, M., Haffray, P., Chatain, B., 2006. Estimates of heritability and genotype-environment interactions for body weight in sea bass (Dicentrarchus labrax L.) raised under communal rearing conditions. Aquaculture 254, 139-147. 
SAS Institute Inc.: 1997. SAS/STAR Software: Changes and Enhancements through Release 6.12 (USA, Cary).

Schreiber, S., Focken, U., Becker, K., 1998. Individually reared female Nile tilapia (Oreochromis niloticus) can grow faster than males. J. Appl. Ichthyol. 14, 43-47.

Thodesen, J., Rye, M., Wang, Y.X., Yang, K.S., Bentsen, H.B., Gjedrem, T., 2011. Genetic improvement of tilapias in China: Genetic parameters and selection responses in growth of Nile tilapia (Oreochromis niloticus) after six generations of multi-trait selection for growth and fillet yield. Aquaculture 322, 51-64.

Trọng, T.Q., Mulder, H.A., van Arendonk, J.A.M., Komen, H., 2013. Heritability and genotype by environment interaction estimates for harvest weight, growth rate, and shape of Nile tilapia (Oreochromis niloticus) grown in river cage and VAC in Vietnam. Aquaculture 384, 119-127.

Trọng, T.Q., van Arendonk, J.A.M., Komen, H., 2013. Genetic parameters for reproductive traits in Nile tilapia (Oreochromis niloticus): I. Spawning success and time to spawn. Aquaculture 416-417, 57-64.

Tsadik, G.G., Bart, A.N., 2007. Effect of feeding stocking density and water-flow rate on fecundity, spawning frequency and egg quality of Nile tilapia (Oreochromis niloticus L.). Aquaculture 272, 380-388.

van der Werf, J., Graser, H.U., Frankham, R., Gondro, C. (Eds.), 2009. Adaptation and Fitness in Animal Populations: Evolution and Breeding Perspectives on Genetic Resource Management. Springer Science+Business Media B.V., Springer, Netherlands (258 pp.).

World Bank., 2013. Fish to 2030. Prospects for Fisheries and Aquaculture. Agriculture and Envi ronmental Services Discussion Paper 3. World Bank Report, number 83177-GLB (102 pp.).

WorldFish Center, 2004. GIFT technology manual: an Aid to Tilapia Selective Breeding, (Penang, Malaysia). 


\title{
4
}

\section{Economic values of growth rate, feed intake, feed conversion ratio, mortality and uniformity for Nile tilapia}

\author{
S.K. Omasaki ${ }^{\text {a }}{ }^{*}$, K. Janssen $^{a}$, M. Besson ${ }^{\text {ac }}$, H. Komen ${ }^{\text {a }}$
}

\footnotetext{
${ }^{a}$ Animal Breeding and Genomics Centre, Wageningen University, P. O. Box 338, $6700 \mathrm{AH}$, Wageningen, The Netherlands, 'Animal Breeding and Genomics Group, Department of Animal Sciences, Egerton University, P.O Box 536, Egerton-20115, Kenya, 'Génétique Animale Biologie Intégrative, INRA, AgroParisTech, Université Paris-Saclay, 78350 Jouy-en-Josas, France.
} 


\section{Abstract}

The aim of the study was to derive the economic value (s) (EVs) of growth rate, feed intake, feed conversion ratio, mortality and uniformity for Nile tilapia (Oreochromis niloticus). A smallholder production system where fish are cultured in earthen ponds and oxygen is a limiting factor for production, was simulated using a deterministic bio-economic model. Traits of interest were: thermal growth coefficient (TGC), thermal feed intake coefficient (TFC), feed conversion ratio (FCR), mortality rate (M) and uniformity of harvest body weight (U). Two breeding objectives were considered: a breeding objective with TGC, TFC, $M$ and $U\left(H_{1}\right.$ model), and a breeding objective with TGC, FCR, $\mathrm{M}$ and $\mathrm{U}\left(\mathrm{H}_{2}\right.$ model). Gross margin (GM) was simulated before and after one genetic standard deviation improvement $\left(\sigma_{a}\right)$ on a trait while other breeding objective traits were kept unaltered. EVs (US\$ $/ \mathrm{kg} / \boldsymbol{\sigma}_{a}$ ) were derived as: change in $\mathrm{GM} /($ farm production before genetic improvement). Results show that EVs of TGC differ depending on the definition of the breeding objective. The EV of TGC was 1.19 when TFC was in the breeding objective. In contrast, EV was only 0.02 when FCR was in the breeding objective. This difference is caused by the way EVs are calculated: the increase in gross margin resulting from a marginal increase in TGC while keeping other traits (FCR or TFC) constant. EV of TFC was 1.25 and the EV for FCR was 0.41 . EVs for M and $U$ were 0.06 and 0.02 , irrespective of the model used. Improving TGC reduced the overall grow-out period, increasing the number of production cycles in the farm. In $\mathrm{H}_{1}$ model, reduced grow-out period was accompanied by a decrease in the amount of feed used in the farm $(-272.24 \mathrm{~kg} /$ year $)$ and in individual fish oxygen consumption $\left(-1.67 \mathrm{~g} / \mathrm{fish} /\right.$ year), resulting in an increase in gross margin. In $\mathrm{H}_{2}$ model, increasing TGC resulted in a reduced grow out period but also increased feed used in the farm $(5.73 \mathrm{~kg} /$ year $)$ and increased individual fish oxygen consumption $(0.57 \mathrm{~g} /$ fish/year). We conclude that the EV of TGC depends on which breeding objective is used. However, faster growing fish consume more oxygen, and unless faster growth is accompanied by improved FCR, this will lead to oxygen limitations, necessitating lower stocking densities. Our results thus strongly confirm the economic importance of reducing FCR, irrespective of the model used.

Key words: Nile tilapia, breeding objective, economic values, feed conversion ratio, growth, smallholder production. 


\subsection{Introduction}

The aim of genetic improvement programmes is to select animals for the production of a succeeding generation that will produce desired products more efficiently under future economic circumstances (Groen, 2000). These desired products or characteristics need to be well defined for genetic improvement to be effective. Defining a good breeding objective that will maximise economic return is therefore the first requirement of any genetic improvement program (Harris, 1970; Ponzoni, 1986). It involves a linear function of traits to be improved genetically, each trait weighed by its economic value (s) (EVs) (Hazel, 1943).

Deriving EVs using profit functions has been the most commonly applied method. EVs express the economic benefit (or loss) obtained from genetic improvement of a trait in a production system; they can be derived if the profit function is defined in economic terms (Groen, 1988; Kahi and Nitter, 2004). EVs are defined as an increase in profit from a marginal increase in the trait level, while keeping all other traits in the breeding objective constant. In fish, only few studies have estimated EVs using profit equations (Henryon et al., 1999; Ponzoni et al., 2007, 2008). However, aquatic production systems are complex in terms of relationships between traits and production factors which makes bio-economic models more suited for estimating EVs because they give a better description of the complex relations between traits levels, input and output of a farm (Besson et al., 2014, 2016; Janssen et al., 2016).

Nile tilapia (Oreochromis niloticus) are the most farmed tropical fish species in the world (World Bank, 2013). Global production was 4.5 million tons in 2013 and is projected to exceed 6.6 million tons by 2030; most of this production is realized in ponds (FAO, 2014).

Breeding programs have been at the basis of this success (Komen and Trong, 2014). However, a proper definition of a breeding objective with economic weights or desired gains for this species is still lacking. The main reason being that production systems are highly diverse in terms of agro-ecological distribution, source of income and market orientation and often far from optimized (Omasaki et al., 2016a).

Recently, we (Omasaki et al., 2016a) defined a breeding objective based on assessment of farming conditions for smallholder farmers that could be used for a 
national breeding program for Nile tilapia, e.g. in Kenya. In that study, growth rate, feed efficiency as well as feed intake were identified as important traits. Estimation of EVs for breeding objective traits to evaluate their economic relevance is the next step.

In the present study EVs for breeding objective traits for Nile tilapia were derived based on a deterministic bio-economic model. The production system considered were smallholder farmers rearing fish in earthen ponds. For Nile tilapia cultured in earthen ponds, oxygen concentration below $3 \mathrm{mg} / \mathrm{L}$ can affect growth rate, feed intake and survival (NACA, 1989; Popma and Lovshin, 1996; Tran-Duy et al., 2012). Dissolved oxygen, therefore may become a production constraint when oxygen requirements of fish exceeds oxygen production in the pond. Groen (1988) recommended modelling production at the farm level to determine EVs of traits while taking into account all factors limiting production. In the presence of limitations, EVs of traits may change and breeding objective has to be adjusted for such limitations (Groen, 1989). We therefore modelled oxygen as a limiting factor for production. The aim of the study was to investigate the economic value for growth rate, feed intake and feed efficiency, and whether these economic values differ depending on the definition of the breeding objective.

\subsection{Materials and methods}

\subsubsection{General model description and definitions}

A typical smallholder production system where fish are cultured in earthen ponds and oxygen is a limiting factor for production, was simulated using a deterministic bio-economic model (Besson et al., 2014) in R (R Development Core Team, 2011). Data from smallholder semi-intensive Nile tilapia farms in Kenya were used to define the production system. The average number of ponds in these farms is 2 , each with a total area of $300 \mathrm{~m}^{2}$ for on-growing fish. In the base line scenario, a total of 900 fish are stocked per pond at a stocking density of 3 fish per $\mathrm{m}^{2}$. Fish are stocked when they are $5 \mathrm{~g}$ and harvested and sold when they are $250 \mathrm{~g}$. The time needed for fish to grow from 5 to $250 \mathrm{~g}$ represents one production cycle. The model consists of 3 parts: fish, pond and farm model. The process of model development involved the description of outputs and inputs. Data provided by Sagana Aquaculture Research Station (National Breeding Centre for Kenya Freshwater Aquaculture, (Omasaki et al., 2016b), from the field survey (Omasaki et al., 2016a) and literature were used for this model. All outputs were valued at the market levels. Fixed costs are not affected by the genetic change of the traits, and therefore they are omitted in this study. Instead change in profit resulting from 
genetic change is equal to change in gross margin (GM). All costs are expressed in US dollars (\$). GM was calculated before and after genetic improvement of the trait with one genetic standard deviation (Van Middelaar et al., 2014), while other breeding objective traits were kept unchanged. EVs for traits are derived relative to the farm production before genetic improvement (farm production_before_ $\Delta G$ ) as:

$$
E V s=\left(\frac{\Delta_{G M}}{\text { farm }_{\text {production_before_ } \Delta G}}\right)
$$

where $\Delta_{G M}$ is the change in gross margin

\subsubsection{Traits of interest}

Five biological traits important for farmers are: growth rate, expressed as thermal growth coefficient (TGC) (Jobling, 2003), feed intake, expressed as thermal feed intake coefficient (TFC) (Janssen et al. 2016), feed conversion ratio (FCR), mortality rate (M) and uniformity (U) (Omasaki et al., 2016a). These traits influence farm income and expense as follows: fish that grow fast will attain market weight early which saves costs. Feed is the major cost of production, therefore, reducing feed intake or FCR increases farm profit. With uniform animal products, famers can increase profit by selling more fish in the preferred price range. Increased fish survival from stocking to harvest means less feed wasted and more fish harvested. In consequence, as stocking density at harvest is usually fixed, less juveniles need to be stocked.

In this study two different breeding objectives were considered in deriving the EV for TGC:

- $\quad$ A Breeding objective $\left(\mathrm{H}_{1}\right)$ with TGC, TFC, $U$, and M. EV for TGC is derived while holding TFC constant $\left(\mathrm{H}_{1}\right.$ model)

- A Breeding objective $\left(\mathrm{H}_{2}\right)$ with TGC, FCR, $U$ and M. EV for TGC is derived while holding FCR constant $\left(\mathrm{H}_{2}\right.$ model).

\subsubsection{Fish model}

Based on the two breeding objectives, we developed two fish models: a $\mathrm{H}_{1}$ and $\mathrm{H}_{2}$ model. First TGC was estimated, which was used in both models to predict fish growth.

\subsubsection{1 $\mathrm{H}_{1}$ model}


Using the data provided by Sagana Aquaculture Research Station, TGC was estimated as:

$$
T G C=\frac{H W^{b}-S W^{b}}{\sum_{i=1}^{n} T} \times 1000
$$

where $H W$ is the final harvest body weight, $S W$ is the stocking body weight, $n$ is the number of days between stocking and harvesting, $T$ is the daily average temperature and $b$ is a weight exponent. The estimated TGC was then used to fit the growth curve of Nile tilapia reared by smallholder farmers in Kenya to obtain a $\mathrm{HW}$ of $250 \mathrm{~g}$ in 195 days from the stocking weight of $5 \mathrm{~g}$. The underlying assumptions of the model are 1 ) growth rate is allometrically related to body weight and 2) the allometric constant of growth rate is directly related to mean daily water temperature averaged over the grow-out period (Jobling, 2003). Equation 2 was fitted to the data obtained from Sagana Aquaculture Research Station using non-linear least squares regression in $\mathrm{R}$ in order to estimate $b$. The values and parameters used in solving the equation are provided in Table 4.1.

Estimation of both fish weight $\left(W_{p}\right)$ and fish daily weight gain $\left(D W G_{p}\right)$ at day $p$ were computed as follows:

$$
\begin{aligned}
& W_{p}=\left[S W^{b}+\left(\frac{T G C}{1000} \times \sum_{i=1}^{p} T_{i}\right)\right]^{1 / b} \\
& D W G_{p}=W_{p+1}-W_{p}
\end{aligned}
$$

Cumulative feed intake at day $p\left(C F I_{p}\right)$ was calculated using the following model (Janssen 2016):

$$
C F I_{p}=\left(S W^{y}+\frac{T F C}{1000} \times \sum_{i=1}^{p} T\right)^{1 / y}-S W
$$

where $y$ is a weight exponent, TFC is the thermal feed intake coefficient and $\sum_{i=1}^{p} T$ the current day. SW is subtracted from the model so that the model goes through the intercept. Equation 5 was fitted to the data obtained from Sagana Aquaculture Research Station using non-linear least squares regression in $\mathrm{R}$ in order to estimate both TFC and $y$. 
Daily feed intake at day $p\left(D F l_{p}\right)$ was calculated as:

$$
D F I_{p}=C F I_{p+1}-C F I_{p}
$$

Similarly, feed conversion ratio at day $p\left(F C R_{p}\right)$ was estimated as:

$$
F C R_{p}=\frac{D F I_{p}}{D W G_{p}}
$$

Oxygen consumption per fish $\left(O_{2 f i s h}\right)$ was estimated using, the oxy-caloric coefficient $\left(Q_{o x}\right)$ of nutrients (Blaxter, 1989). The following equation was used (Besson et al., 2016):

$$
O_{2 f i s h}=\left(F I_{m n} \times N D_{m n}-N R_{m n}\right) \times \frac{E_{m n}}{Q_{o x . m n}}
$$

where $F I$ is the feed nutrient intake, $N D$ is the nutrient digestibility, $N R$ is the nutrient retention, $E$ is the energy content of the nutrient, $Q_{o x}$ is the oxy-caloric coefficient of the nutrient and $m n$ are the main nutrients (protein, fat and carbohydrate). This model assumes that fat deposition in the fish does not exceed the fat intake from feed. The values used in equation 8 are provided in Table 4.2. 
Table 4.1 Input parameters used in the bio-economic model.

\begin{tabular}{llll}
\hline Parameter & Abbreviation & Value & Unit \\
\hline Temperature & - & $25^{\mathrm{a}}$ & ${ }^{\circ} \mathrm{C}$ \\
Intercept & $\mathrm{a}$ & -0.095 & - \\
Weight exponent to predict FCR* & $\mathrm{z}$ & 0.195 & - \\
Weight exponent to predict weight* & $\mathrm{b}$ & 0.38 & - \\
Thermal growth coefficient* & $\mathrm{TGC}$ & 1.30 & - \\
Thermal feed intake coefficient* & $\mathrm{TFC}$ & 1.24 & - \\
Weight exponent to predict CFI* & $\mathrm{y}$ & 0.32 & - \\
Stocking weight & $\mathrm{SW}$ & 5 & $\mathrm{~g}$ \\
Harvest weight & $\mathrm{HW}$ & 250 & $\mathrm{~g}$ \\
Genetic coefficient of variation for HW* & $\mathrm{GCV}$ & 13.7 & $\%$ \\
CFI at harvest* & - & 576 & $\mathrm{~g}$ \\
Additive standard deviation for HW & $\mathrm{HW} \sigma_{\mathrm{a}}$ & 34.3 & $\mathrm{~g}$ \\
Standard deviation for HW & $\sigma \mathrm{H}$ HW & $84^{\mathrm{a}}$ & $\mathrm{g}$ \\
Mortality rate & $\mathrm{M}$ & 0.11 & $\% \mathrm{day}^{-1}$ \\
Additive standard deviation for TGC & $\mathrm{TGC}_{\sigma_{\mathrm{a}}}$ & 0.11 & $\mathrm{~g}$ \\
Additive standard deviation for TFC & $\mathrm{TFC}_{\sigma_{\mathrm{a}}}$ & 0.107 & $\mathrm{~g}$ \\
Additive standard deviation for FCR & $\mathrm{FCR}_{\sigma_{\mathrm{a}}}$ & 0.162 & $\mathrm{~g}$ \\
Additive standard deviation for M & $\mathrm{M}_{\sigma_{\mathrm{a}}}$ & 0.053 & $\mathrm{~g}$ \\
Additive standard deviation for U & $\mathrm{U}_{\mathrm{a}}$ & 6 & $\mathrm{~g}$ \\
Additive standard deviation for SW & $\mathrm{SW}_{\sigma_{\mathrm{a}}}$ & 0.69 & $\mathrm{~g}$ \\
Additive standard deviation for CFI & $\mathrm{CFI}_{\sigma_{\mathrm{a}}}$ & 94.8 & $\mathrm{~g}$ \\
Genetic correlation between HW and CFI & $r_{a}$ & $0.9^{\mathrm{b}}$ & - \\
Mean environmental standard deviation (SD) & $\sigma_{E}$ & $35.2^{\mathrm{a}}$ & $\mathrm{g}$ \\
\hline
\end{tabular}

*estimated from data provided by Sagana Aquaculture Research Institute and Literature;

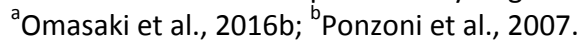

Table 4.2 Oxy-caloric coefficients, digestibility, fish nutrient contents and energy contents of main nutrients (protein, fat and carbohydrate).

\begin{tabular}{llll}
\hline Parameter & \multicolumn{2}{l}{ Main nutrients } \\
\cline { 2 - 4 } & Carbohydrate & Fat & Protein \\
\hline $\mathrm{Q}_{\mathrm{ox}}\left(\mathrm{kJ} \mathrm{g}^{-1} \mathrm{O}_{2}\right)$ & $14.8^{1}$ & $13.7^{2}$ & $13.4^{1}$ \\
Digestibility's (\%) & $74^{3}$ & $97^{3}$ & $93^{3}$ \\
Fish nutrient content $\left(\mathrm{g} \mathrm{kg}^{-1}\right.$ & - & $87^{3}$ & $157^{3}$ \\
Energy content $\left(\mathrm{kJ} \mathrm{g}^{-1}\right)$ & $17.2^{4}$ & $39.5^{4}$ & $23.6^{4}$ \\
\hline
\end{tabular}

${ }^{1}$ Brafield and Solomon, 1972; ${ }^{2}$ Elliott and Davison, 1975; ${ }^{3}$ Schneider et al., 2004; ${ }^{4}$ Brafield and Llewellyn, 1982.

\subsubsection{2 $\mathrm{H}_{2}$ model}

In this model, the estimates of $W_{p}, D W G_{p}, O_{2 f i s h}$ and $N_{\text {fish } \_p}$ were obtained similarly as in the $H_{1}$ model. However, $F C R, D F I$ and $C F I$ were calculated differently. $F C R_{p}$ at day $\mathrm{p}$ was calculated as: 


$$
F C R_{p}=a+\left(W_{p}^{z}\right)
$$

where $a$ is an intercept and $z$ is a weight exponent. Equation 9 was fitted to the data obtained from Equation 7 using non-linear least squares regression in $\mathrm{R}$ in order to estimate both $a$ and $z$. Subsequently, $D F I_{p}$ at day $p$ was modelled as:

$$
D F I_{p}=F C R_{p} \times D W G_{p}
$$

Finally, $C F I_{p}$ at day $\mathrm{p}$ was calculated as:

$$
C F I_{p}=\sum(D F I)
$$

It is important to note that $H_{1}$ and $H_{2}$ models give near identical results for CFI $\left(\mathrm{R}^{2}\right.$ 0.999).

\subsubsection{Pond model}

The pond model represents all the fish that were stocked together at the same time. The inputs into the pond model include the outputs from the fish model. In the baseline scenario, farmers harvest 720 fish per production cycle. It is assumed that at harvest, daily oxygen production in the pond equals daily oxygen consumption by the fish. Daily oxygen consumption at harvest in the baseline scenario is computed from equation 8 , and is used as a constraint on production output in the scenario after genetic improvement.

The maximum number of fish $\left(N F_{-} \max \right)$ that can be stocked and maintained in a pond is determined by oxygen production and oxygen consumption:

$$
N F_{-\max }=\left(\frac{O_{2_{-} \text {pdn }} \text { pond }}{\mathrm{O}_{2} \text { consumed }}\right)
$$

where $\mathrm{O}_{2}$ pdn_pond is the oxygen production in the pond and $\mathrm{O}_{2}$ consumed is the oxygen consumed per fish the day before harvesting.

The number of fish stocked $\left(N F_{\text {stocked }}\right)$ to reach $N F_{-}$harvested includes the cumulative mortality of fish from stocking to harvest (n.d_harvest) which was fixed at $20 \%$. Mortality till harvest (Survival_harvest) was modelled as:

$$
\text { Survival_harvest }=\left(1-\frac{M}{100 \%}\right)^{\text {n.d_harvest }{ }^{1}}
$$

The number of fish stocked to reach $N F_{-}$harvested was then modelled as: 


$$
N F_{- \text {stocked }}=\frac{N F_{- \text {harvested }}}{\text { Survival_harvest }}
$$

Fish production (Pdn fish_pond, in $\mathrm{kg}$ ) and feed consumed (Feed_cons_pond, in $\mathrm{kg}$ ) per pond is given by:

$$
\begin{aligned}
& P d n_{-} \text {fish_pond }_{-}=\left(N F_{\text {_harvested }} \times H W\right) / 1000 \\
& \text { Feed _cons_pond }=\left(N F_{\text {_harvested }} \times C F I\right) / 1000
\end{aligned}
$$

\subsubsection{Farm model}

Output(s) from the pond model becomes the input into the farm model. We modelled a production system where fish is stocked throughout the year. The revenues (from fish production) and costs (feed consumption, fingerlings stocked, fertilizer used, liming and packaging) per pond are first estimated. The estimated average values are then multiplied by the total number of ponds ( $N_{-}$ponds_year $)$that can be produced in a farm in a year, to obtain average farm production ( $\left.P d n_{\text {fish farm }}\right)$ and cost. The $N_{-}$ponds_year that can be produced in a farm in a year depends on the initial number of ponds available in the farm and the growing period $\left(G_{-p e r i o d}\right)$. When TGC increases, ponds are stocked more frequently because $G_{- \text {period }}$ shortens. The number of production cycles per year ( $N_{-}$pdn_cycleyear $)$was estimated as:

$$
N_{-} \text {pdn_cycle_year }=\frac{365}{G_{-} \text {period }}
$$

The number of ponds is 2 , therefore the $N_{-}$ponds_year was calculated as:

$$
N_{-} \text {ponds year }=2 \times N_{-} \text {pdn_cycle }_{-} \text {year }
$$

Average farm production therefore was estimated as:

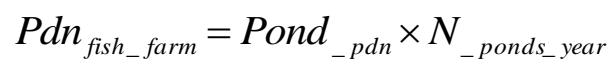

where Pond ${ }_{-p d n}$ is the average pond production.

Finally, farm profit (Farm profit $)$ was derived as: 


$$
\begin{aligned}
\text { Farm }_{\text {profit }} & =\left(F_{\text {price }} \times P d n_{\text {fish_farm }_{-}}\right)-\left(C_{\text {fingerling }} \times S_{\text {fingerling_farm }_{-}}\right) \\
& -\left(C_{\text {feed }} \times F_{\text {consumed_farm }_{\text {far }}}\right)-\left(C_{\text {fertilizer }} \times \text { Fertilizer }_{\text {used_kg }}\right) \\
& -\left(C_{\text {lime }} \times \text { Lime }_{\text {used_kg }_{-}}\right)-\left(C_{\text {packaging }} \times F_{\text {packed_farm }_{-}}\right)
\end{aligned}
$$

where $F_{\text {price }}$ is the sales price per kg of fish, $P d n_{\text {fish_farm }}$ is as defined above, $C_{\text {fingerling }}$ is the cost per fingerling, $S_{\text {fingerlings farm }}$ is the total number of fingerlings stocked in the farm per year, $C_{\text {feed }}$ is the cost per $\mathrm{kg}$ of feed, $F_{\text {consumed farm }}$ is the total feed consumed in the farm $(\mathrm{kg})$ per year, $C_{\text {fertilizer }}$ is the cost per $\mathrm{kg}$ of fertilizer, Fertilizer $_{\text {used } k g}$ is the total fertilizer used in the farm $(\mathrm{kg})$ per year, $C_{\text {lime }}$ is the cost per $\mathrm{kg}$ of lime, Lime $_{\text {used_kg }}$ is the total lime used in the farm $(\mathrm{kg})$ per year, $C_{\text {packaging }}$ is the cost of packaging per $\mathrm{kg}$ of fish and $F_{\text {packed_farm }}$ is the total fish packed in the farm (kg) per year.

\subsubsection{Genetic standard deviation of traits of interest}

In this study, additive genetic standard deviation $\left(\boldsymbol{\sigma}_{a}\right)$ was used to simulate the genetic changes for breeding objective traits. The genetic coefficient of variation (GCV) for a given trait, defined as the ratio of $\sigma_{a}$ and the mean trait value $(\mu)$ multiplied by $100 \%$, was used to estimate the $\sigma_{a}$ for a given trait. The values used to estimate $\sigma_{a}$ are provided in Table 4.1 and 4.4.

To estimate $\sigma_{a}$ for TGC $\left(T G C_{\sigma_{a}}\right)$, the genetic variation in $\mathrm{HW}$ was simulated in R. First, GCV for HW $\left(G C V_{H W}\right)$ was derived from (Omasaki et al., 2016a). Using the average $\mathrm{HW}$ considered in this study, the $\sigma_{a}$ for $\mathrm{HW}\left(H W_{\sigma_{a}}\right)$ was then calculated. $\mathrm{HW}$ was then simulated as: $H W_{i}=\mu+Z_{i} \times H W_{\sigma_{\mathrm{a}}}$, where $\mu$ is the average $\mathrm{HW}$ and $Z_{i}$ is the standard normal distribution with $i=1, \ldots 10^{5}$. From this simulation, TGC $_{\sigma_{a}}$ was then estimated as follows (Janssen et al., 2016):

$$
T G C_{\sigma a}=\sqrt{\left(\frac{(1000}{\sum_{i=1}^{n} T}\right)^{2} \times \operatorname{Var}\left(H W_{i}^{b}\right)}
$$

where $\sum_{i}^{n} T$ is the summation of temperatures from stocking to the day of harvest.

To calculate the $\sigma_{a}$ for TFC (TFC $\left.\sigma_{a}\right), \sigma_{a}$ for CFI $\left(C F I_{\sigma_{a}}\right)$ at harvest was first estimated. This is because the genetic variation of TFC follows from genetic variation in 
stocking weight as well as genetic variation in $\mathrm{CFI}$ at harvest. $\mathrm{CFI}_{\sigma_{\mathrm{a}}}$ was calculated as:

$$
C F I_{\sigma a}=\frac{F C R \times H W_{\sigma a}}{r_{a}}
$$

where FCR is the biological feed conversion ratio, $r_{a}$ is the genetic correlation between cumulative feed intake and $\mathrm{HW}$ and $H W_{\sigma_{a}}$ is as defined above. FCR is assumed to approximate the regression coefficient of CFI on HW, which implies that the intercept of this regression is zero, i.e. maintenance requirements at zero growth can be ignored.

Using $\mathrm{GCV}_{\mathrm{HW}}, \sigma_{a}$ for SW (SW $\left.\boldsymbol{\sigma}_{a}\right)$ was estimated. With the average CFI at harvest and SW considered in this study, both CFI and SW were simulated in R as: $C_{F}=\mu+Z_{i} \times$ $C F I_{\sigma_{a}}$, and $S W_{i}=\mu+Z_{i} \times S W_{\sigma_{a}}$, where $\mu$ represents the average CFI at harvest and average SW considered in this study respectively, and $Z_{i}$ is as defined above. Consequently, TFC $\sigma_{\text {a }}$ was estimated as (Janssen et al., 2016):

$$
T F C_{\sigma a}=\sqrt{\operatorname{Var}\left(\frac{\left(C F I_{i}+S W_{i}\right)^{y}-S W_{i}^{y}}{\sum_{i=1}^{n} T} \times 1000\right)}
$$

For $M, \sigma_{a}\left(M_{\sigma_{a}}\right)$ can be estimated from genetic variation in overall mortality at harvest (OM). Average $\mathrm{OM}$ is $20 \%$. Heritability on the underlying liability scale is assumed to be 0.17 (Vehviläinen et al., 2008), thus $\sigma_{a}$ for overall mortality $\left(\mathrm{O}_{m \sigma_{a}}\right)$ is $0.17^{\wedge} 0.5$. After one $\sigma_{a}$ of genetic improvement, the deviation of the threshold from the mean on the liability scale $\left(x_{A}\right)$ is calculated from the quantile function of a normal distribution in $R$ as: $X_{A}=-$ qnorm $(0.20)+0.17^{\wedge} 0.5=1.25$. The new value of the overall mortality $(\mathrm{OM})$ then becomes: $O M=(1$-pnorm $(1.25)) \times 100 \%=10.5 \%$. The corresponding value for $M$ before genetic improvement $\left(M_{B}\right)$ and after genetic improvement $\left(M_{A}\right)$ were estimated as:

$$
\begin{aligned}
& \left.M_{B}=\left(1-(1-20 / 100)^{1 / 194}\right)\right) \times 100=0.11 \\
& \left.M_{A}=\left(1-(1-10.5 / 100)^{1 / 194}\right)\right) \times 100=0.057
\end{aligned}
$$

The difference between $M_{B}$ and $M_{A}(0.11-0.057=0.053)$ is what is treated as $M_{\sigma_{a}}$.

(Mulder et al., 2007) showed that GCV for environmental variance $\left(G C V_{\sigma E}^{2}\right)$ of body weight can be estimated as: 
$G C V_{\sigma_{E}^{2}}=\frac{s d\left(\sigma_{E}^{2}\right)}{\overline{\sigma_{E}^{2}}} \times 100 \%$

where $s d\left(\sigma_{E}^{2}\right)$ and $\overline{\sigma_{E}^{2}}$ are the genetic standard deviation and the mean for $\sigma_{E}^{2}$ respectively. $\overline{\sigma_{E}}$ for $\mathrm{HW}$ for Nile tilapia in this study was estimated as:

$\overline{\sigma_{E}}=\sqrt{\left(\sigma_{P}^{2}-\sigma_{a}^{2}\right)}$

The estimated $\mathrm{GCV}_{\mathrm{HW}}$ for uniformity in GIFT tilapia is about $17 \%$ (Khaw et al., 2016), using this value, $\sigma_{a}$ for uniformity $\left(U_{\sigma_{a}}\right)$ was estimated. Estimation of $\sigma_{a}$ for FCR $\left(\mathrm{FCR}_{\sigma_{\mathrm{a}}}\right)$ is presented in appendix $\mathrm{A}$.

\subsection{Results}

\subsubsection{Revenues, costs and gross margins for the scenarios studied}

\subsubsection{Baseline Scenario}

Production parameters, revenues, costs and GM for Nile tilapia farming are presented in Table 4.4. For the two models, results were similar; therefore only results for $\mathrm{H}_{1}$ model are presented. The values presented are expressed on a per farm per year basis. Feed costs were the major variable costs accounting for approximately $84 \%$; fingerlings accounted for $11 \%$ while fertilizer, lime and packaging cost contributed only 5\%. The total variable costs were US\$1552.24. Total farm production and revenues were $667 \mathrm{~kg}$ and US\$3161 respectively, while GM was US\$1609. 
Table 4.3 Revenues and cost variables for Nile tilapia in Kenya.

\begin{tabular}{lll}
\hline Parameter & Abbreviation & Values \\
\hline Revenues & Fsale & \\
Fish (g) & $\prime$ & \\
$<100$ & $\prime$ & 3.20 US\$ per kg \\
$100-200$ & $\prime$ & 3.70 US\$ per kg \\
$200-300$ & $\prime$ & 4.74 US\$ per kg \\
$>400$ & & 5.30 US\$ per kg \\
Variable costs & Cfeed & \\
Feed & Cfingerling & 0.79 US\$ per kg \\
Fingerling & Cfertilizer & 0.053 US\$ per piece \\
Fertilizer & Clime & 0.68 US\$ per kg \\
Lime & Cpackaging & 0.053 US\$ per kg \\
Packaging & & 0.26 US\$ per kg \\
\hline
\end{tabular}

US\$, US dollars.

Table 4.4 Production and economic parameters for Nile tilapia farming at the baseline scenario.

\begin{tabular}{|c|c|}
\hline Parameter & TFC model \\
\hline Number of fingerlings used/year & 3335 \\
\hline Total fish produced in the farm (kg/year) & 666.95 \\
\hline Total feed used in the farm ( $\mathrm{kg} /$ year) & 1645.58 \\
\hline Number of ponds stocked/year & 3.69 \\
\hline Average days to harvest & 195 \\
\hline FCR biological ${ }^{a}$ ( $\mathrm{kg}$ feed $/ \mathrm{kg}$ fish) & 2.34 \\
\hline FCR economic $^{b}$ ( $\mathrm{kg}$ feed $/ \mathrm{kg}$ fish) & 2.50 \\
\hline Survival to harvest (\%) & 80.0 \\
\hline Feed cost used in the farm (US\$) & 1300.01 \\
\hline Fingerling cost used in the farm (US\$) & 176.74 \\
\hline Fertilizer cost used in the farm (US\$) & 5.01 \\
\hline Liming cost used in the farm (US\$) & 23.45 \\
\hline Packaging cost used in the farm (US\$) & 47.03 \\
\hline Total variable cost (US\$) & 1552.24 \\
\hline Total farm sales (US\$) & 3161.34 \\
\hline Gross margin (GM, US\$) & 1609.10 \\
\hline
\end{tabular}

${ }^{a} \mathrm{FCR}$ biological, feed consumed/(fish produced/ (weight gain); ${ }^{\mathrm{b}} \mathrm{FCR}$ economic, feed consumed/fish produced; US\$, US dollars. 


\subsubsection{Scenario after genetic change}

Table 4.5 shows the impact of genetic change to production and economic variables on Nile tilapia farming when $\mathrm{H}_{1}$ model is implemented. Improving TGC by 0.11 reduced individual fish oxygen consumption which allowed for more fish stocking and decreased feed used in the farm (- $272 \mathrm{~kg})$. Additionally, improved TGC reduced the overall grow-out period which increased the number of production cycles (0.32), fish produced in the farm and farm GM (US\$792). Improving TFC by 0.107 lowered FCR and individual oxygen consumption but increased the number of fish stocked, fish produced in the farm as well as farm GM (US\$836).

On the other hand, when $\mathrm{H}_{2}$ model was implemented, improving TGC by 0.11 increased TFC, individual fish oxygen consumption, the number of ponds stocked (0.32), fish produced and farm GM (US\$16.05). Furthermore, improved TGC lowered the number of fish stocked per pond and the total number of fish harvested per year. Enhanced FCR reduced both FCR and individual oxygen consumption but increased the number of fish stocked, fish produced and farm GM (US\$271.66) (Table 4.5).

Generally, for the two models, reduced mortality lowered both the number of fingerlings and feeds used in the farm, increasing farm gross margin. Increasing uniformity improved farm gross margin (US\$15.5) but production at the farm level did not change. Improving TFC and FCR recorded the highest gross margins (Table 4.5). 
Table 4.5 Effect of genetic change on production and economic parameters for Nile tilapia production in Kenya using $\mathrm{H}_{1}$ model (1) or $\mathrm{H}_{2}$ model (2).

\begin{tabular}{|c|c|c|c|c|c|c|c|c|c|}
\hline \multirow[t]{2}{*}{ Trait } & \multicolumn{9}{|l|}{ Parameter } \\
\hline & $\begin{array}{l}\Delta \\
\text { FCR/TFC in }\end{array}$ & $\begin{array}{l}\Delta \text { in individual } \mathrm{O}_{2} \\
\text { consumption }(\mathrm{g})\end{array}$ & $\begin{array}{l}\Delta \text { in the no. of } \\
\text { fish stocked }\end{array}$ & $\begin{array}{l}\Delta \text { in }(\mathrm{kg}) \text { fish } \\
\text { harvested }\end{array}$ & $\begin{array}{l}\Delta \text { in the no. } \\
\text { of pond }\end{array}$ & $\begin{array}{l}\Delta \text { of fish in the } \\
\text { farm }(\mathrm{kg})\end{array}$ & $\begin{array}{l}\Delta \text { of feed used in } \\
\text { the farm }(\mathrm{kg})\end{array}$ & GM US\$ & Model \\
\hline TGC & $-0.31^{\mathrm{a}}$ & -1.67 & 165 & 147.40 & 0.32 & 206.44 & -272.24 & 792 & 1 \\
\hline TFC & $-0.46^{\mathrm{a}}$ & -1.67 & 297 & 236.28 & 0 & 217.78 & 108.95 & 835.58 & 1 \\
\hline$M$ & 0 & 0 & -88 & 0 & 0 & 0 & -52 & 41 & 1 \\
\hline$u$ & 0 & 0 & 0 & 0 & 0 & 0 & 0 & 15.5 & 1 \\
\hline TGC & $0.11^{\mathrm{b}}$ & 0.57 & -80 & -51.69 & 0.32 & 6.81 & 5.73 & 16.05 & 2 \\
\hline FCR & $-0.16^{a}$ & -0.54 & 92 & 74 & 0 & 67.83 & 42.18 & 271.66 & 2 \\
\hline$M$ & 0 & 0 & -88 & 0 & 0 & 0 & -52 & 41 & 2 \\
\hline U & 0 & 0 & 0 & 0 & 0 & 0 & 0 & 15.5 & 2 \\
\hline
\end{tabular}

FCR, feed conversion ratio; TFC, thermal feed intake coefficient; GM, gross margins; US\$, US dollars; TGC, thermal growth coefficient; M, mortality; $\mathrm{U}$, uniformity in body weight; ${ }^{\mathrm{a}}$, changes in FCR; ${ }^{\mathrm{b}}$, changes in TFC. 


\section{3.2. Economic values for traits of interest}

EVs (US\$ $/ \mathrm{kg} / \boldsymbol{\sigma}_{a}$ ) are given in Table 4.6. The EVs for TGC varied depending on the model used; they were higher when $\mathrm{H}_{1}$ model was used (1.19) compared to $\mathrm{H}_{2}$ (0.02) model. EVs for TFC and FCR were 1.25 and 0.41 respectively. EVs from the two models were similar for $M(0.06)$ and $U(0.02)$.

Table 4.6 Economic values for traits of interest for Nile tilapia in Kenya.

\begin{tabular}{lllll}
\hline Trait & Baseline trait level & $\Delta_{\text {trait }}$ & \multicolumn{2}{c}{ Economic value (US\$/kg production/ $\boldsymbol{\sigma}_{a}$ ) } \\
\cline { 4 - 5 } & & & $\mathrm{H}_{1}$ model & $\mathrm{H} 2$ model \\
\hline TGC & 1.29 & +0.11 & 1.19 & 0.02 \\
TFC & 1.24 & -0.10 & 1.25 & - \\
FCR & 2.34 & -0.16 & - & 0.41 \\
M & 0.11 & -0.05 & 0.06 & 0.06 \\
U & 84.0 & -6.00 & 0.02 & 0.02 \\
\hline
\end{tabular}

$\Delta_{\text {trait, }}$ genetic change of a trait; US\$, US dollars; TGC, thermal growth coefficient; TFC, thermal feed intake coefficient; FCR, feed conversion ratio; $M$, mortality; $U$, uniformity in body weight.

\subsection{Discussion}

\subsubsection{Main findings}

In this study, we used a bio-economic model to derive EVs for breeding objective traits for Nile tilapia, reared by smallholder farmers using earthen ponds in Kenya. EVs were calculated as an additional profit accrued per $\mathrm{kg}$ of fish produced when breeding objective traits are improved by one genetic standard deviation. Our results show that EV of TGC varies depending on whether FCR or TFC is included in the breeding objective. Improving TGC reduces the overall grow-out period, increasing the number of production cycles in the farm. However, faster growing fish consume more oxygen, and unless faster growth is accompanied by improved FCR, this will lead to oxygen limitations, necessitating lower stocking densities. Our results thus strongly confirm the economic importance of reducing FCR, irrespective of the model used.

\subsubsection{Consequences of changes in trait levels and economic values}

In pond systems, oxygen will be a factor constraining production when oxygen demand of fish surpasses oxygen production. This is typically the case when fish are getting close to harvest size. Stocking density per pond therefore depends on expectations for TGC, TFC, FCR and M. Under these circumstances, farmers will stock less or more fingerlings depending on how oxygen requirements change. 
Accordingly, our model optimizes on stocking density of the pond and derives EVs for breeding objective traits.

Results show that EV of TGC varies depending on the breeding objective. In $\mathrm{H}_{1}$, the EV of TGC was calculated while keeping TFC constant. In $\mathrm{H}_{1}$ model therefore, increase in TGC leads to a lower FCR and higher annual production. Consequently, the EV of TGC is high (1.19US\$/kg), and increasing TGC has a positive effect on annual farm profit. Improving TGC has two main effects: 1) reduced individual fish oxygen consumption as faster growth is realised without increasing TFC. Fish therefore become more efficient. This enables farmers to stock extra fingerlings and grow more fish; 2) a higher growth rate reduces overall grow-out time, allowing farmers to stock more ponds per year, increasing yearly farm production. Feed is a major cost in aquaculture, (Ponzoni et al., 2007; Trong et al., 2013; Besson et al., 2014), and reducing feed cost through improved FCR will enhance farm returns.

In $\mathrm{H}_{2}$, the EV of TGC is calculated while keeping FCR constant. This means that when TGC increases, TFC also increases. Improving TGC in this scenario resulted in faster growing individuals with higher TFC, thus increasing individual fish oxygen requirement. Faster growth therefore leads to 1) reduced number of fingerlings stocked per pond to avert oxygen deficiency and 2) reduced grow-out time allowing farmers to raise additional ponds yearly. Under this situation, the accrued profit at the farm level is due to increased number of ponds produced per year, but corrected for the reduced numbers of fish stocked, hence the low EV for TGC observed, i.e. $98 \%$ lower relative to $\mathrm{H}_{1}$.

Goddard (1998) noted that the EV for a given trait in a breeding objective varies depending on what other traits are included in a breeding objective, which are held constant during the EVs derivation. EVs of improving growth rate when feed intake is held constant for instance will be different compared to when feed conversion ratio is held constant. Similarly, in this study also the EV for TGC were different for $\mathrm{H}_{1}$ and $\mathrm{H}_{2}$.

The EVs for TFC and FCR were 1.25 and 0.41 US US\$/kg respectively. Improvement of TFC in $\mathrm{H}_{1}$ model or FCR in $\mathrm{H}_{2}$ model, while keeping TGC constant, has identical effects: 1) reduced FCR due to reduced feed intake, which reduced feed usage in the farm and 2) reduced individual oxygen fish consumption due to reduced feed intake and reduced FCR, lowering daily feed requirement of the fish, enabling 
farmers to stock more fingerlings per pond. On the other hand, more fingerlings stocked allows for more fish production at farm level per year. More fingerlings per pond coupled with reduced feed cost boosted farm profit.

The EV of $\mathrm{M}$ at stocking to harvest was the same $(0.06 \mathrm{US} \$ \mathrm{~kg})$ in both breeding objectives. By lowering $M$, the number of fish that die during the grow out period is reduced. The consequence is that farmers need to stock fewer fingerlings to comply with increased survival and oxygen demand towards harvest. As a result, both fingerlings and feed cost to be incurred in the farm decreases which increases farm profit.

The estimated EV of improved uniformity (U) in this study was low but positive $(0.02 \mathrm{US} \$ \mathrm{~kg})$ for the two models. By reducing the variation of harvest body weight, farmers are able to deliver fish in the preferred range of market weights. Subsequently, famers sell more fish in the desired price range, increasing their profit margins but production at the farm level remains unchanged. Studies have indicated that revenues from fish might be improved when fish breeders and producers could focus on reducing the coefficient of variation of harvest body weight because in general fish farmers harvest and market their fish by weight (Sae-Lim et al., 2015; Marjanovic et al., 2015; Khaw et al., 2016). With the existence of genetic basis established in fish for $\mathrm{U}$ (e.g, in GIFT tilapia), selective breeding can therefore be used to improve this trait (Khaw et al., 2016). By selecting for improved uniformity, large size differences displayed by individual fish are minimized, subsequently reducing the need to have fish sorted or graded. Furthermore, enhanced $U$ may result to less competition among fish, which may increase growth rate and feed efficiency (Jobling, 1995).

The assumptions in the correlation between growth rate, feed intake and FCR can have a great consequence on profitability of a breeding program. In this study, postulates were made in both models while estimating EV for TGC. In $\mathrm{H}_{1}$ model for instance, the main assumption is the independence of TGC and TFC. We therefore modelled TFC independently from TGC (equation 5 vs equation 2), and a change in TGC does not affect TFC. The implication of this assumption is that improving TGC while holding TFC constant will not increase feed intake but lowers FCR. On the other hand, in $\mathrm{H}_{2}$ model, we predicted $\mathrm{FCR}_{\mathrm{p}}$ as a function of fish weight (equation 9). This assumes that TGC and FCR are independent; daily FCR depends only on fish weight, and a change in TGC does not affect FCR. 
Ponzoni et al. (2007) modelled a Nile tilapia breeding program that considered harvest weight, feed intake and survival in the breeding objective. In that study genetic and phenotypic correlations both of 0.85 between harvest weight and feed intake were assumed. The consequence of this correlation is that an increase in growth rate results in a smaller increase in feed intake so that FCR was reduced which resulted to high economic returns. This is similar to what we observe in this study, in the first breeding objective $\left(\mathrm{H}_{1}\right)$, but not with the second breeding objective $\left(\mathrm{H}_{2}\right)$ where FCR is assumed to be constant. This result highlights the importance of knowing genetic parameters for feed intake and FCR in Nile tilapia. Such parameters are, to our knowledge, currently not available.

Contrary to Ponzoni et al. (2007), our model derives EVs for traits taking into account oxygen as a limiting factor for production. The practical consequences of this assumption is that when survival is improved, stocking density has to be reduced in order to avoid oxygen limitations close to harvest. Farm profit increases because fewer fish die during the grow-out period, paying off for the lower number of fish stocked. This differs with Ponzoni et al. (2007) who simply concluded that better survival results to more fish for sale. Our results show that in order to assess the relevance of EVs and to make correct decisions regarding breeding objectives, EVs for traits need to be derived from a precise setting, taking into account the prevailing limiting factors of production. Oxygen availability is probably the most important limiting factor for fish production but not the only one.

Production in aquatic systems can be constrained by several limiting factors, depending on the rearing system. These constraints render the EV for growth rate zero when FCR is not improved. Besson et al. (2016) showed that improving TGC in sea bass produced in cages under different temperature conditions when oxygen is a limiting factor for production, increased daily feed intake which increased daily oxygen requirement of fish, forcing farmers to stock less fish, similarly to what we see in our study. Improving TGC in African catfish produced in a recirculating system when a bio-filter treatment capacity was the limiting factor for production led to increased daily feed intake and nitrogen emmission which forced farmers to stock less fish to comply with the nitrogen treatment capacity of the biofilter (Besson et al., 2014).

\subsubsection{Implications to a breeding program}

The EVs presented in this study for TFC and FCR are high and ascertains the economic importance of feed efficiency in enhancing farm profitability. Improving 
TFC or FCR through selective breeding is, therefore, desired. However, this is practically difficult because reliable genetic parameters for FCR in fish are lacking, making its selection to rely indirectly on correlated traits like growth rate (Quillet et al., 2007). A favorable genetic correlation between growth rate and feed efficiency has been reported in Atlantic salmon, rainbow trout, European whitefish and in Nile tilapia (Thodesen et al., 1999; Kause et al., 2006; Quinton et al., 2007; Thoa et al., 2016) as well as in other domesticated livestock species like poultry and pigs (Emmerson, 1997; Clutter et al., 1998). Some authors e.g., (Silverstein et al., 2005) reported a moderate correlation of -0.38 between growth rate and residual feed intake in rainbow trout, Oncorhynchus mykiss (Walbaum) and indicated that selection on growth rate alone may not lead to improved feed efficiency. Other studies in brown trout and red sea bream have shown no correlation between growth rate and feed efficiency (Sanchez et al., 2001; Ogata et al., 2002; Mambrini et al., 2004). Taken together, these results combined with our findings show that breeding programs that focus on selection for growth rate alone can be either profitable or not profitable at all.

\subsection{Conclusions}

Economic values were derived for breeding objective traits for Nile tilapia farmed in earthen ponds where oxygen is a limiting factor for production. We found that the economic value of growth rate, depends on which breeding objective is used. Selection on feed efficiency is a key factor to economic profitability of Nile tilapia breeding programs. Our findings are not unique to Nile tilapia or pond systems but can be extended to any fish production system. The key is to identify which limiting factors are acting on the production system and to include these in a bio-economic model to assess the consequences of selection on growth.

\section{Acknowledgements}

This study is part of the first author's sandwich PhD study, funded by Koepon Foundation, their support is acknowledged. We would like to thank staff of Sagana Aquaculture Research Station Kenya, for providing the experimental fish, facilities and helping with the experiment.

\section{Appendix A}

\section{Genetic parameters for feed conversion ratio (FCR)}

Genetic variance $\left(\sigma_{G}{ }^{2}\right)$ and phenotypic variance $\left(\sigma_{P}{ }^{2}\right)$ for feed intake (FI) and FCR were calculated from the variation in stocking weight $(S W)$, harvest body weight 
$(H W)$ and cumulative feed intake (CFI). Genetic coefficient of variation for harvest body weight $\left(G C V_{H W}\right)$ of $13.7 \%$ and heritability $\left(h^{2}\right)$ of 0.21 were derived from (Omasaki et al., 2016b). Mean SW and HW were 5g and 250g respectively. Genetic and phenotypic correlations between $S W$ and $H W$ were assumed to be $(0.1,0.1)$ (Rutten et al., 2005). Genotypes and phenotypes for $S W$ were simulated in $R$ as:

$$
\begin{aligned}
& S W_{G, i}=\mu . S W+Z_{i} \cdot \sigma_{G} \\
& S W_{P, i}=\mu . S W+Z_{i} \cdot \sigma_{P}
\end{aligned}
$$

where subscripts $G$ and $P$ are genotypes and phenotypes respectively, $\mu$. $S W$, is the mean $S W, \sigma$ is the standard deviation, and $Z_{i}$ is a standard normal distribution $\left(Z_{i} \sim\right.$ $N(0,1))$ with $i=1, \ldots, 10^{5}$.

Genotypes and phenotypes for HW were simulated such that SW and HW were bivariate normally distributed:

$$
\begin{aligned}
& H W_{G, i}=\frac{\mu . H W}{\mu . S W} \cdot r_{G, S W_{-} H W} \cdot S W_{G, i}+Z_{i} \cdot \sigma_{G} \cdot \sqrt{1-r_{G, S W_{-} H W}^{2}} \\
& H W_{P, i}=\frac{\mu . H W}{\mu . S W} \cdot r_{P, S W_{-} H W} \cdot S W_{P, i}+Z_{i} \cdot \sigma_{P} \cdot \sqrt{1-r_{P, S W_{-} H W}^{2}}
\end{aligned}
$$

where $\mu$. $H W$, is the mean $H W, r_{G, S W_{-} H W}$ and $r_{P, S W_{-} H W}$, are the genetic and phenotypic correlations between $S W$ and HW. From these vectors, genotypes and phenotypes for body weight gain (BWG) were simulated as:

$$
\begin{aligned}
& B W G_{G, i}=H W_{G, i}-S W_{G, i} \\
& B W G_{P, i}=H W_{P, i}-S W_{P, i}
\end{aligned}
$$

Vectors of genotypes were bound in data frame $G$, and vectors for phenotypes in data frame $P$.

The regression of $C F I$ on $B W G$ has an intercept that is equal to feed requirements for maintenance at zero growth (Janssen et al. 2016). Genotypes and phenotypes feed requirements for maintenance at zero growth (FIM) were simulated as:

$$
\begin{aligned}
& F_{G, i}=T . D E m \cdot\left(S W_{G, i} / 1000\right)^{0.8} / D E \\
& F I M_{P, i}=T . D E m \cdot\left(S W_{P, i} / 1000\right)^{0.8} / D E
\end{aligned}
$$

where $T$ is the number of days from stocking to harvest (194), DEm is the digestible energy requirement for maintenance $\left(47.98 \mathrm{~kJ} / \mathrm{kg}^{0.8} /\right.$ day) (Burnell and Allan, 2009) and $D E$ is the digestible energy content of the diet $(17 \mathrm{~kJ} / \mathrm{g}$ ) (Schneider et al., 2004). 
Average FIM is $194 \times 47.98 \times(5 / 1000)^{0.8} / 17=7.9 \mathrm{~g}$. The average CFI is 576 g. The regression coefficient of $C F I$ on $B W G\left(b_{\mathrm{CFI}, \mathrm{BWG}}\right)$, therefore, is $(576-7.9) /(250-$ 5) $=2.3 \mathrm{~g}$ feed $/ \mathrm{g}$ gain.

Genotypes and phenotypes for CFI were simulated as (Janssen et al. 2016):

$$
\begin{aligned}
& C F I_{G, i}=b_{C F I, B W G} \cdot B W G_{G, i}+Z_{i} \cdot \sigma_{G} \cdot{\sqrt{1-r_{G, C F I, B W G}{ }^{2}}+F_{G, i}}^{2}+\text { FIM }_{P, i}
\end{aligned}
$$

where $r_{G, C F I, B W G}$ and $r_{P, C F I, B W G}$ are the genetic and phenotypic correlations between $C F I$ and $B W G$, here assumed to be 0.9 (Ponzoni et al., 2007), $Z_{i}$ is equal to the number of rows in $G$ and $P$. Vector $C F I_{G, i}$ was bound to data frame $G$, and vector $C F I_{P, i}$ in data frame $P$.

Genotypes and phenotypes for FCR were simulated as:

$$
\begin{aligned}
& F C R_{G, i}=C F I_{G, i} / B G W_{G, i} \\
& F C R_{P, i}=C F I_{P, i} / B G W_{P, i}
\end{aligned}
$$

$h^{2}$ was estimated as:

$$
h^{2}=\operatorname{Var}\left(F C R_{G, i}\right) / \operatorname{Var}\left(F C R_{P, i}\right)
$$

\section{References}

Besson, M., Komen, H., Aubin, J., de Boer, I., Poelman, M., Quillet, E., Vancoillie, C., Vandeputte, M., van Arendonk, J., 2014. Economic values of growth and feed efficiency for fish farming in recirculating aquaculture system with density and nitrogen output limitations: a case study with African catfish (Clarias gariepinus). J. Anim. Sci. 92, 5394-5405.

Besson, M., Vandeputte, M., van Arendonk, J.A.M., Aubin, J., de Boer, I.J.M., Quillet, E., Komen, H., 2016. Influence of water temperature on the economic value of growth rate in fish farming: the case of sea bass (Dicentrarchus labrax) cage farming in the Mediterranean. Aquaculture (in press).

Blaxter, K., 1989. Energy metabolism in animals and man. CUP Archive. 
Brafield, A., Solomon, D.J., 1972. Oxy-calorific coefficients for animals respiring nitrogenous substrates. Comparative Biochemistry and Physiology Part A. J. Physiol. 43, 837-841.

Brafield, A.E., Llewellyn, M.J., 1982. Animal Energetics, Glasgow, Great Britain.

Burnell, G., Allan G., 2009. New Technologies in Aquaculture: Improving Production Efficiency, Quality. CRC Press, Boca Raton, New York, USA. p.436, (1224 pp.).

Clutter, A., Brascamp, E., Rotschild, M., Ruvinsky, A., 1998. Genetics of performance traits. pp. 427-462 in The genetics of the pig. M.F. Rotschild and A. Ruvinsky, Ed. CAB Int., Wallingford, UK.

Elliott, J.M., Davison, W., 1975b. Energy Equivalents of Oxygen-Consumption in Animal Energetics. Oecologia 19, 195-201.

Emmerson, D., 1997. Commercial approaches to genetic selection for growth and feed conversion in domestic poultry. Poult. Sci. 76, 1121-1125.

FAO, 2014. The State of World Fisheries and Aquaculture. Opportunities and challenges. Rome, Italy (243pp.).

Goddard, M., 1998. Consensus and debate in the definition of breeding objectives. J. Dairy Sci. 81, 6-18.

Groen, A.F., 1988. Derivation of economic values in cattle breeding: A model at farm level. Agr. Syst. 27, 195-213.

Groen, A.F., 1989. Economic values in cattle breeding. II. Influences of production circumstances in situations with output limitations. Livest. Prod. Sci. 22, 17-30.

Groen, A.F., 2000. Breeding goal definition: In Galal, S.,Boyazoglu, J., Hammond, K.(Eds), Proceedings of the Workshop on Developing Breeding Strategies for Lower Input Animal Production Enviroments, Bella, Italy, 22-25 September, 1999, (pp. 25-104).

Harris, D.L., 1970. Breeding for efficiency in livestock production: defining the economic objectives. J. Anim.Sci. 30, 860-865.

Hazel, L.N., 1943. The genetic basis for constructing selection indexes. Genetics 28, 476-490.

Henryon, M., Purvis, I.W., Berg, P., 1999. Definition of a breeding objective for commercial production of the freshwater crayfish, marron (Cherax tenuimanus). Aquaculture 173, 179-195.

Janssen, K., Berentsen, P., Besson, M., Komen, H., 2016. Economic values of growth, feed intake, mortality and uniformity for gilthead seabream (Sparus aurata). Genet. Sel. Evol. (submitted). 
Jobling, M., 1995. Simple indices for the assessment of the influences of social environment on growth performance, exemplified by studies on Arctic charr. Aquac. Int. 3, 60-65.

Jobling, M., 2003. The thermal growth coefficient (TGC) model of fish growth: a cautionary note. Aquacult. Res. 34, 581-584.

Kahi, A., Nitter, G., 2004. Developing breeding schemes for pasture based dairy production systems in Kenya: I. Derivation of economic values using profit functions. Livest. Prod. Sci. 88, 161-177.

Kause, A., Tobin, D., Houlihan, D., Martin, S., Mäntysaari, E., Ritola, O., Ruohonen, K., 2006. Feed efficiency of rainbow trout can be improved through selection: different genetic potential on alternative diets. J. Anim. Sci. 84, 807-817.

Khaw, H.L., Ponzoni, R.W., Yee, H.Y., bin Aziz, M.A., Mulder, H.A., Marjanovic, J., Bijma, P., 2016. Genetic variance for uniformity of harvest weight in Nile tilapia (Oreochromis niloticus). Aquaculture 451, 113-120.

Komen, J., Trong, T.Q., 2014. Nile tilapia genetic improvement: achievements and future directions. In Proceedings of The 10th International Symposium on Tilapia in Aquaculture (ISTA10), Jerusalem, Israel, 6-10 October, 2014 (pp. 1-9).

Mambrini, M., Medale, F., Sanchez, M., Recalde, B., Chevassus, B., Labbe, L., Quillet, E., Boujard, T., 2004. Selection for growth in brown trout increases feed intake capacity without affecting maintenance and growth requirements. J. Anim. Sci. 82, 2865-2875.

Marjanovic, J., Mulder, H., Khaw, H., Bijma, P., 2015. Genetic parameters for uniformity of harvest weight in the gift strain of nile tilapia estimated using double hierarchical generalized linear models. Proceedings from the XII International Symposium on Genetics in Aquaculturel (ISGA), Santiago de Compostella, Spain, 21-27 June, 2015, (pp. 71-71).

Mulder, H.A., Bijma, P., Hill, W.G., 2007. Prediction of breeding values and selection responses with genetic heterogeneity of environmental variance. Genetics 175, 1895-1910.

NACA, 1989. Integrated Fish Farming in China. NACA Technical Manual 7. A World Food Day Publication of the Network of Aquaculture Centres in Asia and the Pacific (NACA), Bangkok, Thailand (278 pp.).

Ogata, H.Y., Oku, H., Murai, T., 2002. Growth performance and macronutrient retention of offspring from wild and selected red sea bream (Pagrus major). Aquaculture 206, 279-287. 
Omasaki, S., Arendonk, J., Kahi, A., Komen, H., 2016a. Defining a breeding objective for Nile tilapia that takes into account the diversity of smallholder production systems. J. Anim. Breed. Genet. 133 (2016), 404-413.

Omasaki, S., Charo-Karisa, H., Kahi, A., Komen, H., 2016b. Genotype by environment interaction for harvest weight, growth rate and shape between monosex and mixed sex Nile tilapia (Oreochromis niloticus). Aquaculture 458, 75-81.

Ponzoni, R., 1986. A profit equation for the definition of the breeding objective of Australian Merino sheep. J. Anim. Breed. Genet. 103, 342-357.

Ponzoni, R.W., Nguyen, N.H., Khaw, H.L., 2007. Investment appraisal of genetic improvement programs in Nile tilapia (Oreochromis niloticus). Aquaculture 269, 187-199.

Ponzoni, R.W., Nguyen, N.H., Khaw, H.L., Ninh, N.H., 2008. Accounting for genotype by environment interaction in economic appraisal of genetic improvement programs in common carp (Cyprinus carpio). Aquaculture 285, 47-55.

Popma, T.J., Lovshin, L.L., 1996. Worldwide prospects for commercial production of tilapia. International Center for Aquaculture and Aquatic Environments, Department of Fisheries and Allied Aquacultures, Auburn University, Alabama, p. 36849 (42 pp).

Quillet, E., Le Guillou, S., Aubin, J., Labbé, L., Fauconneau, B., Médale, F., 2007. Response of a lean muscle and a fat muscle rainbow trout (Oncorhynchus mykiss) line on growth, nutrient utilization, body composition and carcass traits when fed two different diets. Aquaculture 269, 220-231.

Quinton, C., Kause, A., Ruohonen, K., Koskela, J., 2007. Genetic relationships of body composition and feed utilization traits in European whitefish (L.) and implications for selective breeding in fishmeal-and soybean meal-based diet environments. J. Anim. Sci. 85, 3198-3208.

R Development Core Team, 2011. R: A language and environment for statistical computing. R Foundation for Statistical Computing, Vienna, Austria. ISBN 3-900051-07-0, URL http://www.R-project.org/.

Rutten, M.J.M., Komen, H., Bovenhuis, H., 2005. Longitudinal genetic analysis of Nile tilapia (Oreochromis niloticus L.) body weight using a random regression model. Aquaculture 246, 101-113.

Sae-Lim, P., Kause, A., Janhunen, M., Vehviläinen, H., Koskinen, H., Gjerde, B., Lillehammer, M., Mulder, H.A., 2015. Genetic (co) variance of rainbow trout (Oncorhynchus mykiss) body weight and its uniformity across production environments. Genet. Sel. Evol. 47, 46. 
Sanchez, M.-P., Chevassus, B., Labbé, L., Quillet, E., Mambrini, M., 2001. Selection for growth of brown trout (Salmo trutta) affects feed intake but not feed efficiency. Aquat. Living Resour. 14, 41-48.

Schneider, O., Amirkolaie, A.K., Vera-Cartas, J., Eding, E.H., Schrama, J.W., Verreth, J.A., 2004. Digestibility, faeces recovery, and related carbon, nitrogen and phosphorus balances of five feed ingredients evaluated as fishmeal alternatives in Nile tilapia (Oreochromis niloticus L.) Aquacult. Res. 35, 1370-1379.

Silverstein, J.T., Hostuttler, M., Blemings, K.P., 2005. Strain differences in feed efficiency measured as residual feed intake in individually reared rainbow trout, Oncorhynchus mykiss (Walbaum). Aquacult. Res. 36, 704-711.

Thoa, N. P., Ninh, N. H., Knibb, W., Nguyen, N. H., 2016. Does selection in a challenging environment produce Nile tilapia genotypes that can thrive in a range of production systems?. Sci. Rep. 6.

Thodesen, J., Grisdale-Helland, B., Helland, S.J., Gjerde, B., 1999. Feed intake, growth and feed utilization of offspring from wild and selected Atlantic salmon (Salmo salar). Aquaculture 180, 237-246.

Tran-Duy, A., van Dam, A.A., Schrama, J.W., 2012. Feed intake, growth and metabolism of Nile tilapia (Oreochromis niloticus) in relation to dissolved oxygen concentration. Aquacult. Res. 43, 730-744.

Trọng, T.Q., Mulder, H.A., van Arendonk, J.A., Komen, H., 2013. Heritability and genotype by environment interaction estimates for harvest weight, growth rate, and shape of Nile tilapia (Oreochromis niloticus) grown in river cage and VAC in Vietnam. Aquaculture 384, 119-127.

Van Middelaar, C., Berentsen, P., Dijkstra, J., Van Arendonk, J., De Boer, I., 2014. Methods to determine the relative value of genetic traits in dairy cows to reduce greenhouse gas emissions along the chain. J. Dairy Sci. 97, 51915205.

Vehviläinen, H., Kause, A., Quinton, C., Koskinen, H., Paananen, T., 2008. Survival of the currently fittest: genetics of rainbow trout survival across time and space. Genetics, 180, 507-516.

World Bank, 2013. Fish to 2030. Prospects for Fisheries and Aquaculture. Agriculture and Envi ronmental Services Discussion Paper 3. World Bank Report, number 83177-GLB (102 pp.). 


\title{
Optimization of Nile tilapia breeding schemes for monosex culture conditions in smallholder production systems
}

\author{
S.K. Omasaki ${ }^{\text {a }}{ }^{*}$, K. Janssen $^{\text {a }}$, A.K. Kahi ${ }^{\text {b }}$, H. Komen ${ }^{a}$
}

\footnotetext{
${ }^{a}$ Animal Breeding and Genomics Centre, Wageningen University, P. O. Box 338, $6700 \mathrm{AH}$ Wageningen, The Netherlands, 'b Animal Breeding and Genomics Group, Department of Animal Sciences, Egerton University, P.O Box 536, Egerton-20115, Kenya
} 


\begin{abstract}
The aim of this study was to optimize the design of a nucleus Nile tilapia breeding program for harvest weight, growth rate and survival in the presence of genotype by environment interaction with monosex (MS) culture of all-male fish. A nucleus breeding program was deterministically simulated using pseudo-BLUP selection index theory, implemented in SelAction. First, we investigated the rates of genetic gain for growth rate, expressed as $\mathrm{TGC}_{\mathrm{ms}}$ using different selection indexes with varying degrees of genotype by environment interaction ( $\mathrm{G} \times \mathrm{E}$ ), expressed as the genetic correlation $\left(r_{\mathrm{g}}\right)$ between the nucleus and a monosex production environment. Selection strategies were (1) mass selection in nucleus only, (2) Best Linear Unbiased Prediction (BLUP) with full/half sib information from the nucleus fish only, and (3) BLUP with information from full and half sibs in the nucleus and in the monosex production environment. In the second step, we extended the breeding goal to include harvest weight $\left(\mathrm{HW}_{\mathrm{ms}}\right)$ and survival $\left(\mathrm{S}_{\mathrm{ms}}\right)$ to derive desired weights and genetic gains for these breeding goal traits. Finally, we maximized genetic gains in $\mathrm{S}_{\mathrm{ms}}$ while restricting the loss in TGC to 5\%. Results: the presence of $\mathrm{G} \times \mathrm{E}$ lowered accuracy of selection $\left(r_{l H}\right)$ which led to a loss in genetic gain for $\mathrm{TGC}_{\mathrm{ms}}$. At $r_{g}$ of 0.7 and less, incorporating half sib information from monosex sibs into the selection index resulted in higher genetic gains of $\mathrm{TGC}_{\mathrm{ms}}$. Using 8 offspring in the nucleus as selection candidates and 32 offspring in monosex production environment, resulted in highest accuracy with lowest rates of inbreeding. This index had the highest relative genetic gains in all $r_{g}$ tested, implying that this index is least vulnerable to $G \times E$. Phenotypic variance ratio had no effects on $r_{I H}$ but had effects on predicted genetic response. Maximizing gains for $\mathrm{HW}_{\mathrm{ms}}$ and $\mathrm{S}_{\mathrm{ms}}$ caused a large reduction of genetic gain in $\mathrm{TGC}_{\mathrm{ms}}$. However, allowing a $5 \%$ loss of genetic gain in both $\mathrm{TGC}_{\mathrm{ms}}$ and $\mathrm{HW}_{\mathrm{ms}}$ resulted in a $33 \%$ increase in genetic improvement of $\mathrm{S}_{\mathrm{ms}}$. A breeding goal that maximizes survival while restricting loss in TGC to $5 \%$ had the highest response in US\$, followed by a breeding goal that contained TGC and survival.
\end{abstract}

Key words: Nile tilapia, genetic gain, genotype by environment interaction, growth, monosex, smallholder production. 


\subsection{Introduction}

In most breeding programs, selection of breeding candidates takes place in the "nucleus", a well-controlled environment, whereas the culture of production individuals takes place in more diverse environments (Falconer, 1990; Mulder, 2007; Omasaki et al., 2016b). In a well-controlled environment, individual genotypes are expressed better than in a less favourable environment, enabling more accurate selection. However, selecting breeding candidates from the nucleus environment may lead to reduced genetic gains in other production environments if genotype by environment interaction ( $\mathrm{x} \times \mathrm{E}$ ) exists (Falconer, 1990; Mulder, 2007). G x E may lead to re-ranking of individuals and heterogeneity of genetic variances (Lynch and Walsh, 1998). Under these circumstances, re-ranking reduces efficiency of a breeding programme if selection targets improving animal performance simultaneously in different production environments (Sae-Lim et al., 2015).

Several studies to optimize specific breeding programs in the presence of $G \times E$ have been conducted, in livestock species as well as in fish (Bijma and Van Arendonk, 1998; Jiang and Groen, 1999; Martinez et al., 2006; Mulder, 2007; Sae$\mathrm{Lim}, 2013)$. The findings of these studies indicated that the presence of $G \times E$ decreased genetic gain in the production environment and that including information from half sib performance from the production environment into the selection index could result in a higher genetic gain.

Most Nile tilapia breeding programs are typically conducted in a nucleus setting (Ponzoni et al., 2011; Trọng, et al., 2013). However, a major limitation in the culture of Nile tilapia is early sexual maturation resulting in unwanted reproduction and overcrowding. This in turn results in suppression of growth and reduction in yields in cultured Nile tilapia populations (Popma and Green, 1990; Bocek et al., 1992; Phelps et al., 1992). To solve these problems, Nile tilapia fry are sex reversed with hormones such as methyl testosterone to make monosex male populations. Males are preferred to females because of their fast growing ability, better food conversion ratio and relatively higher survival (Tran-Duy et al., 2008; Angienda et al., 2010). However, despite the importance of monosex culture of all-male fish in Nile tilapia production, to our knowledge, only one study has investigated the magnitude of $G \times E$ interaction between mixed sex and monosex populations for Nile tilapia breeding goal traits. Heritability estimates for harvest weight, growth and survival were $0.21,0.26$ and 0.12 respectively (Charo-Karisa et al., 2006; 
Omasaki et al., 2016). G x E between monosex and mixed sex Nile tilapia was significant for growth $\left(r_{g}=0.59\right)$ but less so for harvest weight $\left(r_{g}=0.74\right)$. Lower genetic correlations imply that selection in the nucleus may not optimize performance in the production environment. In the presence of $G \times E$, genetic ranks of animals may change and the best performing animal in the nucleus (mixed sex) will not be necessarily the best performing animals in the production (monosex) environment. Strategies to maximize genetic gains in the prevailing monosex culture conditions are therefore required.

In Kenya, Nile tilapia is the most farmed fish species by smallholder farmers. The current family-based national breeding program supplies genetically improved Nile tilapia brood-stock to hatcheries who supply all-male fingerlings to farmers. The breeding program mainly focuses on harvest weight, growth rate and survival as the main traits of interest. Consensus desired gains for these traits in monosex production environment were determined by Omasaki et al. (2016a). Low-input farmers value heavy fish at harvest as these will fetch better market prices at the end of the production cycle for farmers. High-input Nile tilapia farmers are however, more concerned about growth rate during the grow-out period, because high growth rate is associated with higher feed efficiency and reduced grow-out time (Henryon et al., 2002). Selection for improved survival is also paramount; increased fish survival from stocking to harvest means less fingerlings stocked and less feed wasted (Omasaki et al., 2016c). Development of improved Nile tilapia should, therefore, focus on improved harvest weight, growth and fish survival as these traits enhance profitability of Nile tilapia farming in Kenya.

The purpose of this study was to optimize a Nile tilapia breeding scheme for harvest weight, growth rate and survival for monosex culture conditions in smallholder production systems. First, different selection indexes were constructed to investigate the effects of different genetic correlations and heterogeneity of variances between growth rate in the nucleus and in the monosex production environment on response to selection for growth in monosex production environment. The aim was to find a selection index that maximises the response for growth rate in the production environment. We then used this design to optimise a breeding goal for harvest weight, growth rate and survival. The aim was to find weights in the breeding goal for these traits for which genetic gains were closest to the consensus desired gains reported by Omasaki et al. (2016a). 


\subsection{Materials and methods \\ 5.2.1 Population structure}

Deterministic simulations were performed using SelAction computer software (Rutten et al., 2002) to simulate direct and indirect selection strategies, predict accuracy of selection and genetic gain per generation of selection. The software takes into account reduction of variance due to "Bulmer-effect"(Bulmer, 1971), corrects selection intensities for finite population size and for correlation between index values of family members (Meuwissen, 1991). A population with discrete generations and one stage selection was simulated, consisting of 50 males mated to 100 females (1:2 nested mating design) with each female producing 20 male and 20 female offspring. Two environments were considered: a selection environment (nucleus, N) where the breeding candidates are held and selected, and a production environment (monosex, MS) for commercial production of all-male fish. (MS).

\subsubsection{Optimizing growth}

The first step was to optimize selection for growth rate in the production environment. Two traits were considered important: thermal growth coefficient, measured in $\mathrm{N}\left(\mathrm{TGC}_{n}\right)$ and thermal growth coefficient $\left(\mathrm{TGC}_{\mathrm{ms}}\right)$ measured in $\mathrm{MS}$. The breeding goal was defined as: $\mathrm{H}=\mathrm{TGC}_{\mathrm{ms}}$. Three selection indexes $(I)$ were constructed to investigate the effects of genetic correlations between $\mathrm{TGC}_{\mathrm{n}}$ and $\mathrm{TGC}_{\mathrm{ms}}$ and heterogeneity of variances on response to selection for $\mathrm{TGC}_{\mathrm{ms}}$.

- $\quad I_{1}$ where only own performance information from $40 \times 100$ fish on TGC $_{n}$ in the nucleus is available. Animals are not tagged and there is no pedigree information. Selected proportions are 0.025 for males and 0.05 for females.

- $\quad I_{2}$ where own performance information as well as full and half sib information on $\mathrm{TGC}_{\mathrm{n}}$ in the nucleus is available. The assumption here is that all animals are tagged and pedigree information is available. In this situation each selection candidate has information on own performance as well as information on its 39 full sibs and 40 half sibs in the nucleus. Selection intensities are as in index 1.

- $\quad I_{3}$ where own performance information as well as full and half sib information on $\mathrm{TGC}_{n}$ in the nucleus and information from full and half sib on $\mathrm{TGC}_{\mathrm{ms}}$ in the monosex environment is available. Here, each full sib family is divided into two groups: a group of 8,12 or 20 individuals from each family which are held in the nucleus as selection candidates ( $N)$, and 
a second group of 32, 28 or 20 individuals which are sex reversed for commercial production. Selected proportions are based on the number of selection candidates in the nucleus and are $0.125,0.083$ and 0.05 for males, and $0.25,0.167$ and 0.1 for females respectively.

Heritability of 0.26 and 0.32 for $T_{G C}$ and $T G C_{m s}$ respectively and phenotypic variance of 0.27 for $\mathrm{TGC}_{\mathrm{n}}$ and 0.53 for $\mathrm{TGC}_{\mathrm{ms}}$ were used (Omasaki et al., 2016b). To investigate the effect of heterogeneity of variances, a situation with equal variances $(0.27 / 0.27)$ was also simulated. Phenotypic $\left(r_{p}\right)$ and genetic $\left(r_{g}\right)$ correlations were assumed to be equal and positive, with values ranging from 0.9 to 0.5 .

\subsubsection{Relative genetic gain $\left(R_{\Delta G}\right)$}

The loss of genetic gain $(\Delta G)$ due to the presence of $\mathrm{G} \times \mathrm{E}\left(r_{g}=a\right)$ relative to a situation when there is no $\mathrm{G} \times \mathrm{E}\left(r_{g}=1\right)$ was estimated as (Mulder and Bijma, 2005):

$$
R_{\Delta G}=\frac{\Delta G\left(r_{g}=a\right)}{\Delta G\left(r_{g}=1\right)}
$$

where $\mathrm{a}=0.9,0.8,0.7,0.6$ or 0.5 .

\subsubsection{Derivation of desired weights for breeding goal traits}

The second step was to derive breeding goal weights $\left(\omega_{i}\right)$ based on desired gains for growth $\left(\mathrm{TGC}_{\mathrm{ms}}\right)$, harvest weight $\left(\mathrm{HW}_{\mathrm{ms}}\right)$, and survival $\left(\mathrm{S}_{\mathrm{ms}}\right)$. The breeding goal was to improve performance in the MS: $\mathrm{H}=\omega_{\mathrm{i}} \mathrm{TGC}_{\mathrm{ms}}+\omega_{\mathrm{i}} \mathrm{HW}_{\mathrm{ms}}+\omega_{\mathrm{i}} \mathrm{S}_{\mathrm{ms}}$. Consensus desired gains were taken from (Omasaki et al., 2016a) and were $+15 \mathrm{~g}$ for $\mathrm{HW}_{\mathrm{ms}},+0.123$ for $\mathrm{TGC}_{\mathrm{ms}}$ and $+0.19 \%$ for $\mathrm{S}_{\mathrm{ms}}$. To obtain weights for these desired gains, first the maximum genetic gain for $\mathrm{TGC}_{\mathrm{ms}}$ was determined by simulating a breeding goal that consisted only of $\mathrm{TGC}_{\mathrm{ms}}$, with a genetic correlation of 0.6 and variance ratios $\mathrm{TGC}_{n}: \mathrm{TGC}_{\mathrm{ms}}$ of $0.27: 0.53$. This was used as a baseline scenario. Desired gain weights for $\mathrm{HW}_{\mathrm{ms}}$ and $\mathrm{S}_{\mathrm{ms}}$ were then determined iteratively by simulating a two trait breeding goal, $\mathrm{TGC}_{\mathrm{ms}}$ being the first trait and either $\mathrm{HW}_{\mathrm{ms}}$ or $\mathrm{S}_{\mathrm{ms}}$ being the second trait. The resulting weights for $\mathrm{HW}_{\mathrm{ms}}$ or $\mathrm{S}_{\mathrm{ms}}$ were considered as the weights for which genetic gains were closest to the desired gains. Finally, weights were optimized such that genetic gain of $S_{m s}$ in the breeding goal $H=\omega_{i} T G C_{m s}+\omega_{i} H W_{m s}+$ $\omega_{i} S_{m s}$ was maximized while loss in genetic gain for $\mathrm{HW}_{\mathrm{ms}}$ and $\mathrm{TGC}_{\mathrm{ms}}$ was limited to $5 \%$. 
For all the simulated breeding goals in this step, a selection index, $I=b_{1} \mathrm{EBV}\left(\mathrm{HW}_{\mathrm{ms}}\right)$ $+b_{2} \mathrm{EBV}\left(\mathrm{TGC}_{\mathrm{ms}}\right)+b_{3} \mathrm{EBV}\left(\mathrm{S}_{\mathrm{ms}}\right)+b_{4} \mathrm{EBV}\left(\mathrm{TGC}_{\mathrm{n}}\right)$ was used, where $b_{1,2,3,4}$ are the selection index coefficients and EBV the estimated breeding values for each trait. As information sources for each trait, the number of offspring in the nucleus and MS environment were 8 and 32 respectively. The genetic parameters used are presented in Table 5.1; values were chosen from (Charo-Karisa et al., 2006; Ponzoni et al., 2007; Luan et al., 2008; Thodesen et al., 2013; Omasaki et al., 2016). Genetic correlations between $\mathrm{TGC}_{\mathrm{n}}$ and $\mathrm{HW}_{\mathrm{ms}}\left(r_{\text {gTGCn,HWms }}\right)$ and between $\mathrm{TGC}_{\mathrm{n}}$ and $\mathrm{S}_{\mathrm{ms}}$ $\left(r_{\text {gTGCn,Sms }}\right)$ were calculated as:

$$
\begin{aligned}
& r_{g T G C n, H W m s}=\frac{\left(r_{g T G C n, T G C m s}+r_{g H W n, H W m s}\right)}{2} X \frac{\left(r_{g T G C n, H W n}+r_{g T G C m s, H W m s}\right)}{2} \\
& r_{g T G C n, S m s}=\frac{\left(r_{g T G C n, T G C m s}+r_{g S n, S m s}\right)}{2} X \frac{\left(r_{g T G C n, S n}+r_{g T G C m s, S m s}\right)}{2}
\end{aligned}
$$

where $r_{g}$ is the genetic correlation, HW, TGC and $S$ are as defined above, subscript $n$ and $m s$ denote the nucleus and monosex environments respectively. Genetic and phenotypic correlations were assumed to be equal.

Table 5.1 Heritability (diagonal, bold), and genetic correlations (above diagonal) for thermal growth coefficient $\left(\mathrm{TGC}_{n}\right)$, harvest weight $\left(\mathrm{HW}_{\mathrm{n}}\right)$ and survival $\left(\mathrm{S}_{n}\right)$ traits in the nucleus(n) and thermal growth coefficient $\left(\mathrm{TGC}_{\mathrm{ms}}\right)$, harvest weight $\left(\mathrm{HW}_{\mathrm{ms}}\right)$ and survival $\left(\mathrm{S}_{\mathrm{ms}}\right)$ traits in the

\begin{tabular}{|c|c|c|c|c|c|c|}
\hline Trait & & & & & & \\
\hline & $T_{G C} C_{n}$ & $\mathrm{HW}_{\mathrm{n}}$ & $S_{n}$ & $\mathrm{TGC}_{\mathrm{ms}}$ & $\mathrm{HW}_{\mathrm{ms}}$ & $\mathrm{S}_{\mathrm{ms}}$ \\
\hline$T_{G G} C_{n}$ & $0.26^{a}$ & $0.9^{\mathrm{a}}$ & $0.5^{b}$ & $0.6^{a}$ & $0.6^{*}$ & $0.25^{*}$ \\
\hline $\mathrm{HW}_{\mathrm{n}}$ & & $0.21^{a}$ & $0.2^{c}$ & - & $0.74^{a}$ & - \\
\hline$S_{n}$ & & & $0.12^{d}$ & - & - & $0.4^{e}$ \\
\hline $\mathrm{TGC}_{\mathrm{ms}}$ & & & & $0.32^{a}$ & $0.9^{a}$ & $0.5^{b}$ \\
\hline $\mathrm{HW}_{\mathrm{ms}}$ & & & & & $0.24^{\mathrm{a}}$ & $0.2^{c}$ \\
\hline $\mathrm{S}_{\mathrm{ms}}$ & & & & & & $0.2^{\mathrm{e}}$ \\
\hline
\end{tabular}
monosex environment (ms).

${ }^{a}$ Omasaki et al., 2016b; ${ }^{b}$ Thodesen et al., 2013; ${ }^{c}$ Ponzoni et al., 2007; ' Charo-Karisa et al., 2006, ${ }^{\mathrm{e}}$ Luan et al., 2008. *Calculated with equation 2.

In the final step, the breeding goals were compared on total gains in monetary terms (USD /Kg fish produced). Economic values (EV) for growth (1.19 US\$/ $\sigma_{a}$, kg fish produced) and survival ( $0.01 \mathrm{US} \$ / \%, \mathrm{~kg}$ fish produced) were taken from (Omasaki et al., 2016 c). These values represent economic values for high input systems. Harvest weight is the trait of interest for low-input farmers. The economics for low-input farmers are different as they use a fixed grow-out period 
of 6 months and little commercial feed in their system (Omasaki et al., 2016a). Therefore the EV was derived using the following simple profit equation:

$$
\text { Profit }=\frac{1000 \times Q}{H W} \times\left(H W \times \frac{S P-P C}{1000}-C F I \times \frac{1}{0.5+S / 200} \times\left(\frac{F P}{1000}\right)-\frac{J P}{S / 100}\right)-\text { fixed cost [3] }
$$

where $\mathrm{Q}$, is fish production at farm level $(\mathrm{kg}), \mathrm{HW}$, is harvest weight $(\mathrm{g}), \mathrm{SP}$, is sale price per kg of fish, PC, is cost of packaging per kg of fish, CFI, is cumulative feed intake at harvest, S, is survival at harvest, FP, is cost per kg of feed and JP is cost per juvenile.

The economic value is derived from the partial derivative for HW scaled back to the level of fish production:

$$
E V_{H W}=\frac{\partial \text { Profit }}{\partial H W} \times \frac{1}{Q}=\frac{1000}{H W^{2}} \times\left(\frac{C F I \times(F P / 1000)}{0.5+S / 200}+\frac{J P}{S / 100}\right)=0.0054 U S \$ / g, k g f i s h
$$

The economic value for survival for low input system was almost identical to the value for high input system (0.0093). We therefore used $0.01 \mathrm{US} \$ / \%, \mathrm{~kg}$ fish produced. The parameters used to solve equation 4 are presented in Table 5.2.

Table 5.2 Revenues and cost variables for low income Nile tilapia farmers in Kenya.

\begin{tabular}{lll}
\hline Parameter & Value & Unit \\
\hline stocking weight (SW) & 5 & $\mathrm{G}$ \\
harvest weight (HW) & 250 & $\mathrm{G}$ \\
Number of days to harvest & 180 & Days \\
Survival to harvest (S) & 80 & $\%$ \\
Cumulative feed intake (CFI) & 330 & $\mathrm{G}$ \\
Fish production & 720 & $\mathrm{Fish}$ \\
Juvenile price (JP) & 0.053 & $\$ / \mathrm{pc}$ \\
Fish sale price (SP) & 4.74 & $\mathrm{US} \$ / \mathrm{kg}$ \\
Packaging cost (PC) & 0.26 & $\$ / \mathrm{kg}$ \\
Feed Price (FP) & 0.74 & $\mathrm{US \$} / \mathrm{kg}$ \\
\hline
\end{tabular}

g, grams; \%, percentage; pc, piece; kg, kilogram; US\$, US dollars. 


\subsection{Results}

\subsubsection{Genetic gains, accuracy of selection and rate of inbreeding in the presence of $\mathbf{G} \mathbf{x} \mathbf{E}$ interaction}

Tables 5.3 and 5.4 show the predicted genetic gain and accuracy of selection $\left(r_{I H}\right)$ for different phenotypic variance ratios $\sigma_{n}^{2} / \sigma_{p}^{2}$, selection indexes $(I)$ and genetic correlations $\left(r_{g}\right)$ investigated. Genetic gains were highest when $r_{g}$ was 1 and reduced with decreasing $r_{g}$. Higher genetic gains were predicted by indexes $I_{2}$ and $I_{3} 20_{n} 20_{m s}$ compared to $I_{1}, I_{3} 8_{n} 32_{m s}$ and $I_{3} I_{n} 22_{m s}$. Responses were strongly affected by $\sigma_{n}^{2} / \sigma_{p}^{2}$. Highest gains were obtained when the variance in MS was two times larger than in N. Accuracy was highest in the absence of $G \times E\left(r_{g}=1\right)$ and decreased with decreasing $r_{g}$ across all selection indexes. Index $I_{3} 8_{n} 32_{m s}$ always had the highest $r_{I H}$ compared to $I_{1}, I_{2}, I_{3} 12_{n_{-}} 28_{m s}$ and $I_{3} 20_{n} 20_{m s}$ indexes, irrespective of $r_{g}$. The rate of inbreeding ( $\Delta \mathrm{F} \%$, per generation) increased with decreasing $r_{g}$ and was highest when index $I_{2}$ was used. Depending on $r_{g}, \Delta \mathrm{F} \%$ for index $I_{1}$ ranged from $0.715-0.906$ and for index $I_{2}$ the range was $3.48-4.195$. The rate of inbreeding in index 3 depended on the number of full sibs available for selection in the nucleus. Lowest $\Delta \mathrm{F} \%$ was observed with index $I_{3} 8_{n} 32_{m s}(1.233-$ $1.521)$ and highest with index $I_{3} 20_{n} 2 O_{m s}(2.261-3.321)$. 
Table 5.3 Predicted genetic gain for one generation of selection of thermal growth coefficient $\left(\mathrm{TGC}_{\mathrm{ms}}\right)$ for different phenotypic variance ratio $\left(\sigma^{2}{ }_{n} / \sigma^{2} p\right)$, genetic correlations $\left(r_{g}\right)$ and selection indexes (I).

\begin{tabular}{|c|c|c|c|c|c|c|c|}
\hline \multirow[b]{2}{*}{$\sigma_{n}^{2} / \sigma^{2} p$} & \multirow[b]{2}{*}{1} & \multicolumn{6}{|c|}{ Genetic correlations $\left(r_{\mathrm{g}}\right)$} \\
\hline & & 1 & 0.9 & 0.8 & 0.7 & 0.6 & 0.5 \\
\hline \multirow[t]{5}{*}{ 1:2 } & $\mathrm{I}_{1}$ & 0.395 & 0.36 & 0.32 & 0.28 & 0.24 & 0.2 \\
\hline & $\mathrm{I}_{2}$ & 0.473 & 0.43 & 0.382 & 0.335 & 0.287 & 0.239 \\
\hline & $\mathrm{I}_{3} 8_{\mathrm{n} \_} 32_{\mathrm{ms}}$ & 0.326 & 0.319 & 0.313 & 0.309 & 0.305 & 0.301 \\
\hline & $\mathrm{I}_{3} 12_{\mathrm{n}} 28_{\mathrm{ms}}$ & 0.37 & 0.361 & 0.354 & 0.348 & 0.343 & 0.339 \\
\hline & $\mathrm{I}_{3} 2 \mathrm{O}_{\mathrm{n}} 2 \mathrm{O}_{\mathrm{ms}}$ & 0.418 & 0.405 & 0.395 & 0.388 & 0.382 & 0.377 \\
\hline \multirow[t]{5}{*}{$1: 1$} & $\mathrm{I}_{1}$ & 0.282 & 0.257 & 0.228 & 0.2 & 0.171 & 0.143 \\
\hline & $\mathrm{I}_{2}$ & 0.338 & 0.307 & 0.273 & 0.239 & 0.205 & 0.171 \\
\hline & $\mathrm{I}_{3} 8_{\mathrm{n} \_} 32_{\mathrm{ms}}$ & 0.233 & 0.228 & 0.223 & 0.22 & 0.217 & 0.215 \\
\hline & $\mathrm{I}_{3} 12_{\mathrm{n}} 28_{\mathrm{ms}}$ & 0.264 & 0.257 & 0.252 & 0.248 & 0.245 & 0.242 \\
\hline & $\mathrm{I}_{3} 20_{\mathrm{n}} 2 \mathrm{O}_{\mathrm{ms}}$ & 0.298 & 0.289 & 0.282 & 0.277 & 0.273 & 0.269 \\
\hline
\end{tabular}

$\mathrm{I}_{1}$, where only own performance information from $40 \times 100$ fish on thermal growth coefficient in the nucleus is available; $\mathrm{I}_{2}$, where own performance information as well as full and half sib information on thermal growth coefficient in the nucleus is available; $I_{3 \_} 8_{n} \_32_{m s}, I_{3} 12_{n} 28_{m s}$ and $I_{3} 22_{n} \_20_{m s}$ are indexes where own performance information as well as full and half sib information on thermal growth coefficient in the nucleus and information from full and half sib on thermal growth coefficient in the monosex environment is available. Here, each full sib family is divided into two groups, one group in the nucleus (subscript $\mathrm{n}$ ) and the other group in the monosex (subscript ms). Phenotypic variances were 0.27 in $\mathrm{N}$ and 0.54 in MS (1:2) or 0.27 in N and MS (1:1). 
Table 5.4 Predicted accuracy of selection using 2:1 phenotypic variance ratio $\left(\sigma^{2} n / \sigma^{2}\right)$ for one generation of selection of thermal growth coefficient $\left(\mathrm{TGC}_{\mathrm{ms}}\right)$ for different genetic correlations $\left(r_{g}\right)$ and selection indexes $(I)$.

\begin{tabular}{lrrrrrr}
\hline & \multicolumn{6}{c}{ Genetic correlations $\left(r_{\mathrm{g}}\right)$} \\
\cline { 2 - 7 } Index & 1 & 0.9 & 0.8 & 0.7 & 0.6 & 0.5 \\
\hline $\mathrm{I}_{1}$ & 0.479 & 0.428 & 0.375 & 0.323 & 0.274 & 0.226 \\
$\mathrm{I}_{2}$ & 0.607 & 0.538 & 0.466 & 0.399 & 0.336 & 0.276 \\
$\mathrm{I}_{3 \_} 8_{\mathrm{n} \_} 32_{\mathrm{ms}}$ & 0.627 & 0.61 & 0.596 & 0.584 & 0.575 & 0.568 \\
$\mathrm{I}_{3 \_} 12_{\mathrm{n} \_} 28_{\mathrm{ms}}$ & 0.623 & 0.604 & 0.589 & 0.577 & 0.568 & 0.56 \\
$\mathrm{I}_{3 \_} 20_{\mathrm{n}} 20_{\mathrm{ms}}$ & 0.618 & 0.594 & 0.576 & 0.563 & 0.553 & 0.544 \\
\hline
\end{tabular}

For explanation of indexes see legend Table 5.3.

\subsubsection{Relative genetic gain}

Figure 5.1 shows relative genetic gains of $\mathrm{TGC}_{\mathrm{ms}}$ in trait units expressed as a function of $r_{g}$. Phenotypic variance ratio of 1:2 was chosen for illustration. Indexes $I_{3} 8_{n} 32_{m s} I_{3} 12_{n} 28_{m s}$ and $I_{3} 20_{n} 20_{m s}$, had identical values shown by a single line for index 3 in figure 5.1. Relative genetic gain decreased with decreasing $r_{g}$ but much less so for index $I_{3}$ compared to both $I_{1}$ and $I_{2}$ indexes. At $r_{g}(0.5)$, the loss in genetic gain was more than $50 \%$ for both $I_{1}$ and $I_{2}$ versus only $7 \%$ for $I_{3}$ relative to when $r_{g}=1$. The difference in relative genetic gain between $I_{1}$ and $I_{2}$ indexes was minimal. 


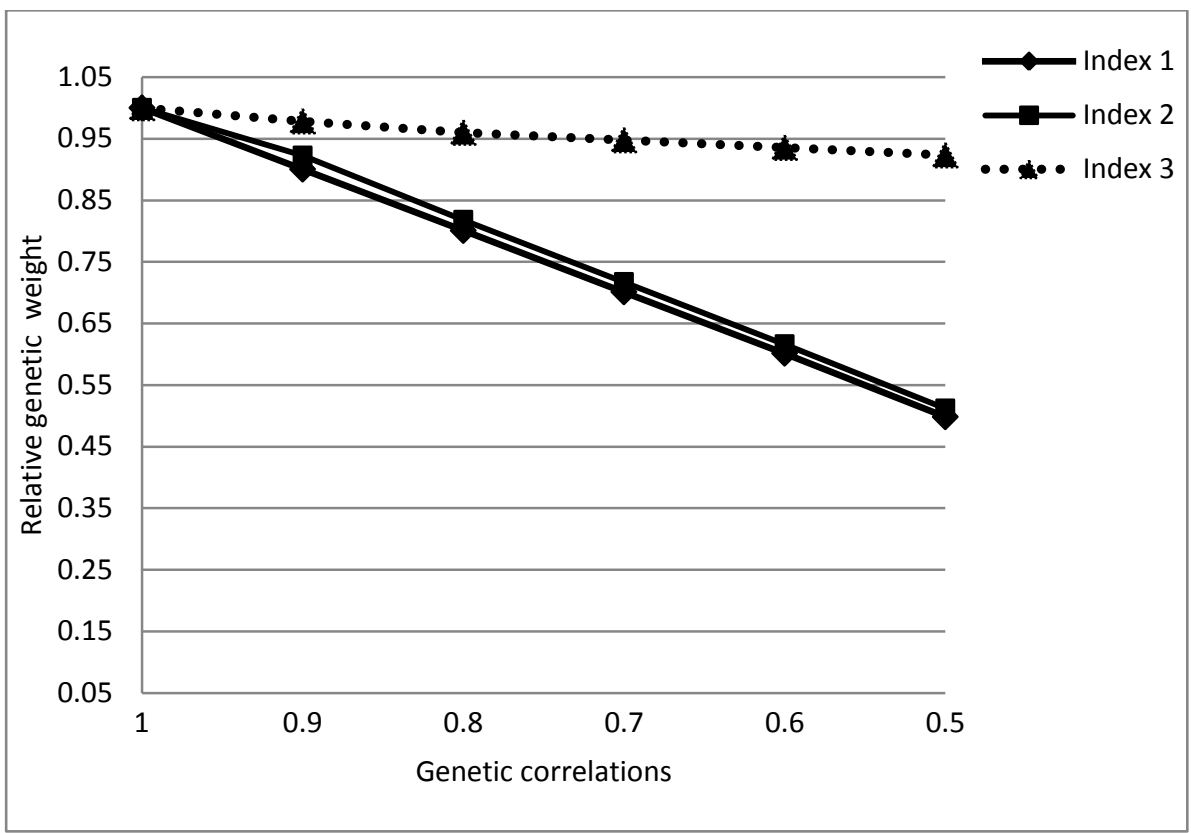

Figure 5.1 Relative genetic gain (value $\left[r_{g}=1,0.9,0.8,0.7,0.6\right.$ or 0.5$]$ )/ (value $\left[r_{g}=1\right]$ ) for thermal growth coefficient $\left(\mathrm{TGC}_{\mathrm{ms}}\right.$ ) for each selection index expressed as a function of genetic correlation and for 1:2 phenotypic variance ratio $\left(\sigma_{P R}^{2}\right)$. For a description of indexes see table 5.3.

\section{3.3 Desired weights and genetic gains}

Figures 5.2 and 5.3 show how the desired weights and genetic gains were derived for both $\mathrm{HW}_{\mathrm{ms}}$ and $\mathrm{S}_{\mathrm{ms}}$. For $\mathrm{HW}_{\mathrm{ms}}$, the weight $\left(\omega_{\mathrm{i}}\right)$ for $\mathrm{TGC}_{\mathrm{ms}}$ was kept at 1 and the $\omega_{\mathrm{i}}$ of $\mathrm{HW}_{\mathrm{ms}}$ was increased until a maximum genetic gain of 14.42 for $\mathrm{HW}_{\mathrm{ms}}$ was attained. The corresponding reduction in TGC was $8 \%$, from 0.123 to 0.112 . Similarly, for $S_{m s}, \omega_{i}$ for $T G C_{m s}$ was kept at 1 and the $\omega_{i}$ of $S_{m s}$ was increased until a maximum genetic gain of $10.2 \%$ for $S_{m s}$ was attained. The corresponding reduction in TGC was $38 \%$ from 0.123 to 0.076 . 


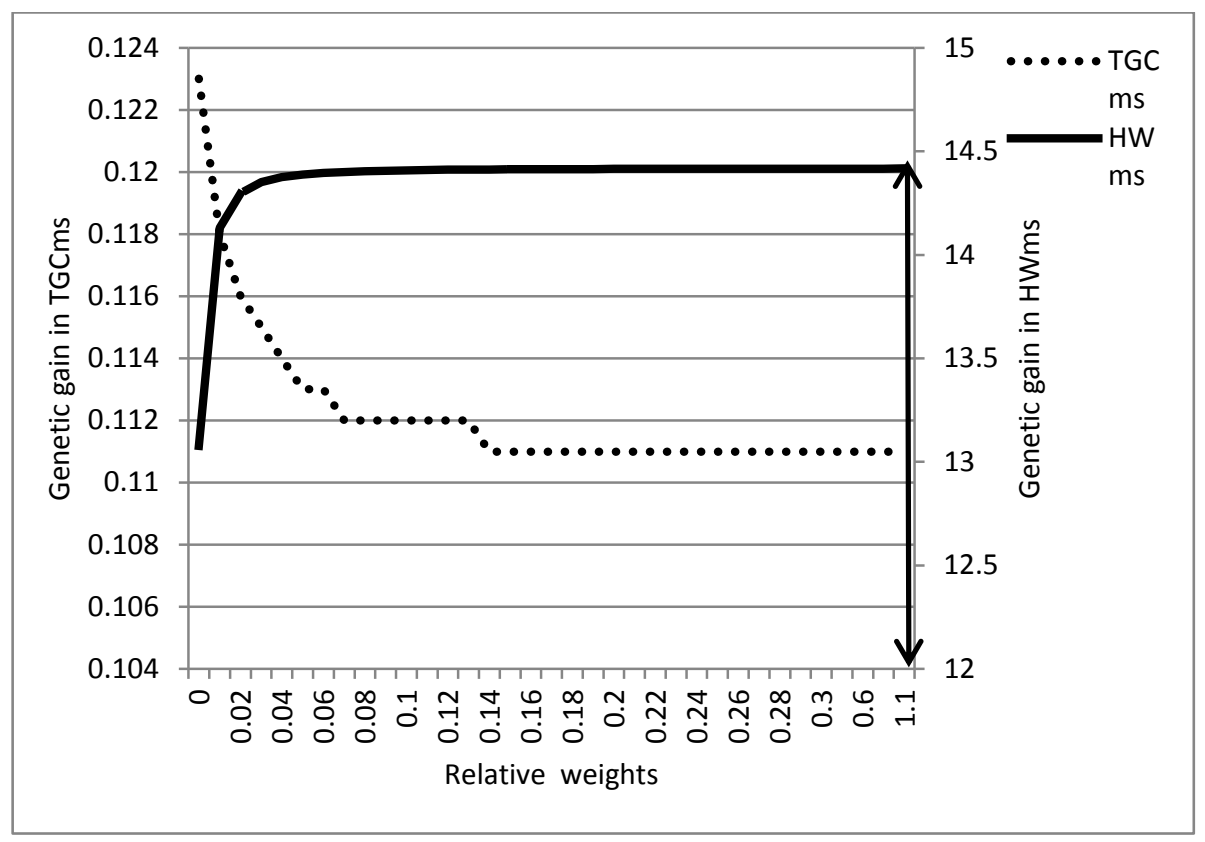

Figure 5.2 Relative weights and genetic gain (in trait units) for growth rate and harvest weight $\left(\mathrm{HW}_{\mathrm{ms}}\right)$. To obtain the desired weights and genetic gains for $\mathrm{HW}_{\mathrm{ms}}$ in the breeding goal $\mathrm{H}_{2}=\omega_{\mathrm{i}} \mathrm{TGC}_{\mathrm{ms}}+\omega_{\mathrm{i}} \mathrm{HW}_{\mathrm{ms}}$, we kept $\omega_{\mathrm{i}}$ for $\mathrm{TGC}_{\mathrm{ms}}=1$ and increased the $\omega_{\mathrm{i}}$ of $\mathrm{HW}_{\mathrm{ms}}$ continuously, until desired genetic gain (14.42) of $\mathrm{HW}_{\mathrm{ms}}$ was attained (shown by arrow). This corresponded to a relative weight for harvest weight of 1.1. 


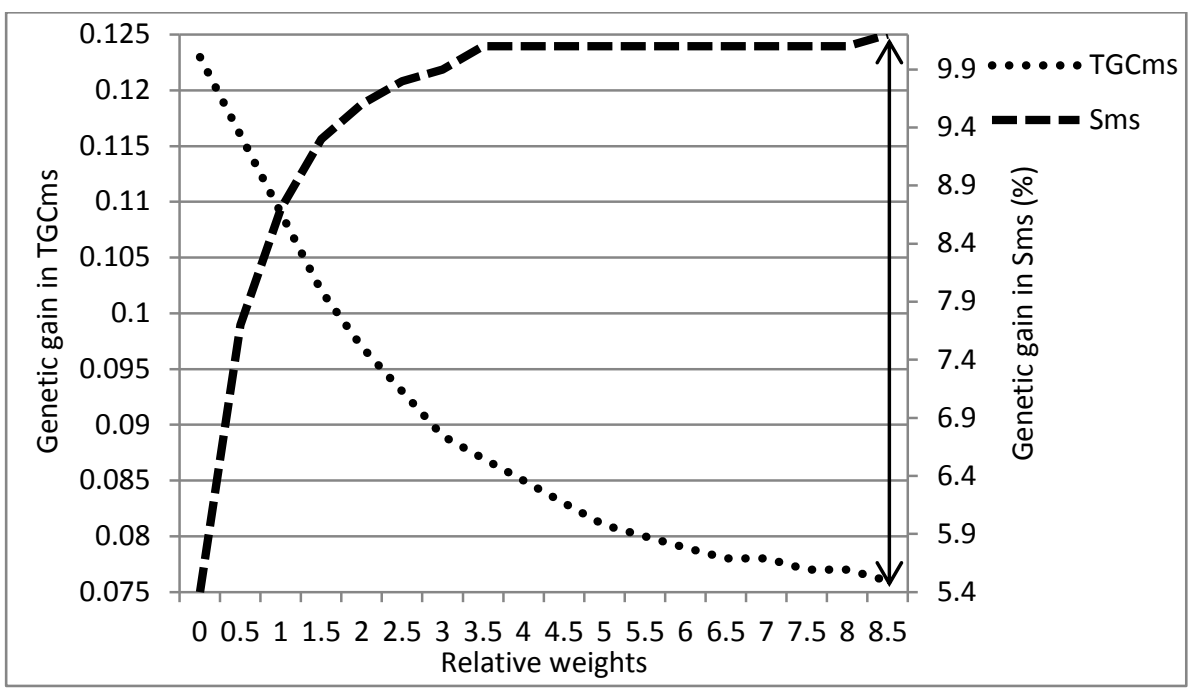

Figure 5.3 Relative weights and genetic gain (in trait units) for growth rate and survival $\left(\mathrm{S}_{\mathrm{ms}}\right)$. To obtain the desired weights and genetic gains for $S_{m s}$ in the breeding goal $\mathrm{H}_{2}=\omega_{\mathrm{i}} \mathrm{TGC}_{\mathrm{ms}}+$ $\omega_{i} S_{m s}$, we kept $\omega_{i}$ for $\mathrm{TGC}_{\mathrm{ms}}=1$ and increased the $\omega_{i}$ of $S_{m s}$ continuously, until desired genetic gain (0.1) of $S_{m s}$ was attained (shown by arrow). This corresponded to a relative weight for survival of 8.5 .

Table 5.5 presents genetic gains and correlated responses (trait and monetary units) for the different breeding goals. Breeding goals $H_{1}$ and $H_{2}$ aimed at maximizing $\mathrm{HW}_{\mathrm{ms}}$ and $\mathrm{S}_{\mathrm{ms}}$ respectively while $\mathrm{H}_{3}$ aimed at maximizing genetic gain in $\mathrm{S}_{\mathrm{ms}}$ without losing more than $5 \%$ in genetic gain for both $\mathrm{TGC}_{\mathrm{ms}}$ and $\mathrm{HW}_{\mathrm{ms}}$. Genetic gains (trait units) for growth rate were high $(5-38 \%)$ in the baseline scenario $H_{B}$ compared to $\mathrm{H}_{1}, \mathrm{H}_{2}$ and $\mathrm{H}_{3}$. Including $\mathrm{HW}$ in the breeding goal $\left(\mathrm{H}_{1}\right)$ resulted in a larger reduction in the correlated response for $\mathrm{S}_{\mathrm{ms}}$, compared to the baseline scenario. Achieving desired gains for $S_{m s}$ resulted in a large reduction of genetic gain in $\mathrm{TGC}_{\mathrm{ms}}$ and $\mathrm{HW}_{\mathrm{ms}}$ especially when optimizing for $\mathrm{S}_{\mathrm{ms}}$ in $\mathrm{H}_{2}$. A $5 \%$ decrease of genetic gain in both $\mathrm{TGC}_{\mathrm{ms}}$ and $\mathrm{HW}_{\mathrm{ms}}$ led to a $33 \%$ increase in genetic gain in $\mathrm{S}_{\mathrm{ms}}$ in $\mathrm{H}_{3} . \mathrm{H}_{3}$ had the highest gain in monetary units (US dollars), followed by $\mathrm{H}_{2}$ and $\mathrm{H}_{B}$ respectively. $\mathrm{H}_{1}$ had the lowest genetic gains in monetary terms. 
Table 5.5 Optimum desired weights for thermal growth coefficient $\left(\mathrm{TGC}_{\mathrm{ms}}\right)$, harvest weight $\left(\mathrm{HW}_{\mathrm{ms}}\right)$ and survival $\left(\mathrm{S}_{\mathrm{ms}}\right)$ traits and their respective genetic gains in both trait and monetary units.

\begin{tabular}{|c|c|c|c|c|c|c|c|}
\hline \multirow[t]{2}{*}{${ }^{1}$ Breeding goal } & \multicolumn{3}{|c|}{ Weights } & \multicolumn{3}{|c|}{${ }^{2}$ Genetic gains in trait units } & \\
\hline & $\mathrm{TGC}_{\mathrm{ms}}$ & $\mathrm{HW}_{\mathrm{ms}}$ & $\mathrm{S}_{\mathrm{ms}}$ & $\mathrm{TGC}_{\mathrm{ms}}$ & $\mathrm{HW}_{\mathrm{ms}}(\mathrm{g})$ & $\mathrm{S}_{\mathrm{ms}}(\%)$ & \\
\hline $\mathrm{H}_{\mathrm{B}}=\omega_{\mathrm{i}} \mathrm{TGC}_{\mathrm{ms}}$ & 1 & & & 0.123 & $13.077^{*}$ & $5.4^{*}$ & \\
\hline $\mathrm{H}_{1}=\omega_{\mathrm{i}} \mathrm{TGC}_{\mathrm{ms}}+\omega_{\mathrm{i}} \mathrm{HW}_{\mathrm{ms}}$ & 1 & 1 & & 0.112 & 14.417 & $2.5^{*}$ & \\
\hline $\mathrm{H}_{2}=\omega_{\mathrm{i}} \mathrm{TGC}_{\mathrm{ms}}+\omega_{\mathrm{i}} \mathrm{S}_{\mathrm{ms}}$ & 1 & & 8.5 & 0.076 & $4.865^{*}$ & 10.2 & \\
\hline \multirow{2}{*}{$\mathrm{H}_{3}=\omega_{\mathrm{i}} \mathrm{TGC}_{\mathrm{ms}}+\omega_{\mathrm{i}} \mathrm{HW}_{\mathrm{ms}}+\omega_{\mathrm{i}} \mathrm{S}_{\mathrm{ms}}$} & 1 & 1 & 100 & 0.116 & 12.43 & 7.2 & \\
\hline & & & & \multicolumn{3}{|c|}{${ }^{3}$ Genetic gains in US\$/kg fish } & Total \\
\hline $\mathrm{H}_{\mathrm{B}}=\omega_{\mathrm{i}} \mathrm{TGC}_{\mathrm{ms}}$ & 1 & & & 0.022 & 0.071 & 0.054 & 0.147 \\
\hline $\mathrm{H}_{1}=\omega_{\mathrm{i}} \mathrm{TGC}_{\mathrm{ms}}+\omega_{\mathrm{i}} \mathrm{HW}_{\mathrm{ms}}$ & & & & 0.020 & 0.078 & 0.025 & 0.123 \\
\hline $\mathrm{H}_{2}=\omega_{\mathrm{i}} \mathrm{TGC}_{\mathrm{ms}}+\omega_{\mathrm{i}} \mathrm{S}_{\mathrm{ms}}$ & & & & 0.014 & 0.035 & 0.102 & 0.151 \\
\hline $\mathrm{H}_{3}=\omega_{\mathrm{i}} \mathrm{TGC}_{\mathrm{ms}}+\omega_{\mathrm{i}} \mathrm{HW}_{\mathrm{ms}}+\omega_{\mathrm{i}} \mathrm{S}_{\mathrm{ms}}$ & 1 & 1 & 100 & 0.021 & 0.067 & 0.072 & 0.160 \\
\hline
\end{tabular}

${ }^{1} \omega_{i}$, desired weights; $\mathrm{H}_{B}$, baseline breeding goal; $\mathrm{H}_{1}$, a breeding goal that maximizes $\mathrm{HW}_{\mathrm{ms}} ; \mathrm{H}_{2}$, a breeding goal that maximizes $\mathrm{S}_{\mathrm{ms}} ; \mathrm{H}_{3}$, a breeding goal that maximizes genetic gain in $\mathrm{S}_{\mathrm{ms}}(33 \%)$ and allows $5 \%$ loss of genetic gain in $\mathrm{HW}_{\mathrm{ms}}$ and TGC $\mathrm{C}_{\mathrm{ms}}{ }^{2} *$ indicates correlated response; ${ }^{3}$ indicates genetic gains in monetary units (US dollars), using economic values of $0.18,0.0054$ and 0.01 for growth, harvest weight and survival respectively; total = sum of US\$ for all three traits. 


\subsection{Discussion}

\subsubsection{Main findings}

Our results indicate that indexes $I_{2}$ and $I_{3} 20_{n} 2 O_{m s}$ had highest responses. Phenotypic variance ratio affected responses and highest gains were obtained when the variance in MS was two times larger than in $\mathrm{N}$. Index $I_{3} 8_{n} 32_{m s}$ always had the highest accuracy of selection. The lowest rate of inbreeding $(\Delta \mathrm{F} \%$, per generation) was observed with index $I_{3} 8_{n} 32_{m s}$ and highest with index $I_{3} 20_{n} 20_{m s}$. At lower $r_{g}(0.5)$, the loss in genetic gain was more than $50 \%$ for both $I_{1}$ and $I_{2}$ versus $7 \%$ for $I_{3}$ relative to when $r_{g}=1$. Derived desired weights and genetic gains for $\mathrm{HW}_{\mathrm{ms}}$ were 1.1 and $14.42 \mathrm{~g}$ respectively and the corresponding reduction in $\mathrm{TGC}_{\mathrm{ms}}$ was $8 \%$. Similarly, desired weights of 8.5 and genetic gains of $10.2 \%$ were derived for $\mathrm{S}_{\mathrm{ms}}$ which corresponded to a reduction of $38 \%$ in $\mathrm{TGC}_{\mathrm{ms}}$. A $5 \%$ decrease of genetic gain in both $\mathrm{TGC}_{\mathrm{ms}}$ and $\mathrm{HW}_{\mathrm{ms}}$ led to a $33 \%$ genetic gain in $\mathrm{S}_{\mathrm{ms}}$. In monetary units (US dollars), $\mathrm{H}_{3}$ had the highest gain followed by $\mathrm{H}_{2}$.

\subsubsection{Accuracy of selection index}

Accuracy of selection is one of the components that determine the total genetic gain that is accrued from selection. Its reduction therefore will subsequently lead to reduction in genetic gain. Factors that affect accuracy of selection include heritability of the traits, the kind of information being used e.g., own, sib or progeny performance, genetic correlation between traits that is used to quantity $G$ $x E$ and the number of records available for certain information sources (Mulder and Bijma, 2005).

Our results show that phenotypic variance ratio had no effects on accuracy of selection. This is because heritability's for the traits were maintained constant in both environments while changing phenotypic variance in the monosex production environment. As a result, only the additive genetic variance component was reduced. However, our results show that different indexes constructed and the presence of $G \times E$ had an effect on the accuracy of predicted breeding values. Using 8 offspring's in the nucleus as selection candidates and 32 offspring in the monosex production environment, higher accuracies were predicted. Reducing the number of candidates available for selection increased selection intensity, which reduced the "Bulmer" effect, thus increasing the accuracy of selection (Bulmer, 1971). As the genetic correlations decreased $\left(r_{g}=0.8\right.$ to 0.5$)$, the contribution and importance of nucleus information in the index decreased. Subsequently, lower accuracy of selection were predicted when both $I_{1}$ and $I_{2}$ indexes were used relative 
to $I_{3}$ irrespective of the $r_{g}$ and $\sigma_{n}^{2} / \sigma_{p}^{2}$ examined. In index $I_{1}$ and $I_{2}$, own performance, full and half sib information from the nucleus were used, which were less informative compared to $I_{3}$ index, which included monosex information. It is important to note that the breeding goal was to improve performance in monosex. In this case the contribution of own performance in the nucleus becomes less important and the information from the monosex becomes paramount. An increase in the number of half sibs from monosex production environment to the index limited the loss in accuracy of selection due to the presence of $G \times E$. Therefore, a selection index, $I_{3}$ guarantees improved accuracy of selection when there is $\mathrm{G} \times \mathrm{E}$.

\subsubsection{Genetic gain}

Phenotypic variance ratio $\left(\sigma^{2}{ }_{n} / \sigma_{p}^{2}\right)$ had effects on predicted genetic response. For all $\sigma_{n}^{2} / \sigma_{p}^{2}$ studied, 1:2 ${ }_{R}$ had higher predicted genetic gains irrespective of selection indexes or genetic correlations. Changing phenotypic variance in monosex production environment affected the additive genetic variance $\left(\sigma_{A}^{2}\right)$ by reducing it since heritability's for the traits were kept the same in both environments. A 1:1 $\sigma_{n}^{2} / \sigma_{p}^{2}$ had lower $\sigma_{A}^{2}$ compared to $1: 2 \sigma^{2}{ }_{n} / \sigma_{p}^{2}$. The expected genetic gain per year $(\Delta G)$ is calculated as $\Delta G=\left(i \times r_{I H} \times \sigma_{A}\right) / L$, where $i$ the selection intensity, $r_{I H}$ the accuracy of selection, $\sigma_{A}$ the additive genetic standard deviation for the trait of interest, and $L$ the generation interval in years. Reducing additive genetic standard deviation for the trait of interest will therefore reduce response to selection as observed in this study.

The use of sibling performance information has been proposed to enhance genetic gain in the nucleus and production environment for breeding programs of livestock and fish species in the presence of $G \times E$ (Mulder and Bijma, 2005; Martinez et al., 2006; Sae-Lim, 2013). In the presence of $G \times E$, the accuracy of selection, selection intensity and genetic variance of the breeding goal may be affected, which subsequently may reduce the gain in genetic response (Mulder and Bijma, 2005; Martinez et al., 2006). Accordingly, in this study also, lower relative genetic gains were predicted for $\mathrm{TGC}_{\mathrm{ms}}$ when the indexes $I_{1}$ and $I_{2}$ were used compared to when $I_{3}$ was used. At lower genetic correlations $\left(r_{g}=0.5\right)$, the loss in genetic gain in both $I_{1}$ and $I_{2}$ were almost $50 \%$ relative to when $r_{g}$ was 1 . This loss of genetic gain can be attributed mainly to a lower accuracy of selection caused by $\mathrm{G} \times \mathrm{E}$. 
Our aim was to increase fish performance in monosex environment, therefore the significance of nucleus sibling information in the index decreased while the importance of monosex sibling information increased. As a result, higher genetic gains were observed in the selection index $I_{3}$ when genetic correlation was below 0.7 compared to $I_{1}$ and $I_{2}$. Our results show that including additional number of half sibs individuals from monosex to the index in the nucleus reduced the loss of genetic gains caused by $\mathrm{G} \times \mathrm{E}$ and increased genetic gains. To our knowledge, there are no studies on genetic correlations of breeding goal traits between the nucleus (mixed sex) and monosex (production environment). Our estimates are the first ones (Omasaki et al., 2016b), making comparison of our results difficult. More estimates between the mixed sex and monosex for $\mathrm{G} \times \mathrm{E}$ are therefore needed.

Martinez et al. (2006) showed that, in the presence of $G \times E$, the improvement in genetic gain when information from the production environment is added into the selection index in the nucleus, response to selection for body weight in rainbow trout (Oncorhynchus mykiss) increased by $20 \%$. Mulder and Bijma, (2005) also indicated that recording of half sibs individuals from the performance environment can limit the loss in genetic gain caused by $\mathrm{G} \times \mathrm{E}$ to $10 \%$. Furthermore, testing of half sibs under commercial conditions has been considered as a good option to maintain genetic gain when G x E exists (Brascamp et al., 1985; Webb and Curran, 1986; Hartmann, 1990). As observed in this study also, the index $I_{3}$ proved to increase the rates of genetic gain when siblings information from monosex was included in the selection index in the nucleus; the loss in genetic gain was restricted, increasing genetic gains. Our findings show that a single nucleus breeding program can be optimized by including information from a monosex test environment, leading to increased genetic gains in the production environment when $G \times$ E exists.

\subsubsection{Desired weights and genetic gains}

In the absence of economic values, desired gain selection index approach can be used to derive relative weights for the breeding goal traits (Gizaw et al., 2010; SaeLim et al., 2012). Desired gains reflect the needs of the farmers, and therefore they indicate the importance of preference traits in small holder fish farming. However, the problem is how to interpret these desired gains to obtain appropriate weights for the breeding goal traits. In deriving desired weights, our results yielded smaller and larger weights for $\mathrm{H}_{\mathrm{ms}}$ and $\mathrm{S}_{\mathrm{ms}}$ traits respectively but these weights resulted in a large reduction in the genetic gain for $\mathrm{TGC}_{\mathrm{ms}}$. Our aim was to derive optimized desired weights for $T G C_{m s}, S_{m s}$ and $H_{m s}$ equivalent to the consensus desired gains 
for these traits derived by (Omasaki et al., 2016a). However, the derived weights resulted in lower values of genetic gain for these traits. A further increase in weights for both $\mathrm{H}_{\mathrm{ms}}$ and $\mathrm{S}_{\mathrm{ms}}$ could not increase genetic gain for these traits, implying that the obtained weights and genetic gains for these traits were optimum.

Our approach has demonstrated that for sustainable Nile tilapia culture, a trade-off between improving production traits e.g., $\mathrm{HW}_{\mathrm{ms}}$ and $\mathrm{TGC}_{\mathrm{ms}}$ with functional traits e.g., $S_{m s}$ may be required for increased genetic gain in one or more traits in the breeding goal. In practice, improving survival is difficult due to its low heritability and difficulties in measuring it. As a result, the genetic progress that can be achieved in this trait is slow. However, survival trait is equally important for production and marketing of fish, and may directly influence farmers income (Ponzoni et al., 2007; Santos et al., 2011). In this study, higher genetic gains (10 g and $85 \%$ ) for $\mathrm{HW}_{\mathrm{ms}}$ and $\mathrm{S}_{\mathrm{ms}}$ respectively relative to $\mathrm{H}_{B}$ were achieved in the breeding goals $\mathrm{H}_{1}$ and $\mathrm{H}_{2}$ by allowing a reduction of genetic gain in $\mathrm{TGC}_{\mathrm{ms}}$. In addition, a 33\% increase in genetic gain for $\mathrm{S}_{\mathrm{ms}}$ was achieved in the breeding goal $\mathrm{H}_{3}$ when a $5 \%$ loss in genetic gain was allowed in both $\mathrm{HW}_{\mathrm{ms}}$ and $\mathrm{TGC}_{\mathrm{ms}}$ traits.

A reduction of genetic gain in survival has been associated with breeding programs that select for higher growth rates. In the GIFT strain for instance, long term selection for increased harvest weights resulted to reduced survival by -0.02 to 0.12 genetic standard deviations after 10 generations of improvement in Malaysia (Ninh et al., 2014). From a theoretical point of view, this implies that if selection aims at improving survival while reducing growth at the same time, then faster genetic improvement in survival can be achieved. Similarly to what we see in this study also, a higher emphasis on $\mathrm{S}_{\mathrm{ms}}$ will reduce selection pressure on $\mathrm{TGC}_{\mathrm{ms}}$. Our results therefore suggest that a trade-off between TGC and survival may be necessary in order to improve survival in the breeding goal.

With regards to genetic gains in monetary terms (US dollars), $\mathrm{H}_{3}$ had the highest gain, followed by $\mathrm{H}_{2}$ and $\mathrm{H}_{\mathrm{B}}$ respectively. Including many traits in the breeding goal e.g., in $\mathrm{H}_{1}$ and $\mathrm{H}_{2}$ relative to $\mathrm{H}_{\mathrm{B}}$, normally reduces the genetic gain per trait in the breeding goal (Nielsen et al., 2011). In addition, increased emphasis on traits like $\mathrm{S}_{\mathrm{ms}}$ reduces genetic gain for production traits because production traits have higher heritability's and marketing value in general. This means that too much reduction in genetic gain in production traits due to increased emphasis placed upon improving $S_{m s}$ creates a large opportunity cost of lost genetic gain for traits 
returning marketing value to farmers. As observed in this study, in breeding goals $\mathrm{H}_{2}$ and $\mathrm{H}_{3}$, a loss of between $5-38 \%$ in genetic gain in growth and $5-63 \%$ in harvest weight was predicted when more emphasis was put on survival. However, the breeding goal $\mathrm{H}_{3}$ had better returns. Therefore improvement in $\mathrm{S}_{\mathrm{ms}}$ needs to be balanced with improvement on production traits for sustainable returns to be achieved.

\subsection{Conclusions}

Optimized Nile tilapia breeding programs for monosex culture conditions can be effective in generating higher genetic gains. The presence of $G \times E$ lowered accuracy of selection which led to a loss in genetic gain of growth. A selection index with monosex information was less sensitive to $G \times E$ and adding full and half sib individuals from the monosex group into the selection index limited the loss in genetic gain due to GxE. Using desired gain approach, weights for desired gains can be derived that maximizes genetic gains in the breeding goal traits. A trade-off between improving production traits e.g., harvest weight and growth with functional traits e.g., survival may be required for increased genetic gain in survival.

\section{Acknowledgements}

This study is part of the first author's sandwich PhD study, funded by Koepon Foundation, we sincerely acknowledge their support.

\section{References}

Angienda, P., Aketch, B., Waindi, E., 2010. Development of all-male fingerlings by heat treatment and the genetic mechanism of heat induced sex determination in Nile Tilapia (Oreochromis niloticus L.). Int. J. Biol. Sci. 6, 38-42.

Bijma, P., Van Arendonk, J., 1998. Maximizing genetic gain for the sire line of a crossbreeding scheme utilizing both purebred and crossbred information. Anim. Sci. 66, 529-542.

Bocek, A., Phelps, R.P., Popma, T.J., 1992. Effect of feeding frequency on sex reversal and growth on Nile tilapia (Oreochromis niloticus). J. Appl. Aquac. 1, 97-103.

Brascamp, E., Merks, J., Wilmink, J., 1985. Genotype environment interaction in pig breeding programmes: methods of estimation and relevance of the estimates. Livest. Prod. Sci. 13, 135-146.

Bulmer, M. 1971. The effect of selection on genetic variability. Am. Nat., 201-211. 
Charo-Karisa, H., 2006. Selection for growth of Nile tilapia (Oreochromis niloticus L.) in Low-input environments (PhD Thesis) Wageningen Universiteit (169 pp.).

Charo-Karisa, H., Komen, H., Rezk, M.A., Ponzoni, R.W., van Arendonk, J.A., Bovenhuis, H., 2006. Heritability estimates and response to selection for growth of Nile tilapia (Oreochromis niloticus) in low-input earthen ponds. Aquaculture 261, 479-486.

Falconer, D., 1990. Selection in different environments: effects on environmental sensitivity (reaction norm) and on mean performance. Genet. Res. 56, 5770.

Gizaw, S., Komen, H., van Arendonk, J.A., 2010. Participatory definition of breeding objectives and selection indexes for sheep breeding in traditional systems. Livest. Sci. 128, 67-74.

Hartmann, W., 1990. Implications of genotype-environment interactions in animal breeding: genotype-location interactions in poultry. Worlds Poult. Sci. J. 46, 197-210.

Henryon, M., Jokumsen, A., Berg, P., Lund, I., Pedersen, P.B., Olesen, N.J., Slierendrecht, W.J., 2002. Genetic variation for growth rate, feed conversion efficiency, and disease resistance exists within a farmed population of rainbow trout. Aquaculture 209, 59-76.

Jiang, B.X., Groen, A., 1999. Combined crossbred and purebred selection for reproduction traits in a broiler dam line. J. Anim. Breed.Genet. 116, 111125.Kause, A., Tobin, D., Houlihan, D., Martin, S., Mäntysaari, E., Ritola, O., Ruohonen, K., 2006. Feed efficiency of rainbow trout can be improved through selection: different genetic potential on alternative diets. J. Anim. Sci. 84, 807-817.

Luan, T.D., Olesen, I., Ødegård, J., Kolstad, K., Dan, N. C., 2008. Genotype by environment interaction for harvest body weight and survival of Nile tilapia (Oreochromis niloticus) in brackish and fresh water ponds. Proceedings from the Eighth International Symposium on Tilapia Aquaculture (10pp.).

Lynch, M., Walsh, B., 1998. Genetics and Analysis of Quantitative Traits. Sinauer Associates, Inc., U.S.A. pp. 980.

Martinez, V., Kause, A., Mäntysaari, E., Mäki-Tanila, A., 2006. The use of alternative breeding schemes to enhance genetic improvement in rainbow trout (Oncorhynchus mykiss): I. One-stage selection. Aquaculture 254, 182-194.

Meuwissen, T., 1991. Reduction of selection differentials in finite populations with a nested full-half sib family structure. Biometrics, 195-203. 
Mulder, H., 2007. Methods to optimize livestock breeding programs with genotype by environment interaction and genetic heterogeneity of environmental variance (PhD Thesis) Wageningen Universiteit (208 pp.).

Mulder, H., Bijma, P. 2005. Effects of genotype $\times$ environment interaction on genetic gain in breeding programs. J. Anim.Sci. 83, 49-61.

Nielsen, H., Olesen, I., Navrud, S., Kolstad, K., Amer, P., 2011. How to consider the value of farm animals in breeding goals. A review of current status and future challenges. J. Agric. Environ. Ethics 24, 309-330.

Ninh, N.H., Thoa, N.P., Knibb, W., Nguyen, N.H., 2014. Selection for enhanced growth performance of Nile tilapia (Oreochromis niloticus) in brackish water (15-20ppt) in Vietnam. Aquaculture 428, 1-6.

Omasaki, S., Arendonk, J., Kahi, A., Komen, H., 2016a. Defining a breeding objective for Nile tilapia that takes into account the diversity of smallholder production systems. J. Anim. Breed. Genet. 133 (2016), 404-413.

Omasaki, S., Charo-Karisa, H., Kahi, A., Komen, H., 2016b. Genotype by environment interaction for harvest weight, growth rate and shape between monosex and mixed sex Nile tilapia (Oreochromis niloticus). Aquaculture 458, 75-81.

Omasaki, S., Janssen, K., Besson, M., Komen, H., 2016. Economic values of growth rate, feed intake, feed conversion ratio, mortality and uniformity for Nile tilapia. Submitted to Aquaculture (2016).

Phelps R.P., Cole, W., Katz, T., 1992. Effect of fluoxymesterone on sex ratio and growth of Nile tilapia (Oreochromis niloticus L.). Aquac. Res. 23, 405-410.

Ponzoni, R.W., Nguyen, N.H., Khaw, H.L., 2007. Investment appraisal of genetic improvement programs in Nile tilapia (Oreochromis niloticus). Aquaculture 269, 187-199.

Ponzoni, R.W., Nguyen, N.H., Khaw, H.L., Hamzah, A., Bakar, K.R.A., Yee, H.Y., 2011. Genetic improvement of Nile tilapia (Oreochromis niloticus) with special reference to the work conducted by the WorldFish Center with the GIFT strain. Rev. Aquac. 3, 27-41.

Popma, T.J., Green, B.W., 1990. Aquaculture production manual: sex reversal of tilapia in earthen ponds. Research and Development Series No. 35. International Center for Aquaculture, Alabama Agricultural Experiment Station, Auburn University, AL, USA (15 pp.).

Rutten, M., Bijma, P., Woolliams, J., Van Arendonk, J., 2002. SelAction: Software to predict selection response and rate of inbreeding in livestock breeding programs. J. Hered. 93, 456-458. 
Sae-Lim, P., 2013. One size fits all?. Optimization of Rainbow Trout Breeding Program Under Diverse Producer Preferences and Genotype-byenviroment Interaction (PhD Thesis) Wageningen Universiteit (200 pp.).

Sae-Lim, P., Komen, H., Kause, A., Van Arendonk, J., Barfoot, A., Martin, K., Parsons, J., 2012. Defining desired genetic gains for rainbow trout breeding objective using analytic hierarchy process. J. Anim. Sci. 90, 1766-1776.

Sae-Lim, P., Gjerde, B., Nielsen, H.M., Mulder, H., Kause, A., 2015. A review of genotype-by-environment interaction and micro-environmental sensitivity in aquaculture species. Rev. Aquacult. 7, 1-25.

Santos, A.I., Ribeiro, R.P., Vargas, L., Mora, F., Alexandre Filho, L., Fornari, D. C., Oliveira, S.N.d., 2011. Bayesian genetic parameters for body weight and survival of Nile tilapia farmed in Brazil. Pesqui. Agropecu. Bras. 46, 33-43.

Thodesen, J., Rye, M., Wang, Y.-X., Li, S.-J., Bentsen, H.B., Gjedrem, T., 2013. Genetic improvement of tilapias in China: Genetic parameters and selection responses in growth, pond survival and cold-water tolerance of blue tilapia (Oreochromis aureus) after four generations of multi-trait selection. Aquaculture 396, 32-42.

Tran-Duy, A., Schrama, J.W., van Dam, A.A., Verreth, J.A., 2008. Effects of oxygen concentration and body weight on maximum feed intake, growth and hematological parameters of Nile tilapia, Oreochromis niloticus. Aquaculture 275, 152-162.

Trọng, T.Q., Mulder, H.A., van Arendonk, J.A.M., Komen, H., 2013. Heritability and genotype by environment interaction estimates for harvest weight, growth rate, and shape of Nile tilapia (Oreochromis niloticus) grown in river cage and VAC in Vietnam. Aquaculture 384, 119-127.

Webb, A., Curran, M., 1986. Selection regime by production system interaction in pig improvement: a review of possible causes and solutions. Livest. Prod. Sci. 14, 41-54. 


\section{6}

General Discussion 



\subsection{Introduction}

Globally, developing countries continue to dominate aquaculture production but the contribution of Africa to aquaculture is still below 2.23\% (FAO, 2014). For a long time now, aquaculture development in Africa has failed to kick off. Reasons that are hindering its growth are lack of good quality of farmed fish feeds, knowledge, extension services, finance and adequate infrastructure (Machena and Moehl, 2001; Brummett and Ponzoni, 2009). Smallholder aquaculture production in Africa accounts for $95 \%$, of which Nile tilapia farming represents the main bulk. Nile tilapia farming is largely characterized by low inputs under semi intensive system using earthen ponds (Charo-Karisa, 2006). The demand for good quality and genetically improved fingerlings is high (Brummett and Ponzoni, 2009) but in order to meet the increasing demand for improved fingerlings, breeding programs that in-corporate farmers prevailing environments for Nile tilapia need to be put in place.

This thesis aimed at designing the optimum breeding program for Nile tilapia (Oreochromis niloticus) in developing countries of the tropics, with a focus on Kenya. In depth information was generated (Chapters 2 to 5 ) that can be used to design an optimum breeding program for Nile tilapia. In Chapter 2, it was noted that for a successful breeding program to be established, understanding farmers' production practices and including farmer preferences in the breeding strategy is essential. Involving farmers in making decisions on relevant breeding objective traits is vital. It was shown that farmers' preferences for traits differed significantly depending on income and market orientation. Consensus preference values were used to derive desired gains for a breeding objective for a national breeding program that best meets the diversity of the farmers. In Chapter 3, genetic parameters for economically important traits were estimated, and additive genetic effects for these traits were observed that can be exploited through selection under low input system. In addition, genotype by environment interaction ( $\mathrm{G} \times \mathrm{E}$ ) between mixed sex and monosex populations for these traits was investigated. Significant $G \times E$ for growth and harvest weight was detected, implying that if selection is based on growth, accounting for $G \times E$ between the nucleus and the production environment becomes important. Subsequently, in Chapter 4, the economic values for breeding objective traits for Nile tilapia were estimated. It was noted that selection on feed efficiency is a key factor for economic profitability of Nile tilapia breeding programs. Finally, in Chapter 5, using deterministic simulation, alternative breeding strategies that maximize genetic response in the prevailing 
monosex culture conditions in the presence of $G \times E$ were evaluated. The presence of $\mathrm{G} \times \mathrm{E}$ lowered the accuracy of selection which led to a reduced genetic gain in growth when only information from the nucleus was used. Including additional information from the monosex group in the selection index increased the genetic gain for growth. It was also noted that improving survival requires that less weight is put on harvest weight and growth.

The present Chapter discusses how, based on the findings described in Chapters 2 to 5 and the literature, an optimized Nile tilapia breeding program for smallholder production system can be established in Kenya.

This Chapter starts by defining a breeding objective using a participatory approach in section 6.2. A base population, selection strategies and production of all-male Nile tilapia for a national breeding program for Kenya are discussed in section 6.3. Finally, in section 6.4, a strategy to disseminate improved fingerlings to farmers is proposed.

\subsection{Defining a breeding objective: a participatory approach}

A well-defined breeding objective is the first requirement of any breeding program. A breeding objective defines the desired rate and direction of genetic change for important traits in a breeding program for a specific species. These desired changes are in most cases expressed using economic terms. However in many cases production systems in developing countries are highly diverse and there is a lack of sufficient farm economic data to develop economic values for breeding objective traits. The lack of sufficient information on costs and revenues for low input systems is mainly due to illiteracy and lack of formal recording amongst farmers. In livestock, the many roles animals play in smallholder systems, makes it difficult to allocate the overall attributes against the factors involved. In developing countries many important functions of livestock are embedded in traits that are not traded on the market, although valuable to the keepers e.g., manure, form of investment, dowry payment, use in traditional ceremonies (Kosgey et al., 2003; Scarpa et al., 2003). In such situations, preference-based methods become useful for quantifying the range and perceptions of trait priorities of farmers (Sölkner et al., 1998; Wurzinger et al., 2006; Gizaw et al., 2010).

Participatory approaches involve local farmers as active analysts and enable them to express, enhance, share and analyze their own situations whereby they rank and list priorities of resources, constraints and opportunities based on their 
circumstances. Farmers produce and rank traits of their choice. Involving and engaging farmers while deciding on which traits to be included in the breeding objective before initiating any breeding program is therefore, important. Kosgey (2004) indicated that, to succeed, it is necessary to consider the whole production system and involve stakeholders at every stage in the planning and operation of the breeding program. Implementation of such approaches have been used successfully for mixed livestock and pastoral systems for definition of breeding objectives in goats (Gizaw et al., 2010), dairy goats (Bett et al., 2009) and small ruminants in Kenya (Kosgey et al., 2008).

Nile tilapia fish farming mainly plays an important role to nutrition and as a source of income. However, as indicated by Charo-Karisa (2006), the success of Nile tilapia breeding program for resource poor countries depends on well-defined breeding objective which support the farmer's needs.

In Chapter 2, a participatory approach was used to estimate farmers' preference values and to determine the desired genetic gains for a breeding objective for Nile tilapia. Surprisingly, farmers with diverse preference values were identified, and breeding goals were defined for two groups of farmers: low and medium (L-M) income farmers who preferred mainly harvest weight, and high income farmers who preferred growth and survival. L-M farmers mostly practiced subsistence farming: rearing fish for up to 6 months before harvesting on local feeds and market live fish; heavy fish at harvest will fetch better market prices for these farmers. On the other hand, high income farmers preferred growth rate and survival as the most important traits because they used better feeding strategies including commercial feeds and had better technical skills for fish farming. These farmers use growth rate to optimize harvest time depending on market prices and feed costs. Growth rate during grow-out period is critical because the cost of feeds are high during this period (El-Sayed, 2006; Parker, 2011). Setting up a breeding program that satisfies these two groups of farmers can be a challenge since more than one breeding program may need to be established. For fish farmers who have different product objectives, consensus preferences values become important. Consensus preference values minimize the disagreement of the most displaced group of farmers as they take both minority opinion and overall disagreement into account, maximizing the average agreement. Consensus preference values were therefore derived, from which a harmonized breeding goal was developed, which can be used to establish a national breeding program that satisfies all farmers. 
Both harvest weight and growth traits are however, equivalent in the breeding goal, as can be shown by common end points; growth is usually measured as body weight at a given harvest age (Sae-Lim et al., 2013). In Chapters 4 and 5, it was shown that both growth rate and harvest weight traits had positive effects on farm profitability. In high input systems, faster growth shortens the rearing period and fish will attain market weight early which saves costs. Higher harvest weight in low input systems increases farm profit due to higher farm gate prices. Feed costs are less important in these systems. Considering these differences in the farming systems for L-M and high income farmers, consensus preference values will help to maximize profit in both farming systems. We therefore recommend a breeding program that target on growth and survival traits to satisfy the needs of these farmers.

\subsection{A National Nile tilapia Breeding Program in Kenya}

A family based national breeding program was initiated in 2011 from a base population of locally available strains to improve the production of this species and hence improve overall aquaculture production. Currently, selection mainly targets improved harvest weight in low-input production ponds. The program uses a one male to three female nested mating design, rears offspring's of each mating separately, and performs individual tagging. All these provide reliable pedigree information. Selection for breeding candidates is based on Best Linear Unbiased Prediction (BLUP) which allows for individual estimation of breeding values for harvest weight. The mandate of the breeding program is to develop and distribute genetically improved Nile tilapia broodstock to hatcheries who produce and supply monosex fingerlings to farmers. Here, I discuss how the current breeding program can be improved.

\subsubsection{Base population}

A base population has to exist for selection to be initiated. The base population has to exhibit high genetic potential as well as high genetic variation for the traits of interest (Falconer and Mackay, 1996). This is essential for selection of the best breeding candidates for the next successive generation of animals. Creating founder populations from improved rather than un-improved locally strains would allow the breeding program to begin from higher genetic levels for the trait of interest, making it more competitive from the start. Testing the founder population from local strains to see whether the strains would fit in Kenya is also a good idea, however this will take more time. The use of locally adapted strains with low performance would be recommended only if unique information for other traits of 
interest is present in them, e.g., strains naturally resistant to diseases. In the ongoing breeding program, the founder population was established by crossing two different locally available strains of Nile tilapia in Kenya, namely a $F_{3}$ generation of a local strain (Kegati strain), where selection was conducted at Kegati Aquaculture Station and a $F_{2}$ generation of Dominion strain. These populations were geographically isolated; fish were sampled in 2011 and mated to produce $F_{1}$ generation. The $2^{\text {nd }}$ generation was produced in 2012 from 50 sires and 100 dams that were selected from the $F_{1}$ generation based on their estimated breeding values for harvest weight. One male mated to two females in a nested design was used and all the broodstock were identified with Floy tags. In the current study, fifty males and 150 females from the $2^{\text {nd }}$ generation were selected based on their estimated breeding values for harvest weight; all the broodstock were identified with PIT tags. In Chapter 3, genetic parameters for breeding objective traits were estimated and it was shown that substantial additive genetic variation existed in this population. However, the findings of Chapter 3 indicate that this founder population had low performance in terms of growth. Despite feeding the strain with a better feed (35\% CP) under a well-controlled environment, low growth rates in monosex fish (1.52) and mixed sex fish (1.43) were observed. In addition, lower survival rates were observed in mixed sex fish (61\%). These findings therefore, suggest that a fast growing strain with better survival rates is required. This can be achieved by sorting different private companies within the country which practice tilapia breeding and obtain improved high performing broodstock animals to be included in the founder population. Alternatively, high performing strains like the GIFT can be introduced to the country and used to produce a founder population.

\subsubsection{Selection strategies}

Selective breeding programs in Nile tilapia that uses family based breeding strategies aimed at improving growth have reported significant responses. Gall and Bakar (2002) for instance showed that using best linear unbiased prediction (BLUP) methods increased response to selection in Nile tilapia, by $20-30 \%$. In Progift Nile tilapia, selection responses of $11.4 \%$ per generation for growth after six generations of selection was reported (Thodesen et al., 2013). In Genomar Supreme Tilapia (GST), over $10 \%$ increase in genetic gain for growth per generation after 17 generations of selection has been achieved (GenoMar Breeding Services, 2016). The highly successful GIFT breeding program which uses combined family and within-family selection strategy to improve growth performance of GIFT tilapia has achieved 10 - 15\% genetic gain per generation over a period of 10 generations 
of selection (Khaw, 2015). Sib-based selection programs provide increased selection accuracy for both low and moderate heritable traits and enable effective selection for carcass and disease-related traits that are difficult to measure. In addition, sib information together with pedigree information can be applied to select individuals with the highest breeding values from the nucleus to perform better in another environment as is shown in chapter 5.

In this study, family based selection was used (Chapter 3) which is generally considered expensive compared to mass selection. Mass selection requires no tagging and spawning hapas, making it cheaper than family based breeding strategies. However, throughout the experiment, we tried to reduce the cost and labor incurred as much as possible. In Chapter 3, we used one male to 3 females mating ratio, as a result fewer hapas were used for fry production. In total, 76 hapas were used to produce and rear 76 full sib families in one pond. Fewer fingerlings per family were also randomly sampled (20) and tagging of full sib individuals was done immediately after the fingerlings attained tagging weight $(>10 \mathrm{~g})$. Before selection of brooders, fish were weighed and returned to the same hapas in the ponds. Similarly, fingerlings were tagged and returned to the same hapas before stocking. All these reduced the number of holding facilities. In addition, fish were scanned using an electronic scanner and the weights together with tag numbers were automatically send to the laptop for recording, which reduced the number of people required to perform the tasks.

By using pictures, we were able to accurately measure body length and height of individual fish. We further showed in Chapter 3 that the genetic correlation between harvest weight/growth and length was high (>0.7), implying that body length can be used as a predictor for harvest weight/growth. Fish can therefore be sorted in large quantities based on length and the best be selected. Furthermore, the genetic correlation between body length and shape was positive (0.4), indicating a possibility of selecting for shape when desired. This can be a good alternative opportunity for field work for Kenya, where digital recording can be done with widely available smart phones. Body measurements can be derived from these pictures later on and used to predict final body weight. All these taken together, made the approach relatively affordable for a developing country like Kenya.

The main disadvantage of family-based selection strategies in tilapia is the time needed to produce families. In Chapter 3 , it was shown that production of fry was 
prolonged. Subsequently, this increased the overall rearing period of fingerlings, which in turn affected both tagging and stocking age. Prolonged time for fry production may also affect the estimation of genetic parameters, by increasing the common environmental effect $\left(c^{2}\right)$ emerging from separate rearing and growing of full-sib families until the tagging weight is achieved (Maluwa et al., 2006; Trong et al., 2013a; Bentsen et al., 2012; Khaw, 2015). This is a common problem with family based selection strategies. To reduce the production period for fry, Trong et al. (2013b) proposed the use of a single male to multiple females mating design (e.g., $1 \mathrm{M}: 10 \mathrm{~F})$. In that study, the authors showed that using this mating strategy, over $80 \%$ spawning and more half sib families could be achieved after a very short time. Although a sex ratio of 3 females to 1 male used in this study was within the range recommended by Trong, we would recommend more females to be used e.g., $1 \mathrm{M}: 5 \mathrm{~F}$. Nile tilapia usually spawns in large groups and is uncooperative when single pair mating is used, which may reduce the chances of fry production. In addition, studies have shown that increasing the females to males ratio in Nile tilapia spawning hapas will reduce aggression in males and increase courtship by territorial males, leading to increased spawning frequency (Fessehaye, 2006). Implementing this mating strategy therefore is expected to reduce the period of family production.

Family based selection enhances accuracy of selection for breeding candidates for medium (e.g., growth) and low (e.g., survival) heritability traits. In a population with medium and low heritable traits, a large portion of the superiority or inferiority of any individual observed will tend to result from environmental influences that are not heritable. Under these circumstances, the mean of an entire family may tell us more about the fish's genetic merit, hence more accurate selection for breeding candidates. In Chapters 3 and 5 , we showed that $G \times E$ existed between the nucleus and the monosex production environment. The presence of $\mathrm{G} \times \mathrm{E}$ lowered accuracy of selection which led to a loss in genetic gain of growth in monosex production environment. We further showed that with pedigree information, including half sibs individuals from the monosex group into a selection index allowed for accurate selection of individuals with the highest breeding values from the nucleus to perform better in the production environment. In this way, a family based breeding strategy enhances optimization of a breeding program.

Alternatively, since the main trait of selection is harvest weight, mass selection could be used. Using mass selection, positive response after five generations of 
selection for harvest weight was reported in Oreochromis aureus (Sanchez et al., 1995). In Nile tilapia, earlier studies indicated that application of mass selection to improve growth resulted in little or no response (Tave and Smitherman, 1980; Hulata et al., 1986; Behrends et al., 1988; Teichert-Coddington and Smitherman 1988; Huang and Liao 1990). However, recent studies by Basiao and Doyle (1999), Basiao et al. (2005) and Rutten (2005) showed that mass selection can yield good response in Nile tilapia. Mass selection is a commonly applied strategy in fish breeding because of its simplicity; no individual identification or maintenance of pedigree records is required, making it cheaper than family based selection strategy. Mass selection can be highly effective for improving single traits recorded on live breeding candidates, e.g. harvest weight (Falconer and Mackay, 1996). In Chapter 3, we showed that harvest weight is a heritable trait, which can be exploited through mass selection. Mass selection therefore, could be an alternative that is easier to implement for Nile tilapia breeding programs in resource poor countries like Kenya. However, the question remains whether a simple, low cost mass selection strategy can be economically more profitable than BLUP when $\mathrm{G} \times \mathrm{E}$ is present between the nucleus and the production environment. In that case, sib information from the production environment is needed to estimate breeding values in nucleus more accurately, which involves more costs in recording.

A comparison of selection responses from the two selection strategies are presented in Table 6.1. SelAction computer software (Rutten et al., 2002) was used to predict the responses. The breeding objective was in both cases to improve harvest weight in monosex populations. A population with discrete generations following one stage selection was simulated, consisting of 50 males mated to 100 females, each female producing 40 offspring (equal proportions of males and females). Here, 40 full sib families were divided into two groups: a group of 8 individuals which are held in the nucleus as selection candidates, and a second group of 32 individuals which are sex reversed for testing under commercial monosex production conditions (Chapter 5 ). A simple selection index, $\mathrm{I}=b \mathrm{EBV}(\mathrm{L})$ was used for mass selection, where $b$ is the selection index coefficient, and EBV is the estimated breeding value for length, the measured trait. For best linear unbiased prediction (BLUP) selection strategy, selection was on harvest weight. EBV were obtained from own information of the breeding candidates, their parents, 7 full sibs and 8 half sibs individuals in the nucleus plus 32 full sibs and 32 half sibs individuals from commercial production environment. Selected proportions are based on the number of selection candidates in the nucleus and are 0.125 for males and 0.25 for females respectively. With the given genetic parameters, (see 
Table 6.1), a correlated response of $7.124 \mathrm{~g}$ in harvest weight can be achieved using mass selection on length, with a rate of inbreeding of $0.5 \%$ per generation. Results in Table 6.1 show that BLUP selection with sib information from the production environment gives higher response but resulted in unacceptable rates of inbreeding ( $>1 \%)$ per generation. In livestock breeding programs, an increase of $1 \%$ per generation is accepted (Bijma, 2000). The high inbreeding predicted in family selection strategies is due to the fact that family information is the same for all family members hence their breeding values are also similar. This implies that if selection is based on breeding values, complete families would be selected. BLUP based selection strategies therefore require additional measures to control rates of inbreeding.

Table 6.1 Selection responses for harvest weight (HW) and corresponding rate of inbreeding for different selection strategies.

\begin{tabular}{lcc}
\hline Selection strategy & $\begin{array}{c}\text { Response to } \\
\text { selection for HW }\end{array}$ & Rate of inbreeding \\
\hline Mass & $4.612^{*}$ & 0.471 \\
BLUP plus sib-information from & $10.531 \mathrm{~g}$ & 1.219 \\
the production environment & & \\
\hline
\end{tabular}

BLUP, best linear unbiased prediction; genetic parameters for harvest weight trait: phenotypic variance $=896$, heritability $=0.21$; for length trait: phenotypic variance $=3.93$, heritability $=0.18$; genetic and phenotypic correlations between harvest weight and length = 0.94 and 0.64 respectively, see chapter $3 .{ }^{*}$, correlated response (CR) for harvest weight in monosex environment was calculated as: $C R=r_{g} \times h_{n} / h_{m s} \times$ response in the nucleus (Falconer and Mackay 1996), where $h_{n}$ and $h_{m s}$ is heritability for harvest weight in the nucleus and monosex environment respectively.

To demonstrate the Economic benefits (EB) of a breeding program, the following calculations were performed:

Assuming the nucleus has 100 females each producing 150 fry/spawning, with survival rate of $61 \%$ (Chapter 3), spawning 10 times/year (Ponzoni et al., 2007) and with equal sex ratio (1male:1female offspring), then the number of females that will be produced for hatcheries are: $(150 \times 100 \times 0.61 \times 9) / 2=41,175$. Here, fry from the first spawn was used for selection while fry from the remaining 9 spawns was used to produce sexual mature females for hatcheries. These females are then used by multiplier hatcheries to produce offspring's which will be sex reversed and supplied to farmers for grow-out.

In Kenya, the estimated number of ponds constructed by ESP by 2014 was 48000 each measuring $300 \mathrm{~m}^{2}$ (Kioi, 2014). With an average stocking density of $3 \mathrm{fish} / \mathrm{m}^{2}$ a 
total annual number of 43 million fry are needed. Assuming a survival rate of $79 \%$ from fingerlings to harvest (Chapter 3 ), the estimated amount of fish that can be produced per year is: $(48000 \times 900 \times 0.79 \times 250 / 1000)=8,532,000 \mathrm{~kg}$.

The economic benefit ((EB, in US\$) for the breeding program is estimated as: the gain in $\mathrm{g} / \mathrm{kg} /$ fish produced $\mathrm{x}$ economic value (EV) $\mathrm{x}$ total amount of fish produced (Kg) by all Kenyan farmers. Given the EV of $0.0054 \mathrm{US} \$ \mathrm{~g}, \mathrm{~kg}$ fish produced for harvest weight, the EB for the breeding program for both mass and BLUP selection strategies is shown in Table 6.2. BLUP selection has higher annual recurrent costs than mass selection. Assuming EB to occur in year 4, when the farmers start to harvest genetically improved fish, the total investment required for a breeding program based on simple mass selection is 15,450 US\$. For a BLUP breeding program, this is 48,183 US\$\$. The estimated benefits at a national scale are 10 times these investment costs. The higher costs of a BLUP breeding program are more than justified by its expected benefits at the national level.

Table 6.2 Economic benefit (EB) and annual recurrent costs (US\$) for a Nile tilapia national breeding program for mass and Best Linear Unbiased Prediction (BLUP) selection strategies in Kenya.

\begin{tabular}{clllll}
\hline \multirow{2}{*}{$\begin{array}{c}\text { Selection } \\
\text { strategy }\end{array}$} & \multicolumn{4}{c}{ Annual recurrent costs } & \multicolumn{4}{c}{ (US\$) $^{*}$} & \multirow{2}{*}{ EB (US\$)/yr } \\
\cline { 2 - 4 } & Year 1 & Year 2 & Year 3 & Year 4 & \\
\hline Mass & 4,895 & 3,002 & 4,304 & 3,247 & 227,184 \\
BLUP & 13,145 & 11,265 & 12,232 & 11,536 & 485,192 \\
\hline
\end{tabular}

*, costs were calculated assuming the breeding program was executed at Sagana. Costs were estimated as the costs incurred for performing one round of selection, as described in chapter 3.

\subsubsection{Male tilapia production for grow out and marketing}

For farmers to invest in fish farming, the accrued profit from the fish enterprise is crucial. On purely economic basis, higher returns on investment in the development and use of all-male Nile tilapia are expected based on higher growth rates, harvest weights and survival. Here, the sustainability of this approach will be discussed and a conclusion drawn at the end.

Several methods have been proposed and developed for production of monosex tilapia populations. This include; manual separation of sexes, temperature manipulation, hybridization and hormonal sex reversal (Fuentes-Silva et al., 2013). 
Sex reversal by use of hormones e.g., $17 \alpha$ methyl-testosterone is the most effective, least expensive and practical method for production of all-male tilapia. This can be done by oral administration of feed incorporated with the hormone, use of live bait that has been enriched with the hormone and by immersion eggs or fries in a hormone-containing solution. Of these, administration of feed incorporated with methyl-testosterone is the most commonly applied method. This technique has achieved successful results of up to 99\% (Fuentes-Silva et al., 2013).

In Kenya, the acceptable market weight for Nile tilapia is $>250 \mathrm{~g}$. Growth has been a major problem in the grow-out ponds where farmers have been keeping mixed sex fish. Consequently, culture of all-male fish was proposed by the national breeding program for Nile tilapia. Production of all-male fingerlings is done using hormones. In Chapter 3, we showed that using $17 \alpha$ methyl-testosterone hormone, a male population of $>94 \%$ with high growth rates $(>1.52 \mathrm{~g})$ was achieved. We showed that average body weights of all-male and mixed sex cultured fish were significantly different with all-male populations recording higher weights. In Chapter 4, we showed that fast growing fish reduced the overall grow-out period which increased the number of production cycles, increasing farm profitability. The practical implication of this to smallholder farmers in Kenya, who rear Nile tilapia for 6 months before harvesting is that they can harvest fish when they weigh $>250 \mathrm{~g}$ on average under good management practice. In Chapters 3 and 4, we also showed that all-male fish had higher survival rates (79\%) vs $61 \%$ in mixed sex fish, and increased fish survival from stocking to harvest is important as less fingerlings will need to be stocked.

Masculinizing tilapia with hormones has raised consumers' concerns that consumption of sex reversed male tilapia using hormones might be harmful for human health. However, several studies have indicated that there is no evidence for any human health hazard (Green and Teichert-Coddington, 2000). In addition, studies by Rothbard et al. (1990) and Green and Teichert-Coddington (2000) have demonstrated that exogenous steroids are rapidly cleared from the tissues after the end of treatment and no residual can be detected within one month of the termination of mono sexing treatment.

There is increasing concern about the implication of hormones when waste water is released into the environment (Heberer, 2002). Use of hormones treatment for allmale tilapia production will result in the release of androgen into the water system 
for up to one month through uneaten feed, fecal, urinary excretion and the gills. The limited number of studies conducted to date indicate that no detectable levels of hormone will enter the general environment, provided that water from the ponds used to hold fry treatment facilities e.g., hapas is recycled and filtered, or is retained for several days before being released into the natural environment (Shore and Shemesh, 2003). However, releasing water containing hormones residues remains a potential hazard that merits a precautionary approach to be taken.

Alternatively, all-male tilapia populations can be produced using thermal treatment technique. Tilapia is a thermo-sensitive species and its male to female ratio increases with temperature and ovarian differentiation is induced by low temperatures. With high temperatures above $32^{\circ} \mathrm{C}$, it is possible to masculinize efficiently Nile tilapia fish if the process starts at around 10 days post fertilization and if applied for at least 10 days (Baroiller et al. 1995b). In the GIFT strain, the experiments conducted to produce all-male fish using this technique at the World Fish Center resulted to $80 \%$ of males (Ponzoni et al., 2011). Similarly, some work conducted in Nile tilapia for two generations of selection using thermal treatment technique resulted in a male percentage of over $90 \%$, with a realized heritability of 0.69 (Wessels and Hörstgen-Schwark, 2007). Therefore, this acceptable technology indicates the possibilities to conduct selective breeding for sensitivity to thermal treatment for sex control in tilapia and perhaps for other fish as well.

\subsection{Production and dissemination of improved fingerlings}

In Kenya, the breeding nucleus for Nile tilapia is conducted at Sagana Aquaculture Research Station. The nucleus serves as the National Breeding Center for Kenya Freshwater Aquaculture, for genetic management of Nile tilapia to be multiplied and disseminated for aquaculture production. The program is funded by the government; initially through the Economic Stimulus Programme (ESP). Currently, it is funded by Kenya Agricultural Productivity and Agribusiness Project (KAPAP). However, offspring's from improved strains need to reach the farmers in a state that makes them capable of prospering during the grow-out period until they reach market weight. In efforts towards achieving this, the breeding nucleus initiated a decentralized approach to distribute the improved fingerlings.

The program established accredited multipliers from the government institutions and certified private hatchery farms across the country. Hatcheries were supplied with improved broodstock from the nucleus for free. The main function of these 
hatcheries was to mass-produce fingerlings, sex reverse them and supply to farmers at a cost. However, successful dissemination of improved fingerlings still remains a challenge. Inconsistent supply of broodstock to multiplication hatcheries by the nucleus at any particular time with the anticipated output of fry is a problem. This would cause the hatcheries not to produce fingerlings on time. In addition, insufficient number of multiplier hatcheries, technical and managerial incompetence at the hatchery level and production of fingerlings of variable size and age from un-harmonized spawning has hindered the program. Even more importantly is the production of low percentage of all-male fish which is supplied to farmers by some hatcheries; an issue that has made most farmers to lose trust with the supplied fingerlings. The current practice shows that some farmers now buy their own broodstock to produce fingerlings (Chapter 2).

With a rejuvenating Nile tilapia industry in Kenya, it is important to develop proper strategies that will allow all farmers to be serviced with improved fingerlings. The initiated decentralized approach is a better option, especially for a resource constrained country like Kenya, because the fingerlings are produced close to the grow-out areas allowing farmers to have a greater control of the seed availability. The approach has been implemented successfully in other developing countries in Asia (Little, 2004). However, for it to work better in Kenyan context, more affirmative actions and plans need to be put in place. It is essential to establish the demand and geographical distribution of the required fingerlings across the country. This would enable the breeding nucleus to determine the number of hatcheries required in order to produce enough fingerlings that can serve all the farmers. Initially, the bulk of the multiplier hatcheries were government institutions and the production of fingerlings was based on the figures provided by ESP, which were far below the expected. Therefore getting better statistics of the required fingerlings is crucial.

Proper selection and accreditation of the multiplier hatcheries is also important; this will ensure that the accredited hatcheries have the potential in terms of facilities, financial capacity, technical and managerial competency to produce quality fingerlings that are supplied to farmers. Personnel with background knowledge of animal breeding and of the aquaculture industry should be given the responsibility of implementation and supervision of the hatcheries involved. Attention to special training on efficient production of all-male Nile tilapia fish need to be done. This should be accompanied with frequent sex examination based on gonadal sex to ensure that the quality is maintained at all times. Better marketing 
strategies to promote the value of improved strains are essential. This can be done through conducting massive local campaigns, field days demonstrations, seminars and workshops to demonstrate the benefits of the improved strain to farmers. This has been done successfully in Bangladesh (Little, 2004), and therefore it can also be implemented in Kenya.

Alternatively, instead of the hatcheries relying on the broodstock supply from the nucleus, they might decide to breed their own broodstock. The success of this strategy will require training of hatchery managers and implementation of procedures for certification of hatcheries that join the nucleus. Enabling hatcheries to produce their own broodstock should be accompanied by systematic exchange of broodstock between the hatcheries at a later stage through rotational mating which supports the maintenance of variability within populations (Ponzoni et al., 2012). Some hatcheries may target to produce improved fingerlings focusing on improved harvest weight only for low and medium income farmers. Other hatcheries may aim at producing fingerlings mainly targeting on improved growth and survival traits for high income farmers. In this way, both low and high income farmers will be served with improved strains.

Developing initiatives for the long term sustainability of the breeding program which requires continuous spending is essential. As a strategy to encourage farmers to engage in aquaculture to jumpstart the industry in Kenya, farmers were initially provided with free fingerlings. In addition, multiplier hatcheries were also supplied with free improved broodstock from the nucleus. However, after the initial phase, farmers were unprepared to pay for improved fingerlings, as they anticipated to be given free fingerlings. Reports have shown that, in sub-Saharan Africa, few aquaculture farms are self-supporting after donor-departure (Coche, 1994). Developing a pricing policy to recover costs is therefore critical for the longterm sustainability of the breeding program, especially in developing countries, which depend on donor or government funding. Fingerlings or brood-stock pricing plays a very critical role in the dissemination program. For instance, giving private hatcheries free broodstock will deny farmers the benefits that they would have benefitted from. On the other hand, if farmers access fingerlings at lower prices than what the private hatcheries expect, the spirit of private sectors investing in hatcheries will be lowered. In both cases, the nucleus will be denied the opportunity to recover the costs incurred in the selective breeding program. 


\subsection{Conclusions}

This study has presented opportunities for sustainable development of a low cost breeding program for Nile tilapia that serves smallholder farmers in Kenya. Evidence on the current success and potential benefits of selective breeding is presented which could be used to improve and enhance the livelihoods of smallholder fish farmers in Kenya in the long term. To fully realize the benefits of genetic improvement, it is important to understand farmer's production practices and define the breeding objective before starting the breeding program. In this regard, involving farmers in every step of the breeding program from selection to dissemination is vital for the success and sustainability of the breeding program. A comparison of selection strategies shows that simple mass selection for harvest weight can be effective but that a national breeding program would benefit more from a family-based selection strategy. In such a program, the traits for selection are growth rate and survival, with weights in the breeding goal that reflect the consensus desired gains for these traits by the farmers. For a national breeding program that aims to develop and distribute genetically improved Nile tilapia broodstock to hatcheries who produce and supply monosex fingerlings to farmers, a well-planned and organized decentralized strategy that will allow dissemination of genetically improved fry of Nile tilapia to farmers in a reliable and predictable way is of critical importance.

\section{References}

Baroiller, JF, Clota, F., Geraz, E., 1995b. Temperature sex determination in two Tilapias species, Oreochromis niloticus and the red Tilapia (Red Florida strain): effect of high or low temperatures. In: Goetz, F W., Thomas, P., (Eds.). Proceedings of the Fifth International Symposium on the Reproductive Physiology of Fish, pp. 158-160.

Basiao, Z.U., Arago, A.L., Doyle, R.W., 2005. A farmer-oriented Nile tilapia, Oreochromis niloticus L., breed improvement in the Philippines. Aquacult. Res. 36, 113-119.

Basiao, Z.U., Doyle, R., 1999. Test of size-specific mass selection for Nile tilapia, Oreochromis niloticus L., cage farming in the Philippines. Aquacult. Res. 30, 373-378.

Behrends, L.L., Kingsley, J.B., Price III, A.H., 1988. Bidirectional backcross selection for body weight in a red tilapia. In: The Second International Symposium on Tilapia in Aquaculture. Pullin, R.S.V., Bhukaswan, T., Tonguthai, K., 
Maclean, J.L. (Eds). pp. 125-133. ICLARM Conference Proceedings 15. Department of Fisheries, Bangkok, Thailand, and International Center for Living Aquatic Resources Management, Manila, Philippines.

Bentsen, H.B., Gjerde, B., Nguyen, N.H., Rye, M., Ponzoni, R.W., de Vera, M.S.P., Bolivar, H.L., Velasco, R.R., Danting, J.C., Dionisio, E.E., 2012. Genetic improvement of farmed tilapias: Genetic parameters for body weight at harvest in Nile tilapia (Oreochromis niloticus) during five generations of testing in multiple environments. Aquaculture 338, 56-65.

Bett, R., Kosgey, I., Kahi, A., Peters, K., 2009. Analysis of production objectives and breeding practices of dairy goats in Kenya. Trop. Anim. Health Prod. 41, 307-320.

Bijma, P., 2000. Long-term genetic contributions: prediction of rates of inbreeding and genetic gain in selected populations (PhD Thesis) Wageningen Universiteit (222 pp.).

Brummett, R.E., Ponzoni, R.W., 2009. Concepts, alternatives, and environmental considerations in the development and use of improved strains of tilapia in African aquaculture. Rev. Fish Sci. 17, 70-77.

Charo-Karisa, H., 2006. Selection for growth of Nile tilapia (Oreochromis niloticus L.) in low-input environments (PhD Thesis) Wageningen Universiteit (169pp.).

Coche, A.G., 1994. Aquaculture Development and Research in Sub-Saharan Africa: National Reviews. Rome, Food and Agriculture Organisations of the United Nations (397pp.).

El-Sayed, A.F.M., 2006. Tilapia culture. CABI.

Falconer, D.S., Mackay, T.F., 1996. Introduction to Quantitative Genetics. 4th edn. Longman Group Ltd., Essex, UK (464 pp.).

FAO, 2014. The State of World Fisheries and Aquaculture, 2014. Opportunities and challenges. Rome, (243 pp.).

Fessehaye, Y., 2006. Natural mating in Nile tilapia (Oreochromis niloticus L.): implications for reproductive success, inbreeding and cannibalism (PhD Thesis) Wageningen Universiteit (149pp.).

Fuentes-Silva, C., Soto-Zarazúa, G.M., Torres-Pacheco, I., 2013. Male tilapia production techniques: A mini-review. Afr. J. Biotechnol. 12, 5496-5502.

Gall, G.A., Bakar, Y., 2002. Application of mixed-model techniques to fish breed improvement: analysis of breeding-value selection to increase 98-day body weight in tilapia. Aquaculture 212, 93-113.

GenoMar Breeding Services, 2016. Superior sustainable brood-stock, DNAverifiable traceability, (9pp.). http://www.longline.co.uk/Documents/CV/d ocuments/Matt\%20Dyck.pdf. Accessed on 23/10/2016. 
Gizaw, S., Komen, H., van Arendonk, J.A., 2010. Participatory definition of breeding objectives and selection indexes for sheep breeding in traditional systems. Livest. Sci. 128, 67-74.

Green, B.W., Teichert-Coddington, D.R., 2000. Human Food Safety and Environmental Assessment of the Use of $17 \alpha$-Methyltestosterone to Produce Male Tilapia in the United States. JWAS. 31, 337-357.

Heberer, T., 2002. Occurance, fate and removal of pharmaceuticals residues in the aquatic environment: a review of recent research data. Toxicol. Lett. 131, 5-17.

Huang, C.M., Liao I.C., 1990. Response to mass selection for growth rate in Oreochromis niloticus. Aquaculture 85, 199-205.

Hulata, G., Wohlfarth, G.W., Halevy, A., 1986. Mass selection for growth rate in the Nile tilapia (Oreochromis niloticus). Aquaculture 57, 177-184.

Khaw, H., 2015. Cooperative and uniform fish?: social interactions and variability in live body weight in the GIFT strain (Nile tilapia, Oreochromic niloticus) in Malaysia (PhD Thesis) Wageningen Universiteit (161 pp.).

Kioi, S.M., 2014. Factors influencing implementation of economic stimulus projects in Kajiado North District, Kenya (65pp.).

Kosgey, I., Rowlands, G., Van Arendonk, J., Baker, R., 2008. Small ruminant production in smallholder and pastoral/extensive farming systems in Kenya. Small Ruminant Res. 77, 11-24.

Kosgey, I., Van Arendonk, J., Baker, R., 2003. Economic values for traits of meat sheep in medium to high production potential areas of the tropics. Small Ruminant Res. 50, 187-202.

Kosgey, I. S., 2004. Breeding objectives and breeding strategies for small ruminants in the tropics (PhD Thesis) Wageningen Universiteit (278 pp.).

Little, D., 2004. Delivering better quality tilapia seed to farmers. In: Bolivar, R., Mair, G., Fitzsimmons, K., (Eds.), New Dimensions in Farmed Tilapia. Proceedings of the Sixth International Symposium on Tilapia in Aquaculture, Manilla, pp. 3-17.

Machena, C., Moehl, J., 2001. "Sub-Saharan African aquaculture: regional summary". In: Subasinghe, R.P., Bueno, P., Phillips, M.J., Hough, C., McGladdery, S.E., Arthur, J.R., (Eds). Aquaculture in the Third Millennium. Technical Proceedings of the Conference on Aquaculture in the Third Millennium, Bangkok, Thailand, 20-25 February, 2000: 341- 355. NACA, Bangkok and FAO, Rome. 
Maluwa, A.O., Gjerde, B., Ponzoni, R.W., 2006. Genetic parameters and genotype by environment interaction for body weight of Oreochromis shiranus. Aquaculture 259, 47-55.

Parker, R. 2011. Aquaculture Science. Cengage Learning.

Ponzoni, R., Nguyen, N., Khaw, H., Rodriguez Jr, B., 2012. Considerations about effective dissemination of improved fish strains. Working Paper: 2012-47. WorldFish, (15pp.).

Ponzoni, R.W., Nguyen, N.H., Khaw, H.L., 2007. Investment appraisal of genetic improvement programs in Nile tilapia (Oreochromis niloticus). Aquaculture 269, 187-199.

Ponzoni, R.W., Nguyen, N.H., Khaw, H.L., Hamzah, A., Bakar, K.R.A., Yee, H.Y., 2011. Genetic improvement of Nile tilapia (Oreochromis niloticus) with special reference to the work conducted by the WorldFish Center with the GIFT strain. Rev. Aquac. 3, 27-41.

Rothbard, S., Zohar, Y., Zmora, N., Levavi-Sivan, B., Moav, B., Yaron, Z., 1990. Clearance of $17 \alpha$-ethynyltestosterone from muscle of sex-inversed tilapia hybrids treated for growth enhancement with two doses of the androgen. Aquaculture 89, 365-376.

Rutten, M., Bijma, P., Woolliams, J., Van Arendonk, J., 2002. SelAction: Software to predict selection response and rate of inbreeding in livestock breeding programs. Heredity 93, 456-458.

Rutten, M.J., Komen, H., Bovenhuis, H., 2005. Longitudinal genetic analysis of Nile tilapia (Oreochromis niloticus L.) body weight using a random regression model. Aquaculture 246, 101-113.

Sae-Lim, P., Komen, H., Kause, A., Martin, K.E., Crooijmans, R., van Arendonk, J.A., Parsons, J.E., 2013. Enhancing selective breeding for growth, slaughter traits and overall survival in rainbow trout (Oncorhynchus mykiss). Aquaculture 372, 89-96.

Sanchez, T., de Ponce Leon, R., Aguilar, M., Vasquez, J., McAndrew, B., 1995. Response to selection and heritabilities for weight in Oreochromis aureus Steindachner after five generations of selection. Aquaculture 137, 271.

Scarpa, R., Ruto, E.S., Kristjanson, P., Radeny, M., Drucker, A.G., Rege, J.E., 2003. Valuing indigenous cattle breeds in Kenya: an empirical comparison of stated and revealed preference value estimates. Ecol. Econom. 45, 409426.

Shore, L.S., Shemesh, M., 2003. Naturally produced steroid hormones and their release into the environment. Pure Appl. Chem. 75, 1859-1871. 
Sölkner, J., Nakimbugwe, H., Valle Zarate, A., 1998. Analysis of determinants for success and failure of village breeding programmes. In: Proceedings of the Sixth World Congress on Genetics Applied to Livestock Production, Volume 25, 11-16 January 1998, Armidale, NSW, Australia, 273-280.

Tave D., Smitherman, R.O., 1980. Predicted response to selection for early growth in Tilapia nilotica. T. Am. Fish Soc. 109, 439-445.

Teichert-Coddington, D.R., Smitherman, R.O., 1988. Lack of response by Tilapia nilotica to mass selection for rapid early growth. T. Am. Fish Soc. 117, 297300.

Thodesen, J., Rye, M., Wang, Y.X., Li, S.J., Bentsen, H.B., Gjedrem, T., 2013. Genetic improvement of tilapias in China: Genetic parameters and selection responses in growth, pond survival and cold-water tolerance of blue tilapia (Oreochromis aureus) after four generations of multi-trait selection. Aquaculture 396, 32-42.

Trọng, T.Q., Mulder, H.A., van Arendonk, J.A., Komen, H., 2013a. Heritability and genotype by environment interaction estimates for harvest weight, growth rate, and shape of Nile tilapia (Oreochromis niloticus) grown in river cage and VAC in Vietnam. Aquaculture 384, 119-127.

Trọng, T.Q., van Arendonk, J.A., Komen, H., 2013b. Genetic parameters for reproductive traits in female Nile tilapia (Oreochromis niloticus): I. Spawning success and time to spawn. Aquaculture 416, 57-64.

Wessels, S., Hörstgen-Schwark, G., 2007. Selection experiments to increase the proportion of males in Nile tilapia (Oreochromis niloticus) by means of temperature treatment. Aquaculture 272, S80-S87.

Wurzinger, M., Ndumu, D., Baumung, R., Drucker, A., Okeyo, A., Semambo, D., Byamungu, N., Sölkner, J., 2006. Comparison of production systems and selection criteria of Ankole cattle by breeders in Burundi, Rwanda, Tanzania and Uganda. Trop. Anim. Health Prod. 38, 571-581. 
Summary 



\section{Summary}

The overall objective of this study was to design a sustainable low cost breeding program for Nile tilapia that addresses both genetic and economic aspects of smallholder fish production systems in Kenya. The specific objectives of the study were: i) to use a participatory approach to develop a sustainable breeding objective based on farmer's preferences and accounting for economic constraints of smallholder fish farmers, ii) to estimate the genetic parameters for traits of economic importance in the breeding nucleus, and to investigate the magnitude of $\mathrm{G} \times \mathrm{E}$ interaction between the nucleus (mixed sex) and production (monosex) environments for these traits, iii) to derive the economic values for breeding objective traits for Nile tilapia and assess their relevance and iv) to design an optimized breeding scheme that maximizes genetic and economic response in the prevailing monosex culture conditions.

For a national breeding program that aims at developing and supplying genetically improved Nile tilapia fish to farmers, it is important to understand farmers production practices and preference values for breeding goal traits. Defining breeding goals from a national perspective may not satisfy all farmers, as farmers may differ in production systems and farming environments. Analytical Hierarchy Process technique can be used to estimate preferences values, which can then be used to derive consensus preference values using weighted goal programming, from which a breeding goal for a national breeding program can be defined. In Chapter 2, we investigated whether smallholder Nile tilapia farmers with diverse production systems and economic constraints have different preferences for breeding goal traits. A field survey was carried out to interview smallholder Nile tilapia famers in Kenya to obtain preference values for traits of economic importance, by using multiple pair wise comparisons. Results showed that farmers differed in trait preference. Low income farmers preferred harvest weight while medium and high income farmers preferred growth rate and survival. Fingerling producers preferred growth rate and survival while fattening farmers preferred harvest weight, height and thickness. Based on the results, we concluded that farmers' preferences for traits differed significantly depending on income and market orientation. Through estimation of consensus preference values, farmers' diverse backgrounds and preferences for traits were accounted for, leading to a harmonized breeding goal that can be used by a national breeding program. 
The existing population has to exhibit high genetic variation for the traits of interest if selection is to be successful. In addition, in pond culture, to avoid excessive reproduction and stunted growth, rearing of all-male populations (monosex) is preferred. For a national breeding program that aims at providing improved broodstock to hatcheries that supply monosex fry to farmers, assessing the genetic correlation $\left(r_{g}\right)$ for traits between the mixed sex breeding candidates in the nucleus and monosex production fish is crucial. In Chapter 3, genetic parameters for harvest weight $(\mathrm{HW})$, daily growth coefficient (DGC) and body shape traits were estimated and $\mathrm{G} \times \mathrm{E}$ for these traits between mixed sex and monosex populations examined. One hundred, 3 days old mixed sex fry from each one of 76 full sib families were divided into two groups of 50 individuals each. One group was sex reversed (monosex) while the other group was not (mixed sex). Fish were reared in hapas, tagged, weighed and randomly divided and stocked in six earthen ponds, three for mixed sex and three for monosex fish. Fish were harvested and weighed after 5 months of rearing. Estimated heritability's for HW, DGC and shape were $0.21,0.26$ and 0.12 for mixed sex respectively. High (0.74) genetic correlations for HW between monosex and mixed sex fish were observed, suggesting low $G \times E$. Low $r_{g}$ for DGC (0.59) and shape (-0.19) were obtained, indicating presence of G $\times E$. Based on the results of this study, we concluded that for a national breeding program that aims at supplying monosex fry to farmers, including siblings information from monosex fish into a selection index is necessary.

Defining a breeding goal that will maximise economic return is the first requirement of any genetic improvement program. A breeding goal is a linear function of traits to be improved genetically, each trait weighed by its economic value (s) (EVs). In Chapter 4, a bio-economic model was used to derive EVs of growth rate, expressed as thermal growth coefficient (TGC), feed intake, expressed as thermal feed intake coefficient (TFC), feed conversion ratio (FCR), mortality (M) and uniformity of harvest body weight $(U)$ for Nile tilapia. The aim of the study was to investigate the economic values for these traits and to see whether these economic values differ depending on the definition of the breeding goal. Two breeding goals were considered: a breeding goal that consisted of TGC, TFC, M and $\mathrm{U}$ and a breeding goal with TGC, FCR, M and U. The economic values (in US\$/kg fish produced $/ \sigma_{\mathrm{a}}$ ) were derived as: change in gross margin/(farm production before genetic improvement). Results showed that improving growth reduced the overall grow-out period, increasing the number of production cycles in the farm. The economic value of TGC differed depending on the definition of the breeding goal. The economic value of TGC was 1.19 when TFC was in the breeding goal while 
economic value was 0.02 when FCR was in the breeding goal. The economic value of TFC was 1.25 and the economic value for FCR was 0.41 . The economic values for $\mathrm{M}$ and $\mathrm{U}$ were the same, 0.06 and 0.02 respectively in both breeding goals. We concluded that the economic value of growth varies depending on which breeding goal is used. Faster growing fish consume more oxygen, and unless faster growth is accompanied by improved FCR, this will lead to oxygen limitations, necessitating lower stocking densities. These results suggest the economic importance of feed efficiency in Nile tilapia breeding programs.

The effect of selection environment on the performance of selected strains over a wider range of production environments is an important issue. In the presence of $G$ $x E$, the question on how to optimize a breeding program to respond to multiple environments is critical. In Chapter $\mathbf{5}$, the results of a study designed to optimize harvest weight $\left(\mathrm{HW}_{\mathrm{ms}}\right)$, growth $\left(\mathrm{TGC}_{\mathrm{ms}}\right)$ and survival $\left(\mathrm{S}_{\mathrm{ms}}\right)$ of all-male fish Nile tilapia in smallholder production system reared in earthen ponds are presented. First, we investigated genetic gain for $\mathrm{TGC}_{\mathrm{ms}}$ using different selection indexes with varying levels of $G \times E$ between the mixed sex (N) and monosex fish (MS). In the second step, we extended the breeding goal to include $\mathrm{HW}_{\mathrm{ms}}, \mathrm{TGC}_{\mathrm{ms}}$ and $\mathrm{S}_{\mathrm{ms}}$ to derive desired gains weights for these breeding goal traits. Finally, genetic gains in $\mathrm{S}_{\mathrm{ms}}$ were maximized while restricting the loss in TGC to $5 \%$. Genetic gains were predicted using deterministic simulations in SelAction. Highest gains were obtained when the phenotypic variance for TGC in MS was two times larger than in N. The presence of $G \times E$ reduced accuracy of selection which led to a reduction in genetic gain of $\mathrm{TGC}_{\mathrm{ms}}$. Incorporating half sibs individuals from the MS group into the selection index limited the loss of genetic gain in $\mathrm{TGC}_{\mathrm{ms}}$. Maximizing gains for $\mathrm{HW}_{\mathrm{ms}}$ and $\mathrm{S}_{\mathrm{ms}}$ caused a large reduction of genetic gain in $\mathrm{TGC}_{\mathrm{ms}}$. $\mathrm{A}$ breeding goal that maximizes survival while restricting a loss in TGC to $5 \%$ had the highest total response in US\$, followed by a breeding goal that contained TGC and survival.

The results presented in this study can be used for developing a sustainable low cost breeding program for Nile tilapia that addresses both genetic and economic aspects of smallholder fish farmers. Chapter 6 gives an outline of the key issues in improving and implementing a Nile tilapia breeding program in Kenya. Involving farmers and accounting for farmers' preferences while defining breeding goal is vital for the success and sustainability of the breeding program. For a national breeding program that aims to develop and distribute genetically improved Nile tilapia broodstock to hatcheries who produce and supply monosex fingerlings to farmers, genotype by environment interaction for growth should be considered 
and monitored. A comparison of selection strategies shows that simple mass selection for harvest weight can be effective but that a national breeding program would benefit more from a family-based selection strategy. A well-planned and organized decentralized strategy that will allow dissemination of genetically improved fry of Nile tilapia to farmers in a reliable and predictable way is of critical importance. 
Publications 



\section{Publications}

Omasaki, SK., Arendonk, J., Kahi, A., Komen, H., 2016a. Defining a breeding objective for Nile tilapia that takes into account the diversity of smallholder production systems. J. Anim. Breed. Genet. 133, 404-413.

Omasaki, SK., Charo-Karisa, H., Kahi, A., Komen, H., 2016b. Genotype by environment interaction for harvest weight, growth rate and shape between monosex and mixed sex Nile tilapia (Oreochromis niloticus). Aquaculture 458, 7581.

Omasaki, SK., Janssen, K., Besson, M., Komen, H., 2016c. Economic values of growth rate, feed intake, feed conversion ratio, mortality and uniformity for Nile tilapia. Aquaculture (2016, Accepted).

Omasaki, SK., Kahi, A., Komen, H., 2016d. Optimization of Nile tilapia breeding schemes for monosex culture conditions in smallholder production systems. To be submitted for publication to aquaculture (2017).

Ngeno, K, Omasaki SK, Bebe B.O., 2014. Assessment of the Vulnerability and Adaptation Strategies to Climate Variability of the Bos-taurus Dairy Genotypes in Nandi and Nakuru Counties in Kenya. J. Anim. Prod. Adv. 4(6): 430-441.

Ngeno, K, Omasaki SK, Bebe B.O., 2013. Assessment of the Vulnerability and Adaptation Strategies to Climate Variability and Change of the Bos-taurus Dairy Genotypes under Diverse Production Environments in Kenya. J. Vet. Adv. 3(7): 186196.

Omasaki, S.K., Charo-Karisa, H., Kosgey, I.S., 2013. Fish production practices of smallholder farmers in Western Kenya. LRRD, Volume 25(3), article 52.

\section{Conference proceedings}

Omasaki, S., Charo-Karisa, H., Kahi, A., Komen, H., 2016. Genotype by environment interaction for harvest weight, growth rate and shape between monosex and mixed sex Nile tilapia (Oreochromis niloticus). International Symposium on Tilapia in Aquaculture (ISTA), Surabaya, Indonesia, April 26 - 29, 2016. 
Omasaki, S., Janssen, K., Besson, M., Komen, H., 2016. Economic values of growth rate, feed intake, feed conversion ratio, mortality and uniformity for Nile tilapia. 1ST World Congress on Innovations for Livestock Development (WCILD), Naivasha, Kenya, June 26 - 30, 2016.

Omasaki, S., Arendonk, J., Kahi, A., Komen, H., 2016a. Defining a breeding objective for Nile tilapia that takes into account the diversity of smallholder production systems. European Association for Animal Production (EAAP), Belfast, UK, August 29 - 2 September, 2016.

Omasaki, S., Janssen, K., Besson, M., Komen, H., 2016. Economic values of growth rate, feed intake, feed conversion ratio, mortality and uniformity for Nile tilapia. European Aquaculture Society (EAS), Edinburgh, UK, September 20 - 23, 2016. 
About the author 

Mr Omasaki was born on $12^{\text {th }}$ November, 1982. He went to Kipsigak Primary School from 1989 to 1997 where he obtained Kenya Certificate of Primary Education. He later joined Kapsabet Boys High School in the year 1998 where he finished and obtained Kenya Certificate of Secondary Education. In 2003 he joined Egerton University (Kenya) for a Bachelor of Science degree in Animal Production where he graduated in 2007. In the year 2007, Mr Omasaki got a scholarship from International Centre for Development and Decent Work, Kassel University, Germany to pursue a Master of Science degree in Animal Production (Animal Breeding and Genetics option) at Egerton University, Kenya, which he completed and graduated in the year 2010. In April 2009 to January 2010, he worked as a Broiler Farm Manager, Kenchic Itd, Kenya. In January 2011, he was employed as an extension manager by Heifer International Organization under the East African Dairy Development Project, where he worked for six months. In 2011 to 2012, he worked as a part time lecturer in various universities and institutions in Kenya, in the Department of Animal Science, among them are: University of Eldoret (UoE), Egerton University and Christian International Training Centre (CITC). In September 2011, he was offered a job at Kenya Dairy Farmers Federation (KDFF) as a Breeding Specialist, under the East African Dairy Development Project. In 2012, he got a scholarship from Koepon Foundation to pursue a PhD Sandwich training in Animal Breeding and Genetics at Wageningen University. 
Training and Education 



\section{Training and education}

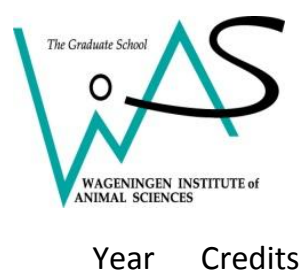

\section{The Basic Package (3 ECTS)}

WIAS Introduction Course (mandatory, 1.5 credits)

$2013 \quad 1.5$

Course on philosophy of science and/or ethics (mandatory, $1.5 \quad 2016 \quad 1.5$ credits)

\section{Scientific Exposure (10.7 ECTS)}

International conferences

International Symposium on Tilapia in Aquaculture (ISTA), April $26 \quad 2016 \quad 1.2$

$-29,2016$

$1^{\text {ST }}$ World Congress on Innovations for Livestock Development $2016 \quad 1.5$

(WCILD), June 26 - 30, 2016

European Association for Animal Production (EAAP), August 29 - $2 \quad 2016 \quad 1.5$

September, 2016

European Aquaculture Society (EAS), September 20-23, $2016 \quad 2016 \quad 1.2$

\section{Seminars and workshops}

WIAS Science Day, February 4, 2016

$2016 \quad 0.3$

Presentations

Genotype by environment interaction for harvest weight, growth

20161.0

rate and shape between monosex and mixed sex Nile tilapia (Oreochromis niloticus), February 4, 2016, WIAS Science Day, Wageningen University, The Netherlands, oral.

Genotype by environment interaction for harvest weight, growth rate and shape between monosex and mixed sex Nile tilapia (Oreochromis niloticus), April 28, International Symposium on Tilapia in Aquaculture (ISTA), Surabaya, Indonesia, oral.

Economic values of growth rate, feed intake, feed conversion $2016 \quad 1.0$ ratio, mortality and uniformity for Nile tilapia. June 28, 2016, 1ST World Congress on Innovations for Livestock Development (WCILD), Naivasha, Kenya, oral. 
Defining a breeding objective for Nile tilapia that takes into $2016 \quad 1.0$ account the diversity of smallholder production systems. European Association for Animal Production (EAAP), Belfast, UK, August 30, 2016, poster.

Economic values of growth rate, feed intake, feed conversion 20161.0 ratio, mortality and uniformity for Nile tilapia. European Aquaculture Society (EAS), Edinburgh, UK, September 22, 2016, poster.

\section{In-Depth Studies (17 ECTS)}

Disciplinary and interdisciplinary courses

Animal Breeding and Genetics summer course in ILRI, Addis 20132.0 Ababa, Ethiopia on Food Security.

Advanced statistics courses (optional)

Statistics for the Life Sciences, June 1-8, 2016.

Advanced statistics

PhD students' discussion groups (optional)

Quantitative Discussion Group, ABG

MSc level courses (only in case of deficiencies)

Genetic Improvement of Livestock, Wageningen

20126.0

\section{Professional Skills Support Courses (2.7 ECTS)}

Research proposal writing, September 13 - 18, 2015, Egerton, 20151.5 Kenya.

ASREML $2013 \quad 0.3$

Introduction to R, May $12-13$, 2016, Wageningen University, The $2016 \quad 0.6$ Netherlands

WGS PhD Workshop Carousel, April 8, 2016

$2016 \quad 0.3$

Research Skills Training (6 ECTS)

Preparing own PhD research proposal (maximum 6 credits) $2013 \quad 6.0$

\section{Management Skills Training (1 ECTS)}

Membership of boards and committees

Kenya Animal Breeding and Genomics Association

$2011 \quad 1.0$

Education and Training Total 40.4 
Acknowledgements 

The successful completion of this thesis has been achieved by the valuable assistance of several individuals and organisations who persevered my relentless questions and inquisitions seeking answers that resulted in; the knocking in and out volumes of knowledge. First and foremost, I would like to thank Wageningen University and Wageningen Institute of Animal Sciences for allowing me to pursue this study. I am grateful to Wageningen University Animal Breeding and Genetics Centre, Koepon Foundation and Egerton University for successfully enabling this study.

My most sincere gratitude goes to my promoter Prof. Dr. ir. J.A.M. van Arendonk, daily supervisor Prof. Dr. ir. Hans Komen and co-supervisor Prof. A. Kahi for their constructive criticism, guidance and enlightening discussions. Your passion and prompt responses were extraordinary. A special thank for Prof. Dr. ir. Hans Komen for his support like a father in times of pain and happiness, his hands-on, challenging and calculated guidance throughout the study. It was of great significance to have free and unlimited access to his wealth of knowledge, wisdom and experience. Always knocking to your office without appointments when in crisis seeking for your help was not easy, but you always accommodated my knock. To all I say thank you for your support that were vital for the timely completion of this thesis. A special thank goes to Prof. Dr. ir. J.A.M. van Arendonk, who always gave me remarkable moral support and encouragement wherever we met..... in the coffee corner, along the corridors of Animal Breeding and Genetics group offices and along the road, my sincere thanks to you Prof. I would also like to thank Dr. Charo-Harisson for his experimental guidance in Sagana.

I wish to acknowledge Animal Breeding and Genetics Centre, Wageningen University for provision of facilities, the group staff and my fellow postgraduate students for providing a comfortable learning environment during my study. Sincere gratitude goes to the secretary Animal Breeding and Genetics Centre, led by Mrs Ada and Mrs Lissette for their undivided attention during the period of my stay. Indeed, you were my parents, both in times of stress and happiness.

Acknowledgement is extended to WorldFish Center for chipping in to support the experiment, Sagana Aquaculture Research Station, Kenya for providing the experimental fish, facilities and helping with the experiment. To all fish farmers that provided the key information about the fish industry in Kenya that formed the baseline for this study. 
Special recognition is also extended to my friends and family members for their encouragement, patience and prayers. I also appreciate all the support and encouragement from all my sisters and brothers. Special thanks are due to Sophy and Fidel, for their ever ending support, patience and determination and their moral support in my absence.

Many thanks goes to everyone who contributed in one way or the other in the success of this study. It is difficult to mention you all, but I am sincerely indebted. 
Colophon 

The research described in this thesis was financially supported by Koepon Foundation, Wageningen University and Egerton University.

The cover of this thesis was designed by Mr. Omasaki Simion Kipkemboi.

This thesis was printed by GVO drukkers \& vormgevers B.V. | Ponsen \& Looijen, Ede, The Netherlads. 